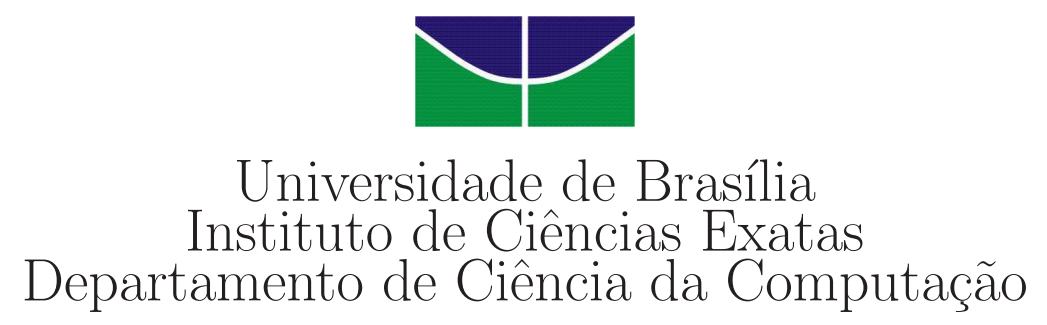

Ferramentas para a Gestão de Mudanças do Modelo ITIL Aplicado a Uma Empresa de Telecomunicações

\author{
Albert Frederico de Menezes Il Pak \\ Felipe Pontes Guimarães \\ Monografia apresentada como requisito parcial \\ para conclusão do Bacharelado em Ciência da Computação \\ Orientadora \\ Prof: Dr Dํ. Célia Ghedini Ralha
}

Brasília

2006 
Universidade de Brasília - UnB

Instituto de Ciências Exatas

Departamento de Ciência da Computação

Curso de Bacharelado em Ciência da Computação

Coordenadora: Prof $\stackrel{a}{a}$ Drẹ Cláudia Nalon

Banca examinadora composta por:

Profạ Drạ Célia Ghedini Ralha (Orientadora) - CIC/UnB

Prof. Dr. Jorge Henrique Cabral Fernandes - CIC/UnB

Geraldo Moacir Soares - Mestre pela UCB

\section{CIP - Catalogação Internacional na Publicação}

Albert Frederico de Menezes Il Pak.

Ferramentas para a Gestão de Mudanças do Modelo ITIL Aplicado a Uma Empresa de Telecomunicações/ Felipe Pontes Guimarães, Albert Frederico de Menezes Il Pak. Brasília : UnB, 2006.

128 p. : il. ; $29,5 \mathrm{~cm}$.

Monografia (Graduação) - Universidade de Brasília, Brasília, 2006.

1. ITIL, 2. Gestão de Mudanças, 3. Requisição de Mudança,

4. RFC, 5. Incidentes, 6. Configuração, 7. CMDB,

8. modelagem de processos, 9. CMM

CDU 004

Endereço: Universidade de Brasília

Campus Universitário Darcy Ribeiro - Asa Norte

CEP 70910-900

Brasília - DF - Brasil 


$$
\begin{gathered}
\text { Universidade de Brasília } \\
\text { Instituto de Ciências Exatas } \\
\text { Departamento de Ciência da Computação }
\end{gathered}
$$

\title{
Ferramentas para a Gestão de Mudanças do Modelo ITIL Aplicado a Uma Empresa de Telecomunicações
}

\author{
Albert Frederico de Menezes Il Pak \\ Felipe Pontes Guimarães \\ Monografia apresentada como requisito parcial \\ para conclusão do Bacharelado em Ciência da Computação

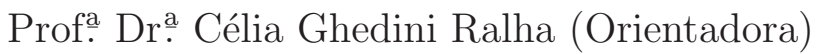 \\ $\mathrm{CIC} / \mathrm{UnB}$
}
Prof. Dr. Jorge Henrique Cabral Fernandes Geraldo Moacir Soares $\mathrm{CIC} / \mathrm{UnB}$
Mestre pela UCB

Profạ Drạ Cláudia Nalon

Coordenadora do Bacharelado em Ciência da Computação

Brasília, 3 de Agosto de 2006 


\section{Dedicatória}

Dedicamos este trabalho aos nossos pais pelo incentivo dado, aos nossos colegas de curso, cujo material possa servir de base para trabalhos futuros, e por fim aos nossos professores pela atenção e empenho na tarefa de lecionar. 


\section{Agradecimentos}

Agradecemos a Prof ̣a Drạ Célia Ghedini Ralha por todos os conselhos que guiaram este trabalho para um bom resultado. Também agradecemos pelo esforço, paciência e apoio neste trabalho.

Ao nosso mentor Moacir, agradecemos a oportunidade do estágio que nos motivou para consolidá-la nesta monografia. O aprendizado pleno no ambiente de trabalho só foi possível pela dedicação e empenho de educador nos demonstrada. Esperamos seguir o seu exemplo de garra, determinação e empenho por toda vida.

Aos professores das disciplinas cursadas durante a graduação continuem firmes na missão de semear em nossas almas o espírito científico.

Aos nossos amigos, pelo apoio, ajuda e colaboração, a empreitada da aprendizagem não seria tão enriquecedora e estimulante.

Aos revisores deste trabalho, estamos gratos pela atenção e crítica construtiva durante a elaboração do documento, visto a dificuldade de se distanciar de uma atividade que nos seguiu por quase todos os dias durante dois semestres.

Aos nossos pais, agradecemos o apoio e incentivo, mesmo que não entendam o quê estudamos tanto.

Não podíamos esquecer de Verônica e Rachel por tentar nos direcionar para a virtude.

Aqueles que esquecemos de agradecer, obrigado pelo pensamento positivo que nos possibilitou colher os melhores frutos. 


\section{Abstract}

This project aims the study of information technology management applied at a telecommunication company. The adopted model is the Information Technology Infrastructure Library (ITIL). This project focuses only on Service Support management units, not covering Service Delivery. Initially Service Support was studied to provide an understanding of the model. Then, process modeling techniques were applied to compare the current procedures adopted by the company with the best practices in the model. The noticed differences were taken to provide a set of solutions directed to the Change Management unit. Two tools for Change Management were designed to help at the process bottlenecks. The presented solution may improve management services, as well as provide a better integration between management units.

Keywords: ITIL, Change Management, RFC, Incident, Configuration, CMDB, process modelling, CMM 


\section{Resumo}

O presente trabalho objetiva o estudo em gestão de tecnologia da informação aplicado a uma empresa da área de telecomunicações. O modelo adotado durante o estudo é o Information Technology Infrastructure Library (ITIL). Este projeto tem foco nas gestões de suporte a serviços, não envolvendo entrega de serviços. Inicialmente, foram feitos estudos teóricos para um entendimento das várias gerências envolvidas. As gestões de suporte a serviços foram estudadas para um melhor entendimento do modelo. Logo após, técnicas de modelagem de processos foram aplicadas para comparar os procedimentos adotados na empresa com as melhores práticas. Com esse panorama montado, foi possível apontar deficiências nos processos da gestão ITIL, e assim realizar uma proposta de melhoria para a Gestão de Mudanças. Duas ferramentas para Gestão de Mudanças foram implementadas para minimizar os gargalos no processo. A solução apresentada pode melhorar os serviços da gestão, assim como uma melhor integração entre as gerências.

Palavras-chave: ITIL, Gestão de Mudanças, Requisição de Mudança, RFC, Incidentes, Configuração, CMDB, modelagem de processos, CMM 


\section{Sumário}

Lista de Figuras

Lista de Tabelas

$\begin{array}{lll}\text { Capítulo } 1 & \text { Introdução } & 15\end{array}$

1.1 Problemática . . . . . . . . . . . . . . . 15

1.2 Objetivo Geral . . . . . . . . . . . . . . . . . 18

1.3 Objetivos Específicos . . . . . . . . . . . . . . . 19

$\begin{array}{lll}\text { Capítulo } 2 & \text { Fundamentação Teórica } & 20\end{array}$

2.1 Modelagem de Processos . . . . . . . . . . . . . . . . . . 20

2.1.1 Definição de Processo . . . . . . . . . . . . . . . . . 20

2.1.2 Como Modelar Processos . . . . . . . . . . . . . . . 21

2.1.3 Modelos As Is, To Be e Simulações . . . . . . . . . . . . . 23

2.2 Modelo ITIL . . . . . . . . . . . . . . . . . . . . . . . . . . . . . . 24

2.2.1 Gestão de Configurações . . . . . . . . . . . . . . . . 24

2.2.2 Gestão de Incidentes . . . . . . . . . . . . . . . . . . 30

2.2.3 Service Desk . . . . . . . . . . . . . . . . . 33

2.2.4 Gestão de Mudanças . . . . . . . . . . . . . . . . . . . . 36

2.2.5 Gestão de Problemas . . . . . . . . . . . . . . . . . 42

2.2.6 Gestão de Liberações . . . . . . . . . . . . . . . . . . . . 44

2.3 Trabalhos Correlatos Sobre Gestão de TI e Modelagem de Processos 49 
2.3.1 Modelagem de Processos . . . . . . . . . . . . . . . . . 49

2.3.2 Gestão de TI . . . . . . . . . . . . . . . . . 50

2.3.3 Modelo de Avaliação Para Gestão de TI . . . . . . . . . . 51

$\begin{array}{lll}\text { Capítulo } 3 & \text { Metodologia Adotada } & 54\end{array}$

3.1 Hipóteses de Solução do Problema . . . . . . . . . . . . . . . . . . 54

3.2 Justificativa . . . . . . . . . . . . . . . . . . . . . 55

3.3 Levantamento da Realidade . . . . . . . . . . . . . . . . . 55

3.3.1 Modelagem As Is para Service Desk e Gestão de Incidentes 57

3.3.2 Modelagem As Is para Gestão de Mudanças . . . . . . . . 58

3.3.3 Modelagem As Is para Gestão de Configurações . . . . . . 60

3.4 Análise da Realidade e Adequabilidade ao Modelo ITIL . . . . . . 61

3.4.1 Análise de Capacidade Sobre as Gestões Existentes na Empresa ......................... 62

3.4.2 Processo Gestão de Mudanças - Visão Geral . . . . . . . . 63

3.4.3 Processo de Gestão de Mudanças - Aprovação do Coordenador 64

3.4.4 Aprovação pela Gestão de Mudanças . . . . . . . . . . . . 64

3.4.5 Execução de Mudanças . . . . . . . . . . . . . . . . 65

3.4.6 Análise do Processo de Mudanças As Is . . . . . . . . 65

3.5 Modelagem To Be .................... 66

$\begin{array}{lll}\text { Capítulo } 4 & \text { Os Protótipos } & 69\end{array}$

4.1 Especificação de Requisitos do Notificador de Pendências . . . . . 69

4.2 Especificação de Requisitos do Sistema Pré-Comitê ...... . 70

4.3 Workflow do Notificador de Pendências . . . . . . . . . . . . . . 71

4.4 Workflow do Sistema Pré-Comitê . . . . . . . . . . . . . . 71

4.5 Desenvolvimento do Notificador de Pendências . . . . . . . . . . . 74

4.6 Desenvolvimento do Sistema Pré-Comitê . . . . . . . . . . . . . . 74

$\begin{array}{lll}\text { Capítulo } 5 & \text { Análise dos Resultados } & 77\end{array}$ 
5.1 Notificador de Pendências . . . . . . . . . . . . . . . . . . 77

5.2 Sistema Pré-Comitê . . . . . . . . . . . . . . . . . . . 78

5.3 Integração do Protótipo no Ambiente Produtivo . . . . . . . . . . 81

Capítulo 6 Conclusões e Trabalhos Futuros 82

Apêndice A Figuras de Processos Gerais para Gestão de Mudanças 86

$\begin{array}{lll}\text { Apêndice B Modelagens Produzidas No Trabalho } & 91\end{array}$

B.1 Modelagem As Is para SD e GI . . . . . . . . . . . . . . . . . . . 91

B.2 Modelagem As Is para GM . . . . . . . . . . . . . . . . . . . 94

B.3 Modelagem As Is para Gestão de Configurações . . . . . . . . . . 97

Apêndice C Código Fonte Das Ferramentas Desenvolvidas 99

C.1 Sistema Notificador de Pendências . . . . . . . . . . . . . . . . . . 99

C.2 Sistema Pré-Comitê . . . . . . . . . . . . . . . . . . 103

C.2.1 Arquivo index.php . . . . . . . . . . . . . 103

C.2.2 Arquivo spc.php . . . . . . . . . . . . . . . 107

C.2.3 Arquivo sugestao.php . . . . . . . . . . . . . . 121

C.2.4 Arquivo sugestao-db.php . . . . . . . . . . . . . 122

C.2.5 Arquivo spc-db.php . . . . . . . . . . . . . . . 123

Apêndice D Proposta de Sistematização para Modelagem de Processos 


\section{Lista de Figuras}

1.1 Registro de Mudanças em 2005. Fonte: CMDB da empresa estudada. 17

2.1 Exemplo de uma aplicação entrando em ambiente produtivo e seus possíveis estados. . . . . . . . . . . . . . . . . 27

2.2 Relação entre Gestão de Configurações, Mudanças e Versionamento. 29

2.3 Processos relativos a Gestão de Incidentes. . . . . . . . . . . . . . 31

2.4 Relação entre Gestão de Incidentes e Problemas. . . . . . . . . . . . 33

2.5 Relação entre o CMDB e a DSL. . . . . . . . . . . . . . . . . 46

3.1 Esquema do sistema de apoio utilizado na empresa. . . . . . . . 56

3.2 Registro de evolução de Mudanças separados por tipos. Fonte: CMDB da empresa pesquisada. . . . . . . . . . . . . . . . 61

3.3 Modelagem To Be realizada na aprovação de RFCs pela GM. Continua na figura $3.4 \ldots \ldots . \ldots 66$

3.4 Modelagem To Be, fim do processo das RFCs programadas. . . . 67

4.1 Fluxograma de funcionamento do Notificador de Pendências. Continua na figura $4.2 \ldots \ldots . \ldots . \ldots . \ldots 72$

4.2 Parte final do fluxograma de funcionamento do Notificador de Pendências. . . . . . . . . . . . . . . . . 72

4.3 Workflow do Sistema Pré-Comitê. Continua na figura 4.4. . . . . 72

4.4 Continuação do Workflow para Sistema Pré-Comitê. Continua na

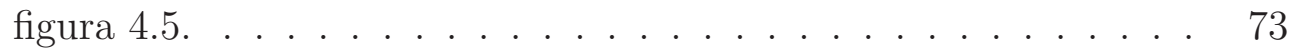

4.5 Parte final do Workflow no Sistema Pré-Comitê. . . . . . . . . . . 73

5.1 Tela de autenticação do sistema Pré-Comitê. . . . . . . . . . . . . 79 
5.2 Tela principal do sistema Pré-Comitê. . . . . . . . . . . . . . . . . 79

5.3 Caixa de diálogo para usuário inserir dados. . . . . . . . . . . . . 80

5.4 Caixa de diálogo para notificar usuário. . . . . . . . . . . . . 80

5.5 Tela de finalização do sistema. . . . . . . . . . . . . . . . . . 80

A.1 Uma abordagem para os processos de Gestão de Mudanças. Continua na figura A.2. . . . . . . . . . . . . 87

A.2 Uma abordagem para os processos de Gestão de Mudanças. Continua na figura A.3 . . . . . . . . . . . . . . . . . . 88

A.3 Uma abordagem para os processos de Gestão de Mudanças. Continua na figura A.4. . . . . . . . . . . . . . . .

A.4 Procedimentos básicos para Gestão de Mudanças. Procedimentos para Requisição Urgente. . . . . . . . . . . . . . . . . . . . . . . . 90

B.1 Processo de recebimento de Incidentes. Continua na figura B.2. 91

B.2 Recebimento de Incidentes. Parte final do processo. . . . . . . . . 92

B.3 Processo de obtenção de informações pessoais dos clientes na GI. O processo continua na figura B.4. . . . . . . . . . . 92

B.4 Processo de obtenção de informações pessoais dos clientes na GI. Processo continua na figura B.5. . . . . . . . . . . . . . 92

B.5 Processo de obtenção de informações pessoais dos clientes na GI. . 93

B.6 Gestão de Mudanças no Modelo As Is. Aprovação de RFCs com visão macro. Continua na figura B.7 f . . . . . . . . . . . . . 94

B.7 Gestão de Mudanças - Modelo As Is. Aprovação de RFCs com visão macro. . . . . . . . . . . . . . . . . . . . . .

B.8 Gestão de Mudanças no Modelo As Is. Processo de aprovação realizada pelo coordenador. Continua na figura B.9. . . . . . . 95

B.9 Gestão de Mudanças. Modelo As Is. Processo de aprovação realizada pelo coordenador. . . . . . . . . . . . . . .

B.10 Gestão de Mudanças no Modelo As Is. Aprovação emergencial, continua na figura B.11. . . . . . . . . . . . . .

B.11 Gestão de Mudanças no Modelo As Is. Final do processo de aprovação emergencial. 
B.12 Gestão de Mudanças. Modelo As Is. Caso de aprovação nas RFCs programadas. . . . . . . . . . . . . . 96

B.13 Gestão de Mudanças no Modelo As Is. Processo de Implantação de RFCs. . . . . . . . . . . . . . . . . . . . . 96

B.14 Visão alto nível da Gestão de Configurações. . . . . . . . . . . . . 97

B.15 Processo de geração de relatórios na Gestão de Configurações. Continua na figura B.16. . . . . . . . . . . . . . . . . 97

B.16 Processo de geração de relatórios na Gestão de Configurações. Parte final do processo. . . . . . . . . . . . . . . . . . . 97

B.17 Processo simplificado de cadastramento para ICs. . . . . . . . . . 98

B.18 Processo de atualização no CMDB. . . . . . . . . . . . . . . . . . 98 


\section{Lista de Tabelas}

2.1 Tabela de níveis de capacidade CMM. . . . . . . . . . . . . . . . 53

3.1 Quantidade de RFCs por tipo e tempo médio gasto. . . . . . . . . 60

3.2 Níveis de capacidade atingidos por cada gestão. . . . . . . . . . . 63

3.3 Resultados da simulação As Is para o processo de mudanças. . . . 66

3.4 Resultados da simulação To Be para o processo de mudanças. . . 67

3.5 Comparativo de resultados entre os modelos To Be e As Is. . . . 68 


\section{Capítulo 1}

\section{Introdução}

O presente trabalho tem como objetivo o estudo de uma parte do modelo Information Technology Infrastructure Library (ITIL), e a sua utilização num ambiente real de uma empresa de telecomunicações do país.

O modelo ITIL, inicialmente proposto nos anos 80, foi estabelecido pelo governo Inglês para que os serviços de Tecnologia da Informação (TI) pudessem melhorar a qualidade e diminuir seus crescentes custos. A agência de telecomunicações inglesa determinou e documentou uma série de práticas, bem como uma organização para otimizar o funcionamento de um departamento de TI. Nos anos 90, o modelo foi amplamente adotado tanto pelo setor público quanto pelo setor privado. ITIL hoje consagra as melhores práticas de gestão de TI [Australian Technology Business Magazine, 2003]. Nos decorridos anos, a dependência entre serviços e tecnologia passaram a ser ponto fundamental em diversos negócios. Com isso, o modelo foi concebido buscando alinhar os objetivos da empresa à qualidade que os clientes esperam ter [Feher et al., 2004].

O futuro do modelo ITIL na área de TI da empresa tende a se consolidar uma vez reconhecidos os ganhos de produtividade, aumento da disponibilidade de serviços e melhores níveis de serviço, conhecido por Service Level Agreement ou SLA [OGC, 2005]. A empresa atualmente passa por uma mudança de paradigmas, devido à abordagem de gestão e trabalho voltados para processos documentados, da mesma forma que há atualmente uma forte tendência para o desenvolvimento de programas estruturados por processos e práticas. Para a sobrevivência do modelo na empresa, é importante uma mudança da cultura organizacional que possivelmente se refletirá nos negócios da empresa suportados pela TI.

\section{$1.1 \quad$ Problemática}

A empresa de telecomunicações, foco do estudo deste trabalho, possui um conjunto numeroso de equipamentos espalhados em uma vasta região do Brasil. Ela 
possui data centers, termo que designa infra-estrutura para suportar redes, servidores e demais equipamentos computacionais [Edison Electric Institute, 2001], localizados em vários centros urbanos. A infra-estrutura é complexa, devido ao número de equipamentos e sistemas que suportam telefonia fixa, móvel e demais soluções tecnológicas para outras empresas. A empresa iniciou a implantação do modelo ITIL em meados de 2002. Desde então, implantou apenas algumas disciplinas consideradas chave. O modelo implantado tem o objetivo de organizar a infra-estrutura de TI e conta com as já implantadas gerências de Service Desk, Incidentes, Configuração e Mudanças.

A empresa de telecomunicações possui áreas voltadas para TI e engenharia. A equipe de engenharia utiliza alguns sistemas de informação que a TI provê. Além disso, existe uma certa interação entre as equipes de TI, engenharia e fábrica de software. Podemos citar, por exemplo, a migração dos números de telefones fixos de 7 para 8 dígitos. A alteração das centrais telefônicas para atender a nova legislação vigente foi planejada, documentada e registrada na Gestão da Mudanças, por meio de uma requisição de mudança. O ITIL existente na empresa agrega uma equipe de engenharia que reconhece a existência do modelo, utiliza-o, e inclusive é um cliente interno. Verifica-se o diferencial deste estudo de caso, pois o ITIL também pode incluir não só a TI, mas abranger uma empresa de telecomunicações.

Segundo estudo realizado na empresa em análise, verificamos que os primeiros passos do processo de adoção do modelo ITIL foram gradativos e altamente interativos (da especificação ao desenvolvimento de ferramentas que automatizam os processos). Inicialmente ocorreu um processo altamente manual, partindo para um nível inicial de automação utilizando um sistema de apoio. Também existiam dificuldades devido a ausência de um sistema que apoiasse satisfatoriamente as disciplinas de Service Desk, Incidentes, Configuração e Mudanças. Assim, diante as necessidades percebidas pelas equipes de cada gestão, o sistema foi especificado, implementado e consolidado nesse sistema de apoio. Pode-se citar como exemplo a situação inicial da Gestão de Mudanças. Suas demandas eram enviadas por e-mail e recebidas pela equipe. Muitas dessas requisições continham informações imprecisas ou incipientes (atualmente o sistema já impõe alguns critérios aos usuários), o que causava demora no tratamento dos casos. Inclusive não existia uma base única para o acompanhamento das requisições pelos usuários do sistema e que fosse acessível por todos envolvidos no processo.

Em um médio prazo, há o objetivo de adotar completamente o modelo ITIL, implantando as melhores práticas em sua infra-estrutura de TI. Essa conformidade total ao modelo ainda não ocorreu e, portanto, a empresa possui imensa fonte de aspectos a serem adequadamente tratados, inclusive pela ausência de algumas das disciplinas do modelo ITIL (por exemplo, Gestão de Problemas e Versionamento).

Dessa implantação em curso derivaram-se vários problemas, dentre eles falta de capacitação nas pessoas a trabalhar com o modelo ITIL, problema de adaptação às ferramentas, deficiências nas ferramentas automatizadas, falta de integração entre gerências. Atualmente, já existe uma ferramenta de automação dos processos 
com funcionalidade restrita e que não permite uma visão global do contexto para as gerências, além de ser muito textual, ou seja, não possuindo uma adequada interface gráfica que permita boa usabilidade e a análise imediata das informações nela apresentadas.

Durante o estudo do modelo ITIL no ambiente real, entre as gerências implementadas (Configuração, Mudança, Incidentes e Service Desk) pudemos perceber inadequações com relação ao modelo teórico, assunto tratado posteriormente no item "levantamento da realidade", seção 3.3, página 55, entre as quais pode-se citar a falta de integração entre as gerências, insatisfação dos clientes internos e a ausência das demais gerências para melhorar a situação atual do modelo.

Para ilustrar melhor a dinâmica operacional da empresa, a figura 1.1 mostra a dinâmica da Gestão de Mudanças. Na figura, é mostrada a evolução da quantidade de Mudanças separadas por tipos, no decorrer do ano de 2005.

Registros de Mudanças

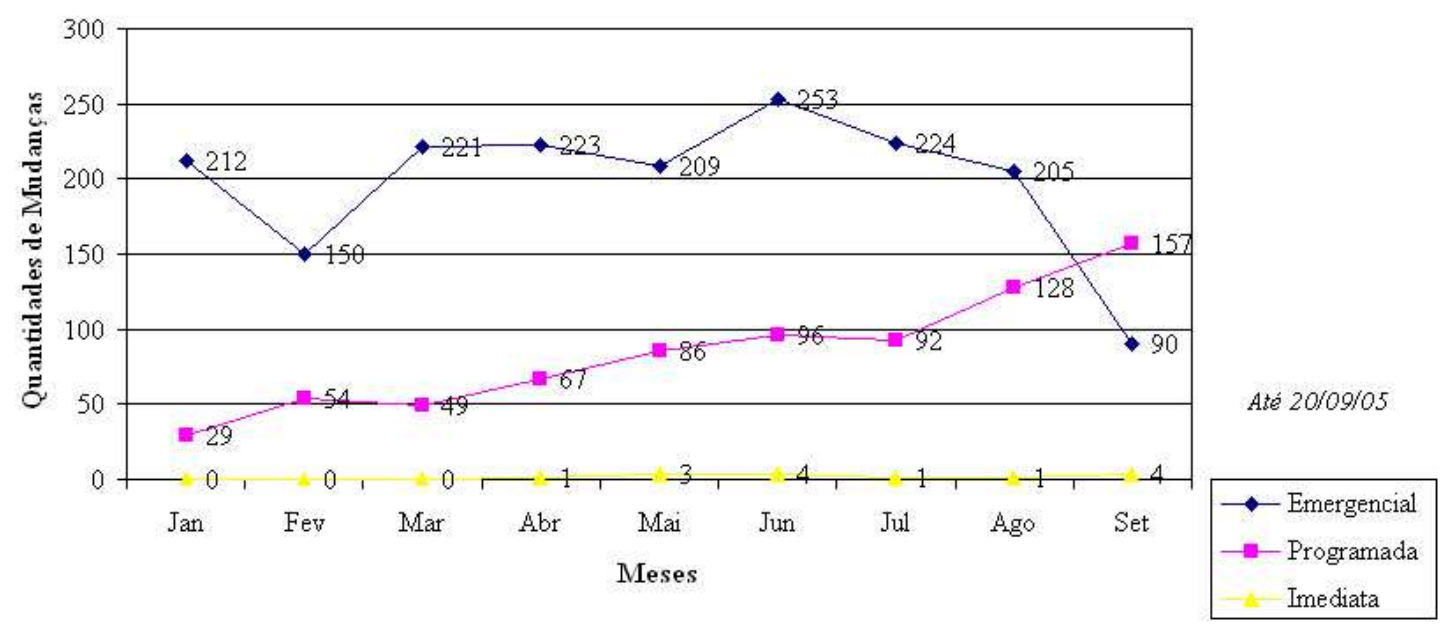

Figura 1.1: Registro de Mudanças em 2005. Fonte: CMDB da empresa estudada.

Na figura 1.1, podemos descrever o panorama geral da Gestão de Mudanças no ambiente produtivo da empresa. O período de 9 meses demonstra o volume de pedidos de Mudanças requisitados por clientes. As Mudanças estão divididas em 3 tipos. As programadas, emergenciais e imediatas.

As Mudanças programadas, no gráfico 1.1, são interpretadas como requisições que têm maior flexibilidade nos prazos, que possam ser avaliadas, planejadas e negociadas com área impactada e equipe técnica com antecedência. Todas programadas são analisadas e discutidas por um grupo de pessoas que formam o Comitê de Mudanças. De acordo com o gráfico, a quantidade de programadas fica abaixo da quantidade de emergenciais, por não haver uma preocupação devida na qualidade do trabalho pelos funcionários habituados à informalidade. Além disso, não há um reconhecimento do Processo de Mudanças e os benefícios que ele proporciona. Por meio do esforço da equipe de mudanças, houve uma preocupação para melhorar gradativamente a situação, fazendo com que mais requisições fossem 
analisadas pelo Comitê e que um treinamento apropriado fosse disponibilizado para as áreas usuárias visando explicitar os procedimentos e melhorias advindos do processo. De acordo com o gráfico, no mês de setembro, as programadas finalmente superaram as emergenciais. Isto ocorreu devido uma pressão da alta administração que passou a exigir a aprovação formal dos gerentes e diretores para todas manutenções emergenciais. Essa medida forçou uma melhoria em qualidade do planejamento por parte dos solicitantes e líderes das diversas áreas de TI.

As emergenciais indicam todos pedidos que não possuem tempo hábil para as devidas aprovações, notificações e ciclo de trabalho ideal e seguro. Esses pedidos são rapidamente decididos à medida do possível para serem urgentemente implementados e executados. A grande quantidade de emergenciais (vide gráfico da figura 1.1) mostra uma baixo nível de capacidade no processo, pois podem causar danos ao ambiente produtivo, por haver pouco tempo para detectar erros antes que eles apareçam. O resultado da emergencialidade resulta em um ambiente instável e uma coleção de prejuízos, como por exemplo, o custo de ter a página principal da empresa indisponível, falha em sistema de vendas de produtos, indisponibilidade em sistemas importantes para centrais de atendimento ao consumidor, e outros. Quando ocorrem essas adversidades, as equipes tentam descobrir quem foi o culpado ao invés de agir proativamente detectando falhas de processo tanto da área de projetos (responsável por desenvolver sistemas), quanto da área de produção (área de suporte a manter os sistemas já ativos). Verifica-se na figura 1.1 entre janeiro e agosto o caráter urgente destes pedidos.

Por último, a curva das manutenções imediatas mostra a problemática de integração entre sistemas. As manutenções imediatas são originadas por Incidentes que geram Mudanças. Esse tipo de mudança realiza alterações imediatas no ambiente produtivo afim de resolver Incidentes significativos. Trata-se de uma integração entre a Gestão de Mudanças e Incidentes. A figura 1.1 mostra uma falha do sistema de apoio nos primeiros três meses. Devido a correções no sistema, conseguiu-se a funcionalidade demonstrada pelos meses seguintes. Entretanto, a utilização foi baixa devido ao desconhecimento dos usuários. Pode-se inferir que caso esse número de imediatas aumentasse, o número de emergenciais poderiam ser menores. Outra alternativa seria a idéia de que aumentando as programadas e imediatas poder-se-iam diminuir as emergenciais. Desta tendência, percebe-se a atual necessidade de uma melhor integração entre sistemas, visto que se superou a dificuldade inicial de construção de um sistema específico para cada gestão.

\subsection{Objetivo Geral}

Este trabalho tem como objetivo principal o estudo de adequabilidade do modelo ITIL por meio de um mapeamento e modelagem de processos para análise da situação atual das gerências já existentes com enfoque na Gestão de Mudanças.

O entendimento do modelo ITIL possibilita um embasamento teórico que permitirá uma transformação da situação atual na área de TI. Mais ainda, esse estudo 
possibilitará uma maior transparência para análise do modelo, uma melhor integração entre gerências, melhoria de confiança entre clientes e otimização de processos com possível redução de recursos despendidos.

\subsection{Objetivos Específicos}

Os objetivos específicos deste trabalho apontam para uma solução de melhoria do modelo em curso na Gestão de Mudanças. Essas soluções são um conjunto ferramentas que possam melhorar o desempenho da área de Mudanças, bem como melhorar a interação entre as gestões implantadas no ambiente real de TI.

Este trabalho também busca os seguintes subprodutos:

- Implementar ferramentas de auxílio na Gestão de Mudanças.

Uma ferramenta a qual possa aumentar a produtividade, melhorar a visibilidade (fácil acesso a informações sobre a gerência), conseguindo métricas confiáveis e nível de capacidade dos processos. Quanto a visibilidade, uma ferramenta na qual as áreas de TI possam estar informadas sobre o cronograma de atividades, preparando-se adequadamente.

- Facilitar o processo decisório e o controle utilizando ferramentas automatizadas.

Na Gestão de Mudanças, há fluxo crescente das Requisições de Mudança, ou do inglês Request For Change (RFCs). Gradualmente, mais projetos estão sendo inseridos ao processo, dificultando o tratamento adequado das RFCs. O Processo de Mudanças ainda é altamente dependente de interações manuais e o tempo de resposta para aprovação das RFCs está além do ideal.

Ao fim do trabalho, espera-se obter esse conjunto de ferramentas que possam auxiliar as atividades da Gestão de Mudanças, como o tratamento mais eficiente de RFCs, auxiliar o Comitê de Mudanças e por fim melhorar a integração entre as gerências. 


\section{Capítulo 2}

\section{Fundamentação Teórica}

Neste capítulo será mostrada uma revisão bibliográfica sobre modelagem de processos e modelo ITIL. Inicialmente, um apanhado de definições sobre processos e como realizar uma modelagem de processos. Logo após, serão explicitadas as gestões relativas ao Suporte a Serviços do ITIL. Por fim, serão mostrados artigos correlatos que utilizaram os dois temas já descritos.

\subsection{Modelagem de Processos}

Esta seção trata definições de processos, como realizar modelagem de processos, e a técnica de análise da modelagem de processos por meio de comparações. As definições são explicitadas por vários autores, com poucas variações na essência das diversas definições. A modelagem mostra uma recomendação geral para construção desses modelos, e por último a análise, comparando o modelo atual com o sugerido.

\subsubsection{Definição de Processo}

A termo processo é definido por diversos autores, sendo que essa definição difere entre as áreas de aplicação. Algumas características, contudo, são comuns a todas essas definições. Serão explicitadas algumas definições encontradas para determinar qual será mais adequada para este estudo.

De acordo com o trabalho de [Lucca, 2005, p.43], são enumeradas definições de cinco autores distintos:

- Processo é uma atividade que recebe uma entrada, agrega valor e gera uma saída pra um cliente, sendo que eles utilizam recursos da organização para obter resultados. 
- Processo é um conjunto de atividades estruturadas (ordenadas no tempo e espaço) para resultar em um produto para um cliente ou mercado. Possuem um começo e fim definidos os quais estruturam as ações.

- Processo é um conjunto de causas tendo objetivo, produz um efeito específico, que será denominado produto do processo. Tem um produto e um cliente.

- Processo é uma série sistemática de ações dirigidas para realização de uma tarefa.

- Processo é uma organização de recursos humanos e materiais, dedicado às atividades necessárias à produção de um produto final específico, independente de relacionamento hierárquico.

Além das definições apresentadas, mais ainda, de acordo com [Cruz, 2000] definese processo como um conjunto de atividades que tem por finalidade transformar, montar, manipular e processar insumos para produzir bens e serviços que serão disponibilizados para clientes. Mais ainda, um processo compreende por um ou mais subprocessos que constituem um conjunto de atividades correlacionadas. Estes por sua vez, são subdivididos em atividades os quais possuem seus procedimentos. Por fim, no nível mais baixo, temos as tarefas que reunidas formam um procedimento [Cruz, 2000].

O tutorial de CMMI conceitua o termo, com o propósito de explicar mais adiante o processo de software. Por [Phillips, 2004], processo é um conjunto de práticas realizadas para atingir um determinado propósito, pode incluir ferramentas, métodos, materiais, ou pessoas.

Dentre os conceitos apresentados nas várias definições, pode-se evidenciar que um processo genérico possui uma entrada, uma ordem de atividades, por fim uma saída com um resultado para que alguma entidade possa utilizar esse resultado.

Acerca da composição de um processo, destacam-se os conceitos de atividades e procedimentos. As atividades são orientadas para um determinado resultado e dependente da eficiência de atividades anteriores. De acordo com [Cruz, 2000], as atividades podem ser agrupadas em três categorias. As atividades principais são aquelas que participam diretamente da criação do bem ou serviço. As atividades secundárias são as que não são diretamente envolvidas mas a auxiliam atividades principais. Por fim, as atividades transversais são aquelas que demandam várias especialidades, são prejudiciais por demandarem muitos recursos e devem ser adotadas com cautela, evitando o caso de não agregar valor ao produto ou serviço.

\subsubsection{Como Modelar Processos}

Atualmente, as empresas estão cada vez mais organizando seus negócios. A modelagem de processos se insere neste escopo, pois ela serve de auxílio para identi- 
ficar possíveis sistemas de apoio, facilitar a identificação de necessidades e maior entendimento da estrutura interna das corporações [Santos, 2005, p.14-17]. Independentemente do nível de organização de qualquer empresa, os processos existem e sofrem influência de diversos fatores. Uma empresa sempre tende ao caos e por isso a necessidade de documentação e auto-conhecimento de uma organização é inevitável [Cruz, 2000].

A modelagem de processos é resultado de uma abstração da organização, que identifica a situação atual da empresa ou identifica também as necessidades. Em geral, o objetivo desse tipo de modelagem é responder a perguntas como quem faz, como é feito, por quê se realiza de uma dada forma e quando se realiza. Uma segunda etapa é a modelagem do vir a ser. Para isso é necessário reunir um conjunto de informações para que os processos possam se adequar de melhor forma em uma empresa. Deve-se entender os objetivos, ou seja, entender o que se quer atingir de acordo com o negócio da empresa. Também é importante entender quais são os serviços disponibilizados (as saídas dos processos) [Santos, 2005].

Os processos podem ser modelados de diversas formas, utilizando a representação Unified Modeling Language (UML) ou a representação em workflow, sendo de destaque a última abordagem. Esse método tem o foco no fluxo de processos nos quais eles são explicitados em uma série de atividades em diagramas com raias e possibilitam uma visão detalhada da modelagem de negócio [Santos, 2005].

Após o trabalho de especificação dos processos, chega-se a um modelo o qual fornece um mapa para esse conjunto de tarefas que ocorrem em um negócio ou organização. Esse modelo é uma descrição formal ou semi-formal das características de um processo de negócio real ou planejado. Os diferentes aspectos de um processo de negócio podem ser analisados de diferentes maneiras, por exemplo, com foco em funções, recursos, organização, qualidade, custos e tempo [Mertins and Jochem, 1999].

O modelo que demonstra como o processo acontece é utilizado para uma análise e uma posterior elaboração de um modelo de como esse processo poderia ser. É recomendado por [Sharp and McDermott, 2001] que seja realizado uma modelagem por etapas. Segue abaixo a ordem das etapas:

- Elaboração do modelo As Is, o modelo de como o processo acontece.

- Análise do modelo As Is para se acumular um entendimento e conhecimento dos pontos fracos do processo.

- Elaboração do modelo de como os processos deverão ser, ou seja, a implementação do modelo To Be.

- Comparação entre a modelagem As Is e To Be para constrastar os resultados e se avaliar os resultados.

A avaliação do modelo é também considerado etapa importante de uma análise. Durante a modelagem, uma vez definidas as atividades e estabelecidos os proce- 
dimentos, funcionários envolvidos, recursos necessários, pode-se definir o tempo despendido por um processo, o um custo associado por meio de simulações do modelo que a ferramenta IBM WBI Workbench possibilita. A metodologia de modelagem adotada neste trabalho será uma análise de modelos $A s$ Is e To Be segundo [Sawy, 2001].

\subsubsection{Modelos As Is, To Be e Simulações}

Para uma análise de um processo, é imprescindível que, preliminarmente, seja realizada uma modelagem do processo atual ao qual chamamos de modelo $A s$ Is (do inglês, como é). Este modelo que permite às ferramentas de modelagem a simulação do processo e estipulação do custo associado. Permite também uma estimativa do tempo demandado e dos pontos de gargalo (similar a um engarrafamento que são pontos onde o fluxo de chegada supera o de saída na maior parte do tempo, gerando atrasos nas tarefas) [Tachizawa and Scaico, 1997].

Segundo [Tachizawa and Scaico, 1997], uma análise do processo As Is deve verificar se eles atingem o objetivo final, se as atividades estão bem relacionadas, se são alocados recursos suficientes, se as interfaces entre gerências estão sendo

previstas e bem administradas. É também interessante verificar a consistência das tarefas, de modo a evitar redundância delas. Nesta análise, a existência de sistemas de apoio devem ser estudadas e se presentes, quais informações esses sistemas poderiam prover para melhorar a qualidade do processo.

Uma vez que o modelo As Is tenha sido elaborado, realiza-se a remodelagem, atividade de reestruturação do processo que inclui a análise do modelo para identificação dos pontos de gargalo e da seqüência de atividades, procurando sempre por alternativas que permitam que várias atividades sejam realizadas em paralelo e formas de desafogar as atividades que geram os pontos de gargalo, facilitando o fluxo e diminuindo o tempo e o custo do processo desta forma [IBM, 2003].

O novo processo, uma vez otimizado da forma mais conveniente, é chamado de processo To $B e$ (do inglês, vir a ser) o qual deve, sempre que possível, se enquadrar num modelo de gestão como o SIX SIGMA, ITIL, COBIT, entre outros. O produto final será o modelo do novo processo a ser implementado na empresa de forma a reduzir os custos e o tempo de cada processo [IBM, 2003].

As ferramentas de modelagem permitem que seja feita uma simulação do processo atual, tomando como base as informações fornecidas a respeito de cada atividade individualmente de forma a gerar uma fonte segura no que tange a comparação entre o processo As Is e o To Be em vários aspectos quantitativos o que possibilita aos envolvidos no projeto conhecerem os resultados esperados, os custos envolvidos e por fim os ganhos a serem obtidos com a implantação do novo projeto [IBM, 2003, p.45-59].

Desta maneira, pode-se medir e avaliar corretamente as vantagens e desvantagens da implantação do novo modelo de processo [IBM, 2003]. 


\subsection{Modelo ITIL}

O modelo ITIL divide-se em duas partes. Primeiro, o livro entitulado entrega de serviços (veja Best Practices in Service Delivery, [Bartlett et al., 2001]) e o segundo entitulado suporte de serviços (veja Best Practices in Service Support, [Berkhout et al., 2000]. As gerências relativas ao suporte de serviços serão descritas nos sub-capítulos a serguir. Resumidamente serão explicadas as gerências relativas à entrega de serviços [Bartlett et al., 2001].

O conjunto de gestões de entrega de serviços são: Gerência de Níveis de Serviço, Gerência de Capacidade, Gerência de Continuidade a Serviços de TI, Gerência de Disponibilidade e Gerência de Finanças.

A Gestão de Níveis de Serviço identifica, monitora e revisa todo o planejamento sobre os Níveis de Serviços que são previamente acordados com os usuários. A Gestão de Capacidade abrange as atividades de gerência de recursos, modelagem de sistemas, gestão de performance e demais atividades que concernem a arquitetura dos sistemas. A Gerência de Continuidade serve para que se tenha um planejamento executável para o caso de uma recuperação rápida de sistemas que venham a entrar em colapso. Nessa gerência são atividades principais a explicitação de contingências, gestão de riscos e teste de contingências. A Gerência de Disponibilidade por sua vez, é responsável por elaborar um plano de disponibilidade que possa adequar aos objetivos de negócio da empresa. Por fim, a Gerência de Finanças avalia o custo total na manutenção da infra-estrutura de TI [Bartlett et al., 2001].

As disciplinas relativas ao suporte de serviços compreendem outra série de disciplinas. São eles o Service Desk, Gestão de Incidentes, Problemas, Liberações, Configurações e Mudanças. Estas gestões serão explicadas nas seções a seguir.

\subsubsection{Gestão de Configurações}

A Gestão de Configurações consiste basicamente em processos e atividades para manter uma base de dados da infra-estrutura da TI. Essa base de dados única e integrada com outras gerências possui informações sobre equipamentos, serviços, e além disso integra as outras disciplinas do ITIL como a gestão de Incidentes, Problemas, Mudanças e Versionamento.

Acerca desta gerência, ela possui processos, atividades e procedimentos específicos para registro de toda infra-estrutura de TI. Esse conjunto de registros englobam todo tipo de tecnologia, seja hardware, software ou serviço além de possuir também dados de pessoas. O conjunto de registros, também chamados de Itens de Configuração (IC ou do inglês Configuration Item, CI) consolidam em uma base de dados. Essa base é chamada na literatura por Configuration Management Database ou CMDB. Esse CMDB por sua vez, se relaciona com outras gerências, e é a base principal para todo o modelo ITIL [Berkhout et al., 2000]. 
A descrição desta gerência pelo ITIL é bastante flexível e pode ser aplicada em diversos domínios. Seja em uma empresa que atua na fabricação de sistemas de computação, telecomunicações, ou um laboratório. Em [Staa, 2000], não é citado ITIL, todavia são mostrados processos, métodos e técnicas muito semelhantes com aquela descrita pelo modelo, por exemplo, a importância de um repositório central (semelhante ao CMDB). São características parecidas, embora a narrativa esteja focada em um ambiente de engenharia de software.

A Configuração possibilita um controle maior sobre os ativos da empresa, melhor análise de impactos para a Gestão de Mudanças, recuperação rápida de ambientes, identificação de elementos problemáticos por meio de relatórios, documentação técnica associada aos itens, entre outros benefícios descritos em [Berkhout et al., 2000].

São objetivos desta gerência a coleta de informações sobre todos ativos da infraestrutura, prover documentação e informações atualizadas para as outras gerências, consolidar uma base de informações coerentes com a realidade a qual servirá como base para as disciplinas de suporte a serviços. Por fim, manter e atualizar toda essa base de dados [Berkhout et al., 2000, p.121].

\subsubsection{Organização Interna da Gestão de Configurações}

De acordo com [Berkhout et al., 2000, p.124-130] muitas empresas de TI já possuem algum tipo base de Configuração. Entretanto, cada equipe possui seu próprio controle e nada mais adiante é documentado ou compartilhado entre equipes. Essa situação impede uma visão generalizada que também possa mostrar a infra-estrutura de TI como se fossem camadas que passam de um item a outro item, assim por diante até chegarmos ao serviço disponibilizado.

O CMDB representa o registro de um conjunto de equipamentos de rede, hardware, software, artefatos, serviços da empresa, enfim, de toda infra-estrutura a qual suportam os negócios da empresa. Além do registro, essa base relaciona ICs a outros, relaciona Incidentes, Erros Conhecidos, Mudanças e Versionamento. São também registrados no CMDB dados de empregados, fornecedores, equipes [Berkhout et al., 2000].

São atividades pertencentes a esta gerência [Berkhout et al., 2000]:

- Planejamento: Escopo, políticas, procedimentos, contexto dentro da empresa.

- Identificação: Nível de detalhe a ser registrado, convenção de nomes, interrelacionamentos, versões, e recebimento no CMDB.

- Controle: Gerenciamento do IC ao longo de todo ciclo de vida.

- Controle de estados: Relatórios sobre o ciclo de vida do IC, tornando as alterações rastreáveis, além da associação entre ICs e Mudanças realizadas. 
- Relatórios: Permitem revisão da gerência, auditoria e correção de algum problema encontrado.

São participantes do processo de configurações o gerente e o bibliotecário de configurações. Resumidamente, as responsabilidades do gerente são relacionados a validação dos processos, funções realizadas pelo bibliotecários, monitoração do trabalho, interpretação dos relatórios, decisão sobre convenções, padrões e políticas. Os bibliotecários são responsáveis por manter atualizada a base de itens de configuração. São eles quem recebem, registram e atualizam o item durante seu ciclo de vida. O ideal é que se tenha um bom processo para gerir o ciclo de vida de todos ICs.

Exemplos de responsabilidades do gerente [Berkhout et al., 2000] :

- Alinhar os objetivos da empresa ao tipo de implementação do CMDB.

- Especificar o sistema o qual possa atender suas necessidades.

- Mostrar os pontos positivos da adoção centralizada de configurações a outras áreas para que se possa contar com a ajuda de todas equipes envolvidas.

- Recrutar pessoas para que possam ser membros da equipe.

- Compatibilizar os recursos disponíveis às necessidades da gestão.

- Planejar a equipe, os processos ou até mesmo reformular os processos.

- Propor padrões de nomes para o CMDB.

- Planejar como popular a base de dados

- Prover o CMDB para que a Gestão de Mudanças possa facilitar a análise de impactos.

- Realizar auditoria para verificar discrepâncias entre o inventário de TI e o CMDB.

- Auxiliar auditores externos em suas atividades pré-estabelecidas.

Ao Bibliotecário do CMDB são atribuídos tarefas. Seu nível hierárquico é logo abaixo do Gestor de Configurações. Os ICs são elementos onde o Bibliotecário deverá interagir, acompanhando-os ao longo de todo seu ciclo de vida. São exemplos de responsabilidades do Bibliotecário [Berkhout et al., 2000]:

- Controlar o recebimento, identificação, retirada e atualização dos ICs.

- Prover informações sobre o estado do IC.

- Manter atualizadas informações sobre ICs. 
- Notificar os responsáveis sobre modificações de ICs.

- Auxiliar na identificação de ICs.

Os processos relacionados a esta gerência atuam no ciclo de vida do IC. Na figura 2.1, a caixa Gestão de Versionamento indica que a gestão pode atuar no IC devido a mudança de seu estado. Veja figura 2.1 baseada da idéia de [Berkhout et al., 2000, p.141], onde podem ser explicitados os seguintes estados para um IC:

- Registro do IC, onde é realizado a identificação, relacionamento entre ICs.

- IC Aceito, onde é incluído no CMDB.

- IC Instalado, os registros são atualizadoa devido estar ativo no ambiente de produção.

- IC Retirado, último estágio onde o IC é excluído, já no fim do ciclo.

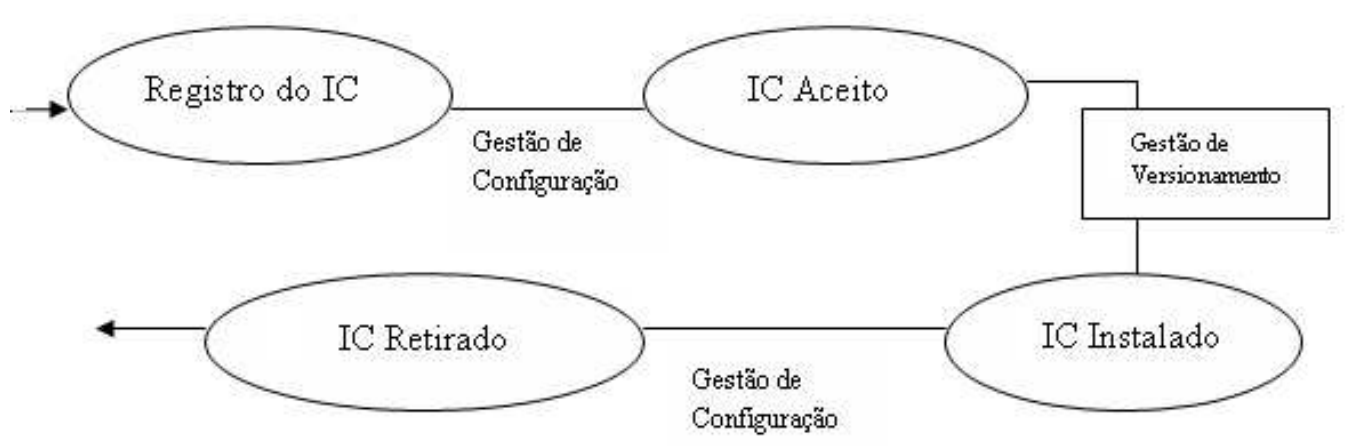

Figura 2.1: Exemplo de uma aplicação entrando em ambiente produtivo e seus possíveis estados.

\subsubsection{Revisão da Gestão de Configurações}

A Gestão de Configuração é altamente dependente para a existência de outras disciplinas como a de Mudanças, Versionamento, Incidentes e Problemas [Berkhout et al., 2000].

Citamos um exemplo de como essas relações poderão ocorrer. Primeiramente, o Incidente é registrado e associado a um Problema. O Problema é resolvido paliativamente e é realizada uma Solução Temporária. Desse Erro Conhecido, é investigada uma solução satisfatória a qual deverá solucionar o Problema pela raiz. A partir daí, é submetida uma Requisição de Mudança, a qual depois de autorizada é validada, implementada e revisada. O CMDB surge neste exemplo como uma base central onde são registrados os Incidentes, mantidos a Base de 
Problemas, Erros Conhecidos, Requisições de Mudanças, dados de pessoas, entre outros [Berkhout et al., 2000]. A figura 2.2 mostra um exemplo de relação entre Gestão de Configuração, Mudanças e Versionamento.

A figura 2.2, baseada na figura descrita por [Berkhout et al., 2000, p.152], mostra o relacionamento entre Mudanças, Versionamento e Configuração. O fluxo de trabalho na área de mudanças é representada à esquerda pelas caixas em uma seqüência cronológica. Podem ser resumidas em um conjunto de etapas planejamento, execução, revisão. A Gestão de Versionamento atuará nos artefatos a serem utilizados na implementação de Mudanças. O termo Liberar software ou hardware indica realizar procedimentos de controle de qualidade, testes, escolher estratégia de Liberação, finalmente investigar relação entre a Liberação aprovada e outros artefatos da infra-estrutura [OGC, 2002, p.49]. A área de Configuração age como um repositório, que provê serviços para outras gerências. Esses serviços são relacionados ao ciclo de vida de um IC, ou seja, acompanhamento, alteração, recebimento, controle de versões para artefatos. Inicialmente, da necessidade de uma alteração no ambiente, é requisitado um Registro de Mudança. Esse CMDB deve guardar essa Requisição para que seja compartilhada entre os diversos atores do Processo de Mudanças. Mais ainda, no CMDB deve constar uma árvore de dependências que associa ICs a outros, melhorando a rastreabilidade dentro da infra-estrutura. Uma vez aprovada a Requisição, as assinaturas das áreas responsáveis são incluídas ao documento de RFC. Após a execução é realizada a revisão a qual verifica o cumprimento dos objetivos.

Uma Configuração concisa pode agregar valor a empresa, devido a um melhor controle dos elementos de TI. Consequentemente, pode-se melhorar o Nível dos Serviços providos tanto para as equipes técnicas como para as outras gerências baseadas no CMDB. Como anteriormente enunciado, o CMDB traz maior transparência para investigações, controle de custos, re-estabelecimento de ambientes, análise de impacto, e tendências sobre os ICs no domínio da gerência.

São indicadores de performance [Berkhout et al., 2000]:

- Casos de ICs não autorizados.

- Incidentes e Problemas causados por Mudanças implementadas incorretamente.

- Inconsistências em auditoria nos ICs.

- Componentes de TI não autorizados e não documentados em ambiente de produção.

- Número de Incidentes e Problemas relacionados a ICs.

- Número de vezes em que o Acordo de Nível de Serviço não foi cumprido.

- Número de atualizações no CMDB devido a inconsistências. 


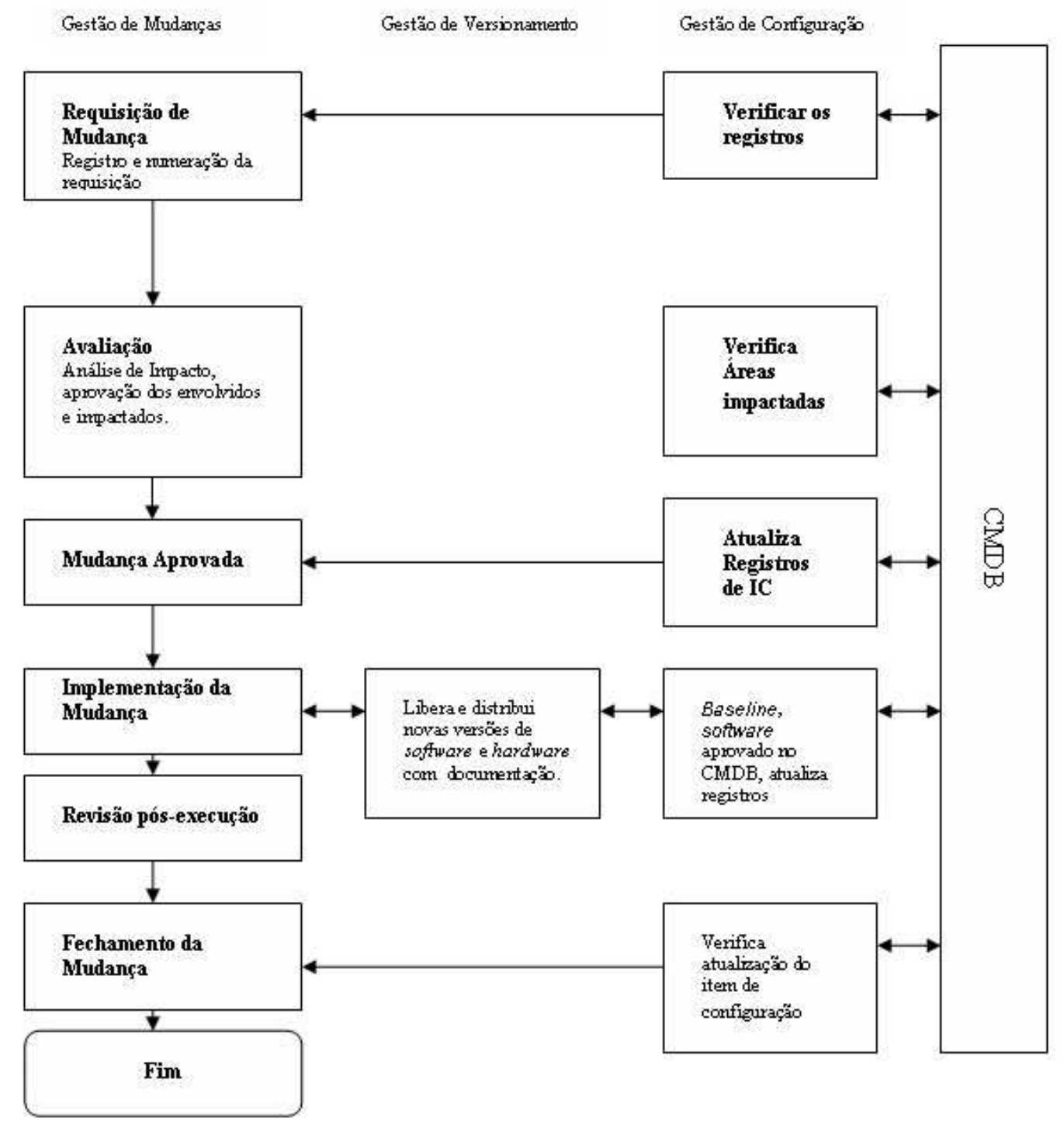

Figura 2.2: Relação entre Gestão de Configurações, Mudanças e Versionamento.

A Gestão de Configurações é a base de todo o modelo ITIL. Dela parte toda a informação a qual as outras gerências trabalham. Não é uma tarefa simples a especificação deste banco de dados, uma vez que além de formulários e documentos, é também responsabilidade dessa base o controle de versões de aplicativos do ambiente de produção. O conceito do CMDB abrange tanto a persistência de informações para o suporte de sistemas quanto a liberação de versões no ambiente produtivo. Cabe a cada caso decidir o que e como será implementado esse banco de dados. Um CMDB conciso e atualizado possibilita um ganho substancial para todos, para o negócio da empresa e principalmente a área de TI. 


\subsubsection{Gestão de Incidentes}

De acordo com [Berkhout et al., 2000], o objetivo principal da Gestão de Incidentes (GI) é restaurar a normalidade dos serviços rapidamente e minimizar o impacto nos negócios da empresa, assegurando níveis satisfatórios de qualidade e disponibilidade dos serviços. Os níveis satisfatórios são definidos junto ao cliente em um documento entitulado Acordo de Níveis de Serviço (Service Level Agreement, SLA). Pela definição ITIL, o termo Incidente é definido como qualquer evento o qual não faz parte da operação padrão de um serviço que causa ou possa causar descontinuidade, redução ou interrupção do serviço [Berkhout et al., 2000, p.71].

\subsubsection{Organização Interna da Gestão de Incidentes}

O registro do Incidente cabe ao Service Desk, e para tal atividade, são preenchidas informações relevantes para a resolução do fato. Neste registro, devem conter prioridades (importância do serviço para o negócio), classificações (para designar qual o grupo solucionador será encaminhada), dados de quem requisitou o Incidente para rapidamente retornar uma solução para o Incidente, descrição do evento, indicação de qual IC ocorreu o evento, entre outros. Além disso, é importante existir uma classificação por categorias. Isso significa separar os Incidentes por tipos como hardware, software, serviços, e demais classificações que poderão ser úteis para estruturar e organizá-los [Berkhout et al., 2000, p.71-72].

$\mathrm{Na}$ GI, a resolução passa por todo um fluxo de trabalho, ou ciclo de vida, e durante esse ciclo, o cliente deve ser atualizado com informações como a etapa do Incidente no fluxo, informações de resolução e tempo estimado para finalização. Durante o fluxo, a gerência pode dividir as equipes de solução por níveis. A equipe de maior nível possuem mais conhecimento e experiência. Por exemplo, caso a equipe de nível 1 não consiga resolver o Incidente, ele é passado para a equipe de nível 2 e assim por diante [Berkhout et al., 2000, p.74-75].

A implementação satisfatória da GI não deve ser isolada. De acordo com o modelo ITIL, é necessário que haja outras disciplinas como a Gestão de Configuração, Problemas, Service Desk, Mudanças, Versionamento e Nível de Serviço. Deve ser fortemente considerada uma integração com as demais gerências. Por exemplo, não se pode inferir a prioridade de um Incidente caso não haja um SLA já estabelecido. A resolução completa de um dado Incidente poderá não ocorrer por definitivo sem uma Gestão de Problemas e Mudanças.

Uma base de conhecimento é essencial para que o Service Desk possa resolver rapidamente problemas recorrentes, diminuindo esforço da equipe de Incidentes em determinar uma solução que já foi estabelecida [Berkhout et al., 2000, p.76-77].

Considerando uma visão processual da gerência, segue a figura 2.3, baseada na figura de [Berkhout et al., 2000, p.72], indicando as entradas, saídas, tarefas 
principais e relações com outras gerências.

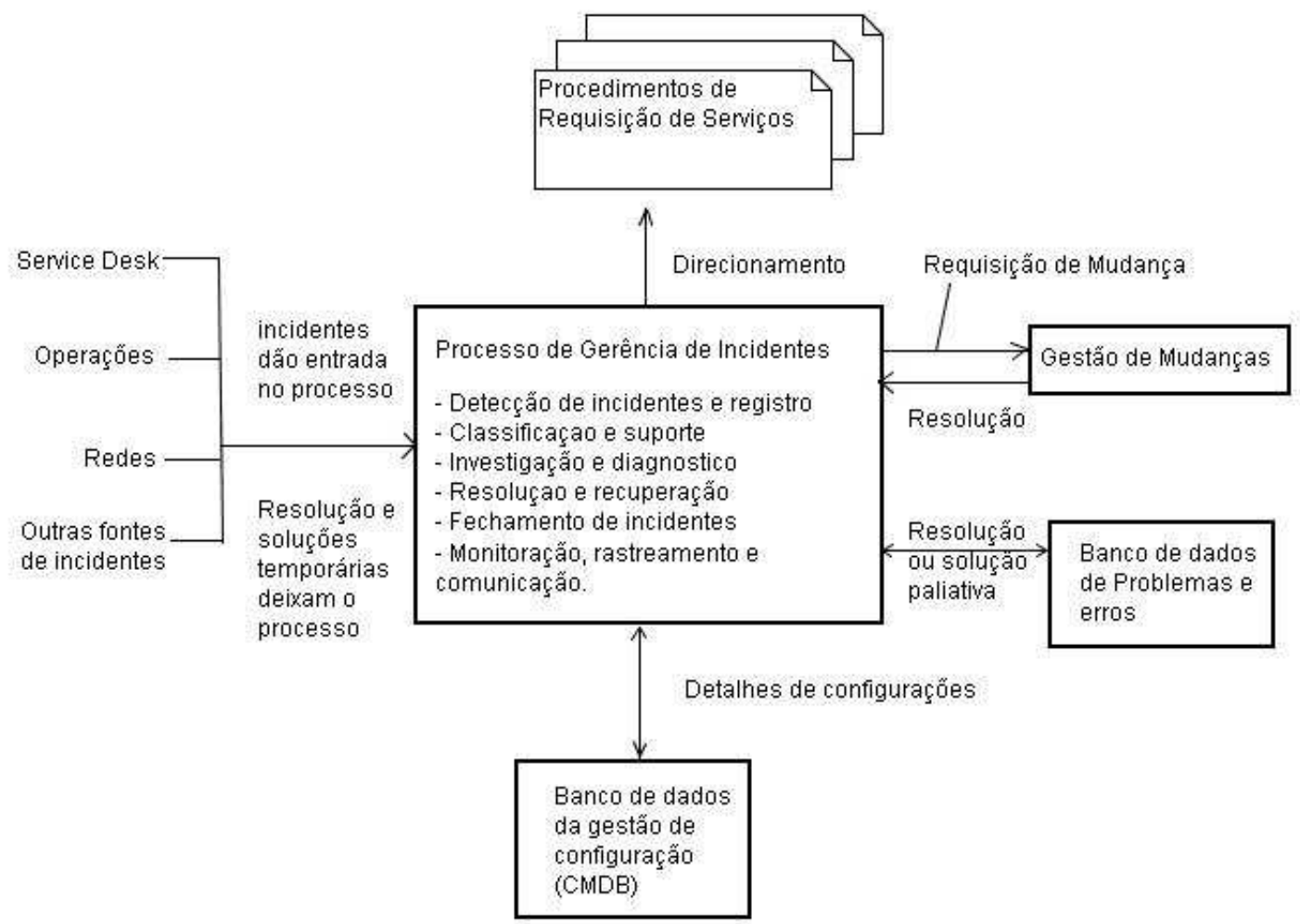

Figura 2.3: Processos relativos a Gestão de Incidentes.

Na figura 2.3, podemos enunciar as entradas principais:

- Detalhes dos Incidentes.

- Detalhes de configuração obtidos pelo CMDB.

- Associação a Problemas e Erros Conhecidos.

- Detalhes de resolução dos Incidentes.

- Retorno da resolução de uma RFC para atualização de Incidentes.

Saídas para processos da GI:

- RFC para resolução de Incidentes.

- Status de resolução dos Incidentes.

- Comunicação dos Incidentes para com os clientes.

- Relatórios gerenciais. 
São também estabelecidas como atividades e tarefas da GI:

- Registro e detecção de Incidentes.

- Classificação e tratamento.

- Avaliação, diagnóstico e investigação.

- Resolução de Incidentes e recuperação de serviços.

- Monitoração, rastreamento e comunicação de todos Incidentes.

Podemos destacar 2 principais papéis na GI: O Gestor de Incidentes e a equipe de suporte a Incidentes. Cabe ao gestor verificar a eficiência do processo, elaborar relatórios gerenciais, gerir a equipe de suporte, manter e refinar os sistemas de apoio a Incidentes.

$\mathrm{Na}$ equipe de suporte a Incidentes, a equipe de primeiro nível é designada ao Service Desk. São responsáveis pelo registro, monitoração, tratamento e classificação dos Incidentes. A equipe de nível 2 é responsável pelas mesmas atividades anteriores, porém possuem mais experiência. Além disso, a equipe também é responsável para reportar Incidentes para a Gestão de Problemas.

Cabe ao Service Desk iniciar o processso. Primeiramente há o registro do Incidente, verificação de erros no CMDB (com possível atualização), notificação ao cliente do prazo de resolução e iniciar procedimentos para tratar o Incidente. Após o registro, ocorre a classificação e é dado o início na resolução do evento.

Na etapa de classificação e início da resolução, são realizadas tarefas de investigação para a causa geradora do fato. Dada a classificação devida, determina-se a prioridade para resolução do fato. São realizadas pesquisas na Base de Erros e Problemas Conhecidos, é reportada a Gerência de Problemas a existência de novos Problemas. A solução poderá ocorrer nas equipes de nível 1, 2 ou até escalar para a Gerência de Problemas. Por fim, com a resolução do fato, os resultados dessa etapa serão uma possível RFC, e por diante a atualização e o fechamento do mesmo (junto à pessoa que originou registro).

\subsubsection{Revisão da Gestão de Incidentes}

A figura 2.4, baseada em [Berkhout et al., 2000], mostra a integração entre gestões. Inicialmente, erros na infra-estrutura podem gerar Incidentes. Estes são analisados, e verificados se existem soluções já conhecidas na Base de Problemas (Gestão de Problemas). Caso seja conhecido, o Problema é rapidamente resolvido. Caso não seja conhecido, é realizada uma força tarefa para resolver o Erro. Esse Erro Desconhecido é registrado para a Gestão de Problemas analisar, investigar e adotar uma resolução. Essa resolução adotada poderá se tornar uma Requisição 
de Mudança para uma solução mais abrangente do conjunto de Problemas registrados. Por seguinte, a Base de Erros é atualizada, tornando o Problema desconhecido para conhecido.

Finalmente, os Incidentes podem resultar em soluções paliativas, ou RFCs para resolução de curto prazo. Mais ainda, podem também ser escaladas para a gerência de problemas.

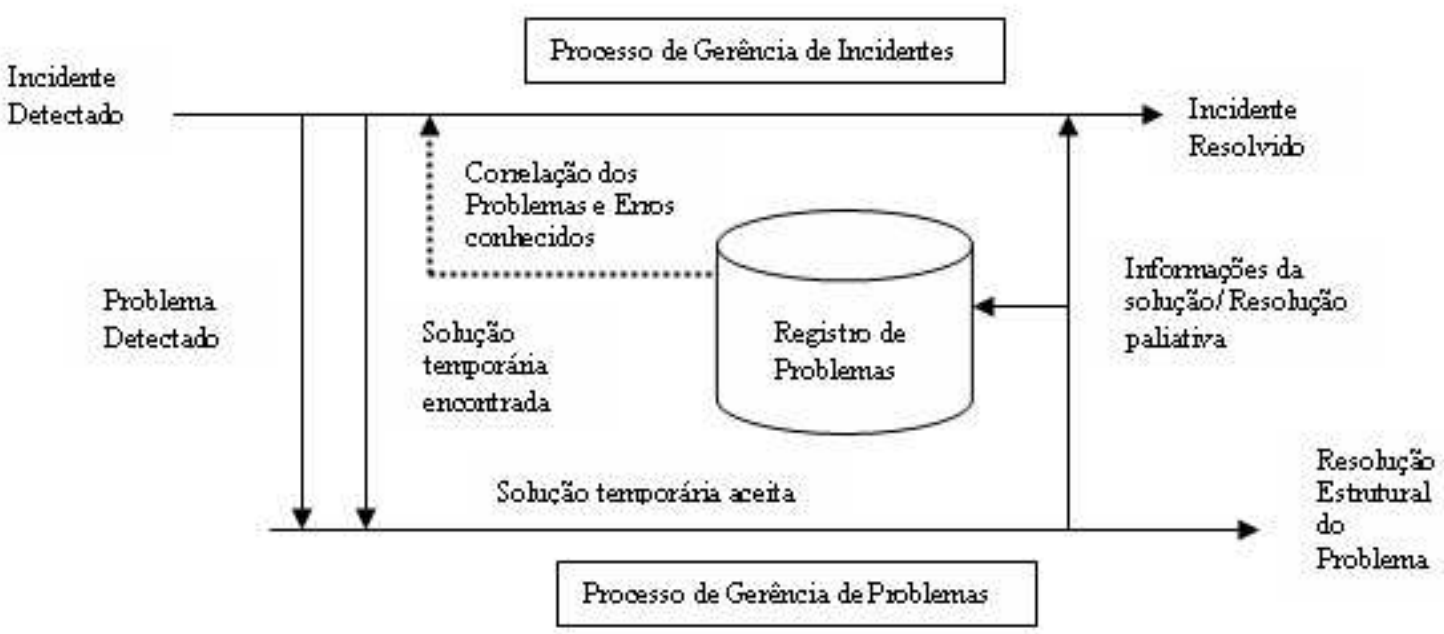

Figura 2.4: Relação entre Gestão de Incidentes e Problemas.

Para julgar o processo, e checar o desempenho com os objetivos definidos são necessárias algumas métricas. Por exemplo, o número total de Incidentes, o tempo de resolução, custos por Incidente, o número de Incidentes resoilvidos remotamente, e assim por diante. Os relatórios devem ser visíveis para os gerentes, e grupos especialistas. Se possível, também para os clientes e usuários por meio de relatórios de SLA.

\subsubsection{Service Desk}

O Service Desk ou SD atua como um ponto focal entre os clientes e os serviços de uma organização. São também responsáveis pelo controle de Incidentes e comunicação aos clientes das áreas de negócios bem como da área de TI.

A necessidade de uma organização como o SD é minimizar os custos, tornando o serviço de atendimento mais eficiente, evitando que este tratamento siga um procedimento confuso, passando a tarefa de resolução de um Problema de pessoa a pessoa até que esta seja entendida e resolvida. O atendimento ao cliente passa a ser um ponto só, para que o mesmo possa ter uma visão clara e transparente com um nível de qualidade satisfatório na resolução de Problemas. 
Dentre os objetivos designados para o SD, o mais importante é a melhoria dos serviços prestados frente aos negócios que são suportados pela TI. Também é de igual relevância, a idéia de ponto focal de contato. Isso permite que a equipe perceba as oportunidades de negócio, receba críticas dos clientes, comunique aos clientes a resolução de Incidentes e os atualize sobre demais informações relacionadas. Finalmente, o SD tem como objetivo facilitar a normalização dos serviços que a TI fornece ao negócio da empresa. A normalização dos serviços devem ocorrer com menor impacto possível, dentro de um SLA.

\subsubsection{Organização Interna do Service Desk}

O papel do SD para algumas organizações é registrar todos Incidentes, bem como gerenciar todos os estágios do processo de resolução dos Incidentes da empresa. O SD como ponto focal, poderá resolver até $85 \%$ dos Incidentes dependendo do nível de experiência da equipe [Berkhout et al., 2000, p.76-77]. Caso a resolução do Incidente não seja trivial, a resolução pode ser escalada para a responsabilidade de outros grupos solucionadores de maior nível. Por última instância, a resolução pode ser passada para a Gestão de Problemas.

Como ponto focal na comunicação, o SD tem também como função prover informações aos clientes. Essas informações poderão ser o tempo de resolução do Incidente, o cronograma da solução planejada, onde conseguir mais informações sobre algum assunto relevante, resolução de Erros Conhecidos, entre outros. Essas informações também poderão ser utilizadas pelos gerentes para auxiliar a decisão de ações, performance de SLA, entre outros.

São funções do SD o recebimento e registro dos Incidentes (seja por e-mail, telefone, sistema de apoio, fax, dependendo da implementação adotada), ao abrir o Incidente será atividade do SD indicar o IC relacionado bem como atualizar as informações relativas aos ICs junto aos clientes. Também é tarefa informar aos clientes os chamados e eventos do ambiente produtivo, monitoração de SLA, bem como comunicar aos usuários a alteração do mesmo, gerenciar Incidentes durante todo o processo de resolução, coordenar os grupos de suporte (para os casos em que é necessário escalar para resolver Problemas), identificar Problemas (contribuindo para base de Erros Conhecidos mantida na Gestão de Problemas) e o treinamento da sua equipe.

Podemos listar algumas atividades principais pertencentes ao SD [Berkhout et al., 2000, p.65-66]:

- Revisar a validade dos processos tomados bem como atualizá-los.

- Organizar e estruturar técnicas de abordagem para com os clientes.

- Manter a base de dados da clientela atualizadas.

- Promover a confiança e reforçar a relação com o cliente 
- Manter base de informação, manuais e procedimentos utilizados pelos clientes e usuários atualizados .

\subsubsection{Revisão do Service Desk}

A implementação de um SD é um conjunto de tecnologias que devem seguir de antemão um objetivo bem definido. Uma vez que para conseguir um sistema bem construído é necessário uma especificação suficientemente satisfatória, concisa e completa [Berkhout et al., 2000].

A adoção de uma estrutura de SD depende de diversos fatores, por exemplo, custo benefício, vantagens e agregação de valor. Basicamente existem 3 tipos de estruturas. O SD Local, Central e Virtual. O mais indicado pelo baixo custo é o tipo Central. Nesta estrutura, os custos operacionais são menores devido a ausência de duplicidade de recursos (hardware, software, pessoas). Há uma melhor visão de gerenciamento, uma vez que existe apenas uma base de dados e a utilização mais econômica de recursos.

Existem uma série de tecnologias que podem ser incluídas na implementação de um SD como serviços de telefonia avançados (voice over internet protocol, computer telephony integration), sistemas de e-mail, ferramentas de diagnóstico, gerencia de redes, entre outros [Berkhout et al., 2000, p.43-45].

O software de suporte aos Incidentes deve possuir seus processos bem documentados, seguindo a recomendação ITIL. Deve também ter uma base de pessoas adequada para ser utilizada na comunicação de eventos aos clientes. Uma base de conhecimento também auxiliará na resolução de Incidentes, bem como ajudar na filtragem de pedidos recebidos.

Somente a tecnologia não possibilita a solução de problemas. Um outro fator para uma solução completa são as pessoas. As mais adequadas a realizar o atendimento aos clientes são aquelas que possuem um encontro de habilidades técnicas bem como habilidades com pessoas. O objetivo é que se promova um ambiente onde os papéis estejam bem definidos, bem como os processos e pessoas motivadas. Um colaborador motivado por seguinte demonstrará um bom nível de serviços aos clientes.

Algumas características são recomendadas para a equipe como o foco no cliente, profissionais articulados e metódicos e que tenham habilidades com pessoas. Em [Berkhout et al., 2000, p.62-63] são ilustradas técnicas de comunicação importantes no tratamento de clientes. Também é necessário que sejam capazes de entender os objetivos da empresa e que também tenham atitude positiva com o nível de qualidade de suas atividades.

Alguns quesitos podem ser enumerados para que o SD atinja satisfatoriamente seus objetivos. São eles: um conhecimento razoável do negócio da empresa, um sistema de apoio confiável, uma equipe com habilidades suficientes, treinamento 
contínuo para a equipe, divulgação dos serviços do SD, a satisfação do cliente e a retenção do mesmo.

São igualmente importantes as métricas que podem ser incorporadas aos sistemas de apoio, por exemplo, dados gerenciais sobre o tempo de resolução de Incidentes, monitoração do trabalho sobre os Incidentes, número de ligações, requisições de serviços, entre outros. Tudo isso pode ser utilizado para melhorar os processos e funções e conseqüentemente o atendimento.

Uma implementação satisfatória não é um processo onde existe um fim, mas sim um constante ajuste entre as demandas de serviços da organização. Isso exige que as demandas de negócios estejam bem estabelecidas, as sugestões dos clientes sejam bem compreendidas, bem como os objetivos e metas. Deve-se seguir uma implementação que reduza os custos, detenha a satisfação dos clientes, e garanta um alto nível de comprometimento na equipe.

\subsubsection{Gestão de Mudanças}

O objetivo da Gestão de Mudanças (GM) é assegurar a continuidade do negócio no ambiente produtivo. Por meio de métodos e procedimentos, as Mudanças são implementadas com maior eficiência. Consequentemente, o impacto no ambiente produtivo será minimizado o que pode melhorar a área de operações de TI em uma empresa.

Define-se como Mudança toda transição de um estado a outro. Nesta transição a gestão abrange todo tipo de hardware, software, equipamento de rede, sistema, documentação e procedimentos associados a manutenção e suporte desses elementos [Berkhout et al., 2000]. Qualquer artefato ou componente sob controle de uma equipe de desenvolvimento não é escopo da gerência. Entretanto, para que esse artefato venha para o ambiente produtivo, é necessário que passe por essa gerência.

As entradas nesta gestão são as Requisições de Mudanças, o CMDB, e o Cronograma de Mudanças Futuras. As atividades a serem realizadas são a classificação, priorização, filtragem, a realização de reuniões, controle dos processos de manutenções e geração de relatórios. São saídas da gerência o Cronograma de Mudanças Futuras, as Requisições de Mudanças, as decisões do Comitê e os relatórios.

A GM não é responsável pela identificação de ICs ou a atualização do CMDB, nem é responsável pela liberação de um componente em ambiente de produção. É de responsabilidade da gerência o registro e controle das Mudanças, a análise de impacto, custo e risco de implementação, obtenção de aprovação, gestão da implementação, revisão e fechamento das RFCs.

A importância da GM está no fato de que os negócios da empresa estão baseados fortemente em sistemas de informação e tecnologia. A gestão eficiente promove 
redução de custos, com diminuição de horas de manutenção, economia de recursos, sejam eles tecnológicos ou humanos.

Os limites entre GI e GM está principalmente no objetivo final do trabalho realizado. Em relação a um Incidente, o que se pede é um serviço. Por exemplo, uma instalação de programa em um computador, a criação de uma conta de e-mail, entre outros. Já uma Mudança envolve uma alteração na infra-estrutura a qual resulta em uma resolução de Problema e assim uma alteração de um estado para outro. São exemplos de Mudanças a Liberação de uma nova versão a qual um certo grupo de usuários utiliza diariamente, implementação de uma nova arquitetura, entre outros. É importante que se delimite as fronteiras das gerências estabelecendo funções bem definidas para cada área [Berkhout et al., 2000].

Os conceitos relacionados a Mudanças são principalmente processuais e gerenciais. Os aspectos técnicos são relevantes, porém para a equipe de Mudanças não é o foco principal do trabalho se compararmos com a GI, por exemplo. Para cada organização deverá ser decidido o processo de Mudanças evitando que se torne ineficiente e não adequado à dinâmica da organização. Serão explicados nos próximos parágrafos alguns elementos que compõem essa gerência.

A RFC é um documento formal que contém um conjunto de informações necessárias para planejamento, execução e revisão de uma alteração no ambiente.

Devem conter na RFC [Berkhout et al., 2000]:

- Número da RFC.

- Estado da RFC que demonstra o estágio dela no ciclo de vida da Mudança.

- Motivo justificando o porquê da realização.

- O efeito da não implementação.

- O Incidente que gerou essa RFC.

- Os responsáveis pela RFC.

- Serviços impactados.

- ICs envolvidos na alteração.

- Planejamento com a estratégia de implantação.

- Plano de rollback.

- Datas de execução.

- Log de revisões da RFC, log contendo datas e horários de aprovação e alterações, entre outros. 
Em resumo, uma RFC deverá ter espaço para conter informações para todo o processo de mudança, incluindo o processo final de revisão. Durante o processo, o CMDB pode ser atualizado para estar em conformidade com as alterações realizadas.

As RFCs englobam qualquer parte da infra-estrutura de TI, incluindo serviços. Os motivos podem ser legais, uma solução de um Incidente ou Problema, introdução ou remoção de ICs. Ao fim do ciclo de uma RFC, por fim, serão coletados dados para análise, geração de relatórios, consultas futuras, indicadores de Mudanças, e outra série de interpretações que poderão vir a ser úteis para a melhoria do processo.

O Change Advisory Board (CAB), é um grupo de pessoas habilitadas a aprovar Mudanças e auxiliar a gestão das mesmas. No CAB, poderão estar presentes tanto técnicos, quanto pessoas ligadas a administração da organização, representantes de todas as áreas de prestação de serviços, equipe de desenvolvimento e os grandes usuários. Essas reuniões são compostas pelo Gerente de Mudanças, clientes, administrador de sistemas, consultores técnicos, entre outros. Poderá também participar do CAB, equipes da gerência de SLA, SD, Problemas e Incidentes [Berkhout et al., 2000].

A equipe de Mudanças poderá realizar tarefas pré-comitê, como por exemplo, circular documentos para que os envolvidos possam analisar previamente, evitando uma decisão imprópria. Para o CAB, são indicadas pessoas que possuem conhecimento técnico ou informações sobre à continuidade dos serviços e satisfação do cliente. Durante a reunião é verificada a viabilidade de recursos técnicos, humanos, materiais e a aceitação pela área de negócios. É importante que o CAB consolide um processo bem definido de análise das Mudanças para que possa existir um conjunto de critérios em concordância com os membros do CAB [Berkhout et al., 2000].

A gerência deverá disponibilizar um Cronograma de Mudanças Futuras, contendo RFCs agendadas e esta deverá estar disponível a todas pessoas da empresa, com isso qualquer imprevisto poderá ser verificado pela Gestão de SLA, áreas de negócio, SD, GI, equipe técnica, gerência de continuidade, e demais interessados no acompanhamento das manutenções e impactos relacionados [Berkhout et al., 2000].

\subsubsection{Organização Interna da Gestão de Mudanças}

No processo da GM, existem práticas adotadas pelo modelo ITIL. Todos funcionários da organização poderão requisitar Mudanças, porque se houver alguma restrição, poderá existir um ambiente de baixa inovação e melhoria. Outra prática, é o log de eventos na RFC. Todos estados deverão ser gravados na RFC, bem como a data e hora de alteração. São também exemplos de boas práticas a filtragem das RFCs, devolução da mesma com seu respectivo motivo, alocação de prioridades, comunicação, condução das CABs, aprovação de uma mudança, 
o agendamento das RFCs, e inclusive a análise de impactos. De acordo com a urgência, a RFC pode passar pelo $\mathrm{CAB}$ ( $\mathrm{RFC}$ requisitadas com antecedência) ou podem ser urgentes (o qual possui maior risco pela ausência de tempo para teste da implementação e análise de riscos) [Berkhout et al., 2000].

As atividades da GM são estabelecidas ao longo de seu processo. Desde a elaboração da RFC até o fim, no processo de revisão. Podemos enunciar as atividades da gerência cronologicamente [Berkhout et al., 2000]:

- Planejamento da implementação.

- Filtragem e alocação de Prioridades para as RFCs.

- Classificação das Mudanças de acordo com o risco para o negócio da empresa.

- Condução das reuniões do comitê.

- Análise de impacto.

- Aprovação de Mudanças.

- Agendamento de Mudanças.

- Coordenar as Mudanças.

- Revisão da RFC.

São atividades realizadas pelo Gerente de Mudanças [Berkhout et al., 2000]:

- Receber, registrar, designar prioridade, em colaboração com o solicitante todas RFCs.

- Reprovar RFCs.

- Conduzir as reuniões do CAB, notificar os membros do comitê sobre as RFCs que serão discutidas.

- Decidir quais pessoas participarão do CAB.

- Convocar reuniões do CAB emergenciais para RFCs emergenciais.

- Publicar o Cronograma de Mudanças Futuras.

- Atualizar o log de RFCs com o progresso das Mudanças, incluindo ações ou sugestões para melhoria do serviço.

- Participar da revisão de todas Mudanças implementadas para certificar de que seus objetivos foram alcançados.

- Analisar as RFCs para identificar tendências ou problemas no processo. 
- Fechar RFCs.

- Gerar regularmente relatórios gerenciais.

Tarefas dos participantes do CAB [Berkhout et al., 2000]:

- Revisão de todas RFCs submetidas.

- Certificar os impactos e a estratégia de implementação, bem como os custos envolvidos.

- Autorizar ou reprovar as RFCs, e opinar sobre as manutenções submetidas.

- Disponibilizar tempo para que sejam consultados para o caso das Mudanças emergenciais.

- Dar conselhos à equipe de GM sobre as Mudanças emergenciais.

As figuras A.1, A.2, A.3, A.4, baseados na idéia de [Berkhout et al., 2000, p.171189], veja apêndice A, página 86. Elas ilustram as atividades, processos e interações na GM. Na figura A.1, o processo inicia por força de uma nova RFC. O passo seguinte é a sua aprovação e análise. O Gestor de Mudanças filtra essas Requisições por meio de aprovações. Todas RFCs são guardadas no CMDB. Elas nunca são excluídas ou guardadas temporariamente. Inicialmente aceita a RFC, a equipe de Mudanças atribui prioridades. Caso seja urgente, a Requisição será tratada com procedimentos específicos descritos na figura A.4. Nesse caso, dependendo do tempo disponível a mudança pode passar por uma reunião de Comitê Emergencial, testes, e o próprio Gestor de Mudanças coordena a implantação do planejamento realizado. Por fim, é realizada uma revisão sobre a Mudança.

A figura A.3 mostra um tipo de categorização que uma RFC pode ser submetida. Dependendo da magnitude da Mudança, podem ser aplicados processos distintos. Por exemplo, uma Mudança de grande porte não pode ter as mesmas exigências de uma Mudança trivial. Daí a necessidade desta categorização para diferenciar os processos a serem seguidos. Tanto no processo padrão quanto no emergencial são enfatizados realização de testes prévios à implementação da Mudança. A realização de testes fica a cargo da organização ou da Equipe de Mudanças escolherem esse procedimento.

Deverão ser escolhidas medidas que demonstrem o aumento de disponibilidade dos serviços e sistemas, indicadores que mostrem a velocidade e a eficiência a qual a equipe de TI responde as necessidades de negócio. Além disso é necessário que sejam demonstradas melhoria no SLA ao longo do tempo e as tendências da gestão [Berkhout et al., 2000]. 


\subsubsection{Revisão da Gestão de Mudanças}

Para iniciarmos a demonstrar os benefícios desta gerência, precisamos indicar o que seja a eficiência e a eficácia da gerência de serviços. Enquanto a eficiência está relacionada a coerência e correções bem sucedidas, a eficácia está relacionada a satisfação dos clientes para as mudanças. São benefícios desta gerência [Berkhout et al., 2000]:

- Melhor alinhamento das áreas de TI antes das RFCs serem implementadas. Cada equipe entende o que se pede na RFC, concorda com as atividades em nível micro, o qual com todas as outras equipes envolvidas concordam no nível macro, por exemplo passagem de resultados de uma equipe a outra, com menos desentendimentos no momento de implantação o qual deve ser bem planejada.

- Maior visibilidade e comunicação tanto para áreas de negócios quanto para áreas técnicas.

Equipes que precisam acompanhar o cronograma possuem uma mesma visão macro para o conjunto de RFCs, bem como um canal de comunicação para com a gerência.

- Melhor análise de riscos, uma vez que a gerência é centralizada.

Uma gerência central pode ser importante para uma melhor eficiência. A centralidade permite uma melhor visibilidade para aqueles que utilizam serviços da GM e uma melhor comunicação para os riscos de todas RFCs submetidas.

- Melhoria do SLA, com menor tempo de indisponibilidade.

- Menor taxa de Roll Back na implementação das RFCs.

- Melhoria para outras gerências como a de Problemas e Disponibilidade.

As RFCs fechadas constituem um artefato para análise de outras gerências, como por exemplo, solução para Mudanças imediatas, tempos de execução para contabilizar a disponibilidade de ICs, entre outros.

- Maior produtividade para os clientes uma vez que o impacto é acordado e negociado entre as partes.

As Mudanças são realizadas em um horário de impacto baixo ou nulo para áreas afetadas, com isso aumentando a disponibilidade em momentos os quais as áreas técnicas muitas vezes desconhecem.

Possivelmente a GM encontrará uma forte resistência para implementação desta disciplina. Podem ser diversos os motivos que dificultarão a equipe, por exemplo, falta de atitude, falta de uma cultura a qual acredite no processo, falta de treinamento, falha nos serviços providos entre disciplinas, falta no sistema de apoio, 
entre outros. Seguem abaixo alguns problemas mais críticos [Berkhout et al., 2000]:

- Dificuldade de auditoria;

- Controle de CIs e detecção de mudanças não autorizadas no CMDB;

- Atualização de CIs;

- Treinamento das equipes de TI envolvidas;

- Desconhecimento do modelo ITIL pelas áreas técnicas.

\subsubsection{Gestão de Problemas}

A Gestão de Problemas (GP) tem por objetivo principal corrigir Problemas e prevenir a ocorrência continuada de Incidentes, identificando a causa geradora dos mesmos. Tem também por objetivo reduzir o número de Incidentes e manter uma Base de Erros Conhecidos e Problemas Conhecidos. Prevenir Incidentes significa documentar soluções, para que o próprio SD tenha capacidade de resolver imediatamente o caso. Na prevenção de Incidentes a GP pode ter dois tipos de atitudes. O reativo e o pró-ativo. O aspecto reativo é relacionado à resolução dos Problemas gerados pelos Incidentes, enquanto o pró-ativo é a correção de Problemas antes que um Incidente ocorra [Berkhout et al., 2000].

Define-se por Problema todo tipo de causa desconhecida que gere um ou mais Incidentes. Define-se Erro Conhecido como um Problema para o qual existe uma solução temporária. Os processos dessa gestão estão voltados para o gerenciamento do ciclo de vida de Erros na infra-estrutura. A identificação, classificação, investigação e diagnóstico de Erros são exemplos de atividades nos processos da GP. Além desses processos reativos, os pró-ativos lidam com a identificação de tendências, prevenção de Incidentes e Problemas na infra-estrutura. Os processos da GP estão divididos entre Problemas e Erros Conhecidos. Cada aspecto possui seus processos de registro, classificação, atualização, diagnóstico e ciclo de vida. Em [Berkhout et al., 2000, p.101-102] são mostradas algumas figuras que mostram em alto nível os processos de controle de Problemas e casamento entre Incidentes e problemas.

\subsubsection{Organização Interna da Gestão de Problemas}

Seguem abaixo as entradas, saídas e atividades relativas ao processo da GP [Berkhout et al., 2000]. Entradas da GP:

- Detalhes de Incidentes vindos da GI. 
- Detalhes do CMDB;

- Soluções Temporárias obtidas pela GI.

São consideradas saídas da GP:

- Base de Erros Conhecidos;

- RFCs;

- Atualização nos registros de Problemas;

- Registro de resolução dos Problemas;

- Relacionamento entre Problemas e Erros Conhecidos.

- Relatórios

São atividades da GP:

- Controle de Problemas;

- Identificação e classificação

- Controle de Erros

- Prevenção pró-ativa de Problemas (investigação, levantamento de dados)

- Identificação de tendências

- Revisão dos Problemas.

A GP deve ser composta de um gerente e uma equipe de suporte. O gerente monitora os processos de resolução de Problemas e Erros Conhecidos. É responsável também por gerar relatórios para serem analisados pela equipe de suporte. O gerente tem como papel manter, aprimorar e revisar os processos de controle para Problemas. Cabe a ele alocar recursos para a resolução, verificar a eficiência do controle de Erros, analisar e verificar a eficiência e eficácia da GP. A equipe de suporte é responsabilizada pela identificação e classificação dos Problemas, investigação e monitoração dos Erros Conhecidos, recomendação de soluções para a GI, auxílio na resolução de Incidentes, diagnóstico da causa geradora do Problema Berkhout et al. [2000]. 


\subsubsection{Revisão da Gestão de Problemas}

A relação entre SD, GI, GP, Gestão de Configurações e GM é de complexidade maior, envolvem mais conceitos e a noções de integração entre gestões. A Gestão de Configurações é a base de todo modelo, assim SD, GI e GP se demonstram altamente relacionados, interagindo eventualmente com a GM para solucionar a causa raiz de Problemas e Incidentes. A GP é responsável por manter um processo próprio o qual auxilia a GI na resolução dos Incidentes em menor tempo possível. Para isso, é recomendável que a equipe disponibilize uma base de conhecimento que conste tanto os Problemas quanto os Erros Conhecidos. Ao manter essa base de erros conhecidos, juntamente com as Soluções Temporárias obtidas, o SD poderá atender seus clientes em tempo mínimo. Caso o Erro seja desconhecido, esse Incidente poderá gerar um Problema. Por última instância, a resolução poderá ser escalada para a GP. A diagnóstico e correção definitiva do Problema poderá ser implementada por uma RFC. O planejamento da RFC poderá contar ainda com o auxílio do $\mathrm{CAB}$, aumentando as chances de seguir um bom planejamento. A RFC segue sua implementação que por sua vez causará a atualização da Base de Problemas e Erros Conhecidos. Em relação a Gestão de Configurações, os ICs podem apontar para uma lista de Problemas detectados assim como uma lista de Erros Conhecidos [Berkhout et al., 2000].

Um sistema de apoio automatizado para o registro de Incidentes é necessário para melhor operação da GP. Isso se justifica porque com um sistema de apoio, a recuperação de informações torna-se mais ágil. Para maior sucesso da gerência, trazer os melhores talentos da empresa é um outro ponto chave. Por fim, uma boa interação entre GI e GP é necessária para balancear os objetivos parecidos das duas gerências. São métricas importantes para a gerência [Berkhout et al., 2000]:

- Número de RFCs submetidas e o impacto na disponibilidade dos serviços;

- Tempo gasto em diagnóstico e investigação pelo grupo solucionador;

- Número de Incidentes relacionados a um tipo de Problema ou Erro Conhecido;

- A relação entre a solução imediata e planejada de Problemas;

- Listagem de ICs com maior número de Problemas;

- Tempos de resolução nos Problemas;

- Adequação aos processos da gestão.

\subsubsection{Gestão de Liberações}

A Gestão de Versões ou Liberações tem como objetivo final a entrega de um software ou hardware em ambiente produtivo. Até que se atinja esse objetivo, a 
Gestão de Liberações segue um processo de planejamento e gerenciamento para que se tenha uma Liberação satisfatória para o cliente. Alguns objetivos são o planejamento, implementação de procedimentos, rastreamento de Mudanças relativas a software ou hardware, verificação de Liberações testadas e autorizadas. Esta gestão também tem como objetivo maior proteger o ambiente produtivo de alterações que venham a causar Incidentes, reduzindo eventuais prejuízos por falta de preparação e planejamento [Berkhout et al., 2000].

A Gestão de Liberações possui seus processos que definem esta disciplina e atua num contexto onde necessita fortemente das Gerências de Configuração e Mudanças. Ao introduzir um novo software ou hardware no ambiente produtivo é necessário que estes passem pelo processo de Configuração para que sejam incluídos e validados no CMDB. Ao estar em operação, é necessário que o processo de Mudanças ocorra ajudando a implementação. Além de utilizar os dois processos auxiliares, é mantida uma Biblioteca de Software Defitiva (Definitive Software Library, DSL) para que se tenha um local centralizado que abrange todo software utilizado no ambiente de testes e produção [Berkhout et al., 2000].

A ausência dessa gestão possui uma implicação séria para os serviços de TI, pois sem o controle dos sistemas que entram em ambiente produtivo pode-se chegar a um ambiente imprevisível, complexo e vulnerável. De acordo com [Berkhout et al., 2000], o custo de implementação desta gerência é bem menor do que o custo de uma Liberação sem planejamento, gerenciamento e controle.

Liberação é utilizado neste contexto como um conjunto de Mudanças aprovadas para um dado serviço de TI. Uma Liberação é criada por uma RFC a qual coloca em ação o planejamento que é descrito.

Teoricamente existem 3 tipos de liberações: a Total, o Delta e Por Pacotes.

- A Total envolve um conjunto de correções ou componentes que são testados com antecedência e possui menor risco de implementação.

- A Delta ou também chamada de parcial inclui apenas aqueles ICs que precisam ser alterados. No caso da Delta o CAB deverá realizar uma análise e decidir se a Liberação é apropriada. A análise compreende uma verificação do esforço que será despendido, dos recursos necessários, os riscos para os negócios da empresa, entre outros.

- A Liberação Por Pacotes é a do tipo que engloba várias alterações a serem realizadas e também podem conter uma alteração concorrente de sistemas. Com esse pacote, diminui-se o número de Mudanças com maior coerência para o resultado final.

A Biblioteca de Software Definitivo é uma coleção de ICs do tipo software os quais foram autorizados e precisam ser protegidos dos ambientes de desenvolvimento, testes e produção. Essa área de armazenamento é gerenciada pela Gestão de Liberações. Recomenda-se que sejam utilizados padrões para estrutura de 
diretórios, versões, bem como reter informações sobre o tipo de ambiente relacionado, tempo de retenção de versões temporárias, políticas de segurança, procedimentos de auditoria, entre outros.

Na figura 2.5, baseada na figura de [Berkhout et al., 2000, p.209], é mostrada a relação forte entre Gestão de Configurações e Liberações. No CMDB é guardado um registro de cada Liberação, sendo assim possível construir a versão liberada. O DSL constitui o repositório central.

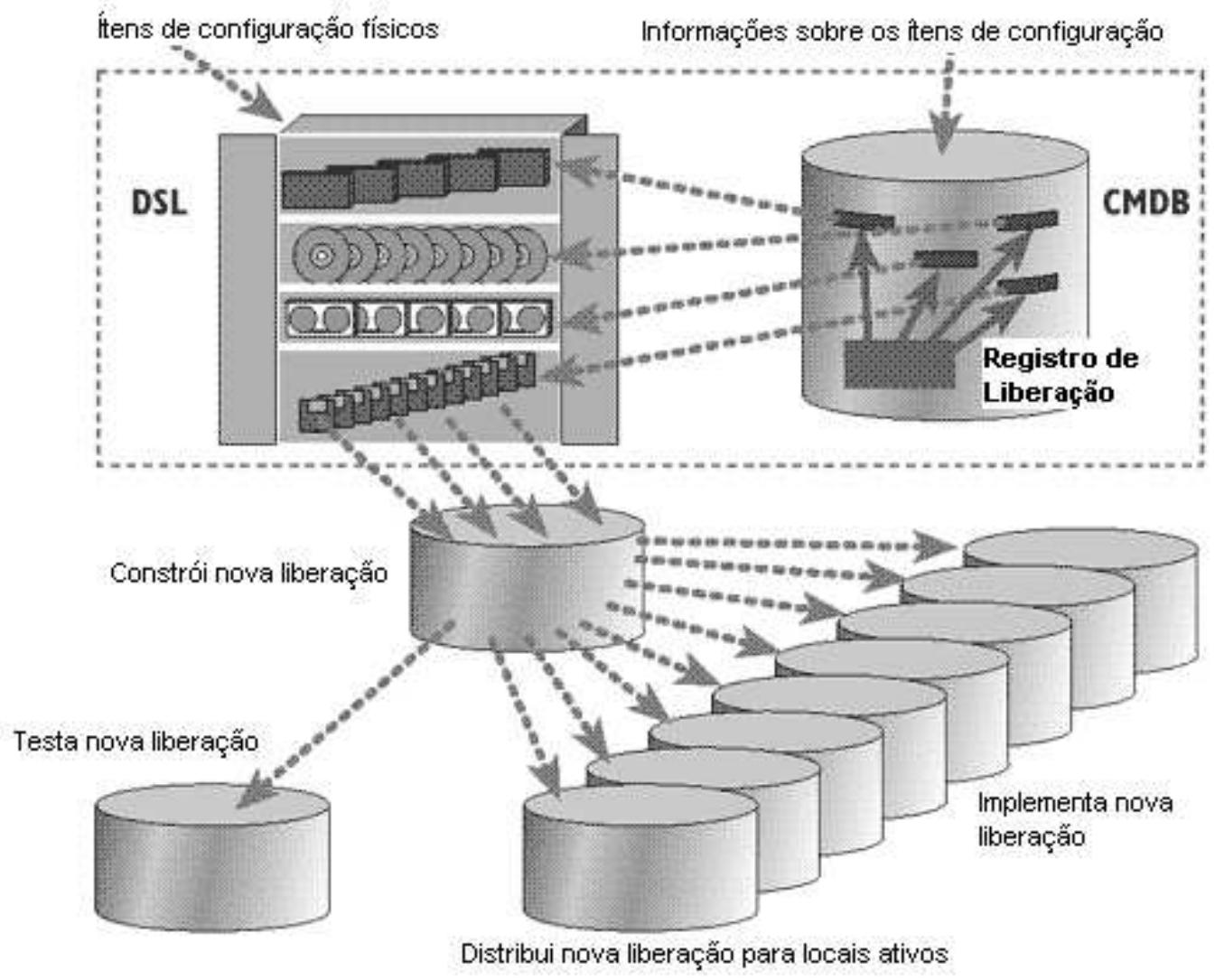

Figura 2.5: Relação entre o CMDB e a DSL.

A Biblioteca de Hardware Definitivo consiste em um acervo de hardware que é utilizado na infra-estrutura para cobrir eventuais Incidentes relativos a falha física de equipamentos. É recomendável que esteja registrado no CMDB essa biblioteca de hardware. A existência desta biblioteca pode não ser viável dependendo da empresa, devido o alto custo desse serviço [Berkhout et al., 2000].

\subsubsection{Organização Interna da Gestão de Liberações}

As atividades mais comuns desta gestão são o planejamento, gerenciamento, realização de testes a critérios estabelecidos, preparação, comunicação, treinamento, armazenamento de software validados, gerenciamento de construtos. De acordo com [Staa, 2000, p.62-63], um construto ou build é um conjunto de artefatos 
operacionais que implementam uma versão parcial e operacional de um sistema. Outras atividades desta gestão são a determinação de normas e regras para entrada de produtos em ambiente de produção, gerenciamento da Biblioteca de Software e Hardware [Berkhout et al., 2000].

Nesta gerência é importante a presença de um gerente de Liberações, um gerente de testes e a participação adicional do gerente de Mudanças, Configurações, entre outros. O gerente de Liberações deve ter um conhecimento do ambiente de TI e conhecer tanto a área de Mudanças quanto a de Configurações [Berkhout et al., 2000].

É importante o planejamento da equipe técnica nas diversas tarefas como a instalação de hardware, software, adequação ao SLA, modificação no suporte, entre outros. Os papéis desta gerência devem ser bem definidos para que se tenha um entendimento da importância de cada função e nível de autoridade entre os envolvidos no processo [Berkhout et al., 2000].

\subsubsection{Revisão da Gestão de Liberações}

As métricas a serem coletadas devem objetivar a melhoria do processo da gerência. Sendo assim podem ser enunciadas como medidas de performance [Berkhout et al., 2000]:

- Número de Liberações realizadas;

- Índice de Liberações que tiveram que retroceder;

- Índice de falhas em Liberações;

- Processo de revisão para as Liberações realizadas;

- Número de Problemas e Incidentes relacionados as Liberações.

A Gestão de Liberações constitui uma interdisciplinaridade a qual possui comunicação com várias outras áreas. Enunciamos abaixo algumas dessas interfaces [Berkhout et al., 2000].

- Gestão de Configuração: Quando novas versões de Softwares são incluídas na Biblioteca de Software Definitivo, as mesmas são atualizadas no CMDB utilizando o processo adotado pela gestão. Podem ser utilizados serviços da Configuração para auxiliar o Processo de Liberações.

- Gestão de Mudanças: O CAB com o auxílio de Liberações é responsável pelo planejamento, análise e determinação de cronogramas. A Gestão de Liberações atua somente naquelas aprovadas pelo CAB. A implementação das alterações fica a cargo da área de Mudanças. 
- Gestão de Problemas e Service Desk: Problemas podem ser encerrados devido às correções realizadas. Os Problemas gerados e os Incidentes relativos às Liberações devem ser reportadas ao Gestor de Liberações.

As empresas dependentes de TI devem ficar atentas a um modo de trabalho o qual não piore a qualidade de seus serviços. As correções e melhorias são inevitáveis aos sistemas e por isso devem ser mais controladas e bem gerenciadas. A Gestão de Liberações serve para esse objetivo sendo abaixo listados os pontos positivos mais importantes [Berkhout et al., 2000]:

- Maior taxa de sucesso na implementação de Liberações;

- Minimizar o impacto nos serviços suportados pela TI;

- Maior controle de qualidade por meio de testes e aceitação do usuário;

- Ambientes de produção mais estáveis devido a menos implementações de Mudanças;

- Redução de Erros evitando implementações de RFCs sem sucesso;

- Registros das Liberações para detectar onde ocorreu insucesso;

- Menor chance de utilização de software ilegal;

- Melhor transição dos sistemas entre desenvolvimento e produção.

A Gestão de Liberações como as outras gestões possuem seus próprios desfios. Especificamente as Liberações constituem uma disciplina complexa, pois existe um esforço de integração e relacionamento de ICs, o qual não é trivial na maioria das vezes. Passemos a citar os principais problemas a serem superados [Berkhout et al., 2000]:

- Falta de interesse das pessoas em seguir novas regras;

- Dificuldade em decidir qual a abordagem mais aplicável desta gestão para os negócios da empresa;

- Falta de recursos para manter uma Biblioteca Definitiva de Hardware;

- Desmotivação das equipes de projetos para se alinharem com auxílio da Gestão de Liberações;

- Desorganização nas equipes de desenvolvimento o qual aumentam o número de Liberações desnecessariamente;

- Desconhecimento do ambiente de TI com implementações mal planejadas que geram Incidentes. 


\subsection{Trabalhos Correlatos Sobre Gestão de TI e Modelagem de Processos}

Nesta seção, serão mostrados alguns trabalhos relacionados aos tópicos principais deste trabalho de graduação: modelagem de processos e modelos de gestão aplicados em um ambiente real. A primeira sub-seção estrutura o conhecimento sobre processos, modelagem, e mostra diversos paradigmas de modelagem segundo o artigo de [Curtis et al., 1992]. A segunda sub-seção mostra iniciativas sobre gestão e casos de estudo em várias empresas no país. Por último, um framework de qualidade, abordado por três diferentes fontes ao qual duas delas abordam o mesmo tema que é a associação do ITIL a um modelo de qualidade como forma de avaliação dos processos.

\subsubsection{Modelagem de Processos}

O artigo de [Curtis et al., 1992] aborda a modelagem de processos voltados para a gestão de desenvolvimento de software. Nele, são explicitados os tipos de linguagens de representação, os tipos de paradigmas de modelagem, e os modelos de programação em que processos podem ser modelados.

Um processo é uma representação para alocação de tarefas e responsabilidades entre humanos e computadores. Um processo pode ter diversas perspectivas, a funcional (indicação de quais tarefas estão sendo realizadas), a organizacional (sobre quais agentes estão atuando), a de informações (elicitar quais artefatos ou entidades de informação estão sendo manipulados), e a de comportamento (referente a como as tarefas são realizadas).

A modelagem de processos tem como propósito reduzir a complexidade de entendimento ou interação com um fenômeno, eliminando detalhes que não influenciam o comportamento desse fenômeno. O autor identificou elementos comuns em modelagens desse tipo. São elementos os agentes, papéis e artefatos.

A modelagem de processos possui vários entraves. São eles a falta de fidelidade entre o comportamento real e o comportamento definido, ambigüidade nos modelos, falta de consistência, o nível de granularidade adotado, consenso geral nas representações utilizadas e atualização dos modelos documentados.

Na área de computação, a modelagem de processos é utilizada como instrumento para gerenciamento de um processo de desenvolvimento, e o artigo baseia-se nessa definição de processo, como um conjunto de etapas para se atingir um objetivo final. O processo definido pode ser utilizado como forma de dirigir um projeto e controlar custos, prazos, produtividade e qualidade.

Em outras áreas, o contexto de modelagem muda. Por exemplo, na modelagem de negócios (forma de re-organização de atividades para atingir melhor eficiência), um iniciador de um processo pode ser uma pessoa e não um computador. Esse 
contexto difere da modelagem utilizada em computação. Nele, humanos são tratados como agentes que interagem com computadores, interfaces, ou transformam dados em um sistema. Em geral, a modelagem de processos também se preocupa em descrever a interação entre agentes, seja humano ou não.

A pesquisa nessa área é ainda recente, sendo os resultados dessa área espalhados além de serem conhecidos poucos métodos.

\subsubsection{Gestão de TI}

Em [Funke, 2004] são mostradas a iniciativas de algumas empresas na adoção do ITIL. São citadas algumas empresas no país e o que se aprendeu ao longo da adoção do modelo.

Segundo [Funke, 2004], ITIL não se implementa, se adota e se adapta. Essa é uma das suas dificuldades. ITIL é ainda mais abstrato que software. Consultorias e fabricantes de sistemas possuem seus modelos próprios de implementação. Empresas como Sonopress, Banco ABN Amro Real, Cassi, Metrô de São Paulo, TIM são exemplos de empresas que adotaram ITIL.

Seguem alguns casos resumidos retirados de [Funke, 2004]:

Na empresa Cassi, processos estruturados e contato com clientes internos são essenciais para uma TI com bons resultados. De acordo com a experiência deles, a TI era centrada para si, existiam sobreposição de tarefas em alguns processos, enquanto outros não tinham responsáveis. Eis aí a importância de se conhecer os processos de qualquer organização. O artigo conta também as experiências de diversas empresas, como a dificuldade de implementação, a mudança de valores na área de TI, a importância de treinamento e certificação para funcionários, e o contínuo melhoramento dos processos internos e ferramentas utilizadas.

Na ABN Amro Real, o treinamento de funcionários resultou na formação de um time de consultoria interna com o propósito de redesenhar os processos existentes na empresa. Além disso, essa equipe teria outras tarefas como nivelar conceitos, terminologias, elaborar um catálogo de serviços numa lista de processos, definir um fluxo de trabalho para cada um desses processos. O resultado dessa internalização foram diminuição de custos, simplificação da organização, menor número de Incidentes relatados.

Um outro estudo de caso, na área de telecomunicações é da empresa TIM. Na TIM, a implementação de ferramentas ITIL não foi suficiente. Foi necessário mapear todos serviços e sistemas, além de fazer uma integração e correlação entre sistemas. O problema na empresa era a falta de integração, o que não permitia a área de TI antecipar possibilidades de falta de serviço. Por exemplo, no caso de recarga de um celular pré-pago. Isso envolve trabalho da operadora, bancos e empresas de cartão de crédito. A solução da empresa foi investir em recursos de análise de impacto e busca de causa-raiz. 
Em [Ferreira, 2006], seu artigo descreve um estudo de caso em otimização de processos para uma empresa da área bancária. Foram utilizados conceitos sobre modelagem de processos, modelos ITIL e COBIT. O processo analisado foi a Gestão de Incidentes. Nessa gestão todo tipo de tarefa ou processo que causa ineficiência foi revisto e redesenhado. O COBIT, além de conter as práticas de TI como no ITIL, possui outros assuntos não abordados pelo ITIL, daí sua importância. Por exemplo, a avaliação do nível de capacidade da gestão de TI. A metodologia empregada foi positiva, pois houve diminuição de custos para as simulações realizadas nos processos redesenhados.

A conclusão do artigo [Ferreira, 2006] demonstrou que a modelagem de processos é importante, pois durante sua elaboração foram constatadas ambigüidades de tarefas, gargalos e desperdícios de recursos. Com o uso de informações estruturadas, foi possível projetar um novo processo otimizado.

\subsubsection{Modelo de Avaliação Para Gestão de TI}

O artigo [Niessink and Vliet, 1998] propõe uma forma de avaliação de processos de TI baseados no modelo de capacidade Capability Maturity Model, CMM. Esse modelo chamado de Information Technology Service CMM é utilizado como forma de avaliação do nível de capacidade dos processos de TI e identificação de melhorias futuras. Como um framework de qualidade, o IT Service CMM é uma abordagem para melhoria de qualidade nos serviços prestados pela TI.

Para melhoria contínua dos processos de TI, segundo [Niessink and Vliet, 1998] é importante entender o modelo CMM e agregá-lo ao modelo de gestão adotado como o ITIL, por exemplo.

No artigo de [Niessink and Vliet, 1998] é definido o termo Software Capability Maturity Model, seus níveis de capacidade, limites e o que cada nível descreve. Uma avaliação da situação atual e uma possível sugestão de melhoria podem ser atingidos utilizando o IT Service CMM.

O artigo [Niessink and Vliet, 1998] faz referências ao ITIL, inclusive críticas sobre suas limitações. Por exemplo, a ausência de diretivas em como implementar um catálogo de serviços. Adicionalmente, o artigo mostra alguns estudos de caso, cada qual com suas dificuldades enfrentadas. Dentre os casos abordados, destacase a dificuldade enfrentada na implementação de uma Gestão de Problemas. No caso de estudo, fica claro que Incidentes mal classificados e documentados podem tornar a base de dados de Incidentes inconsistente. Com isso, a eficiência e objetivos da Gestão de Problemas podem ser impactados.

Quanto ao IT Service CMM, o framework de qualidade proposto tem por objetivo melhorar a confiabilidade dos processos de TI, assegurar melhoria contínua nos processos e avaliar os níveis de capacidade da área focado na visão de negócios e cliente, ou seja, não voltado para TI. 
O CMM é dividido em 5 níveis: inicial, repetido, definido, gerenciado e otimizado. Termos em português foram retirados de acordo com [Leite, 2003]. No inicial, segundo [Niessink and Vliet, 1998], os processos de entrega a serviços de TI são caóticos, com poucos processos definidos, e neste caso, o sucesso depende de esforço individual. No repetido, processos de gestão de serviços conseguem rastrear custos, cronogramas e performance da TI. São repetidos os sucessos anteriores para novos projetos. O nível definido compreende processos documentados, padronizados, integrados com outros processos. São definidos templates para os projetos seguirem seus passos para uma entrega de serviços satisfatória. No nível gerenciado são coletadas métricas de projetos e processos para elaboração de indicadores de eficiência. Por fim, o último nível, otimizado, um processo de melhoria contínua é facilitada por uma revisão dos processos e tecnologias adotadas.

Em [Pink Elephant, 2004], a avaliação do modelo ITIL também é realizada com bases no conceito do CMM. De acordo com o artigo já referenciado, a avaliação permite que as melhores práticas possam ser repetidas e comunicadas para outras equipes. Além disso, permite que o número de variações de práticas adotadas se reduzam, melhorando a coerência das tarefas realizadas. Finalmente, a melhoria contínua dos processos.

A avaliação das gestões, proposta por [Pink Elephant, 2004], pode ser realizada uma a uma, tomando como referência a tabela 2.1.

A título de exemplo mostrado pelo artigo de [Pink Elephant, 2004], a avaliação é crucial para priorizar os esforços de melhoria. Primeiro para definir os recursos necessários, por seguinte a decisão de melhoria pode depender do nível de capacidade de outras áreas, por fim, decidir quais melhorias podem ser realmente atingidas.

Um exemplo priorização é a decisão de melhorias entre a gestão de configuração e mudanças. Primeiro, detecta-se a dificuldade de manter o CMDB atualizado. Isso acontece devido RFCs que não são adequadamente aprovadas ou registradas. Diante de um caso como esse, uma avaliação indica que melhorias na gestão de mudanças deverão ser implementadas antes de melhorias na gestão de configuração [Pink Elephant, 2004].

Um outro exemplo de [Pink Elephant, 2004], é a interdependência forte entre gestão de Incidentes e problema. Detecta-se que nem todos Incidentes são registrados na base de Incidentes. Além disso, um grande volume de Incidentes são categorizados de forma indevida com falta de informações. Conclui-se que sem uma gestão de Incidentes madura, é difícil que a gestão de problemas possam implementar controle de problemas e erros dentro de uma proposta eficaz. 


\begin{tabular}{|c|c|c|}
\hline Nível & Capacidade & Descrição \\
\hline 0 & Ausente & $\begin{array}{l}\text { Nenhuma evidência de atividades suportadas } \\
\text { por processos }\end{array}$ \\
\hline 1 & Inicial & $\begin{array}{l}\text { Existem definições sobre tarefas e atividades, } \\
\text { mas não se sabe como elas se relacionam em um } \\
\text { único processo. } \\
\text { - Não existe documentação. } \\
\text { - Recursos escassos ou baixo comprometimento. }\end{array}$ \\
\hline 2 & Percebido & $\begin{array}{l}\text { Existe percepção de processos, mas algumas } \\
\text { atividades estão incompletas } \\
\text { ou inconsistentes, não há métricas coletadas } \\
\text { ou de controle. } \\
\text { - Processos são definidos apenas nas } \\
\text { ferramentas utilizadas e não no amplo contexto. } \\
\text { - Posições de trabalho são criadas, mas papéis } \\
\text { e responsabilidades são definidos sem clareza. }\end{array}$ \\
\hline 3 & Controlado & $\begin{array}{l}\text { Processos são bem definidos, entendidos e } \\
\text { seguidos. } \\
\text { - Tarefas, responsabilidades e autoridades } \\
\text { estão bem definidas e comunicadas. } \\
\text { - Quesitos de qualidade estão definidos e seus } \\
\text { resultados medidos. } \\
\text { - Planejamento formal é seguido. }\end{array}$ \\
\hline 4 & Integrado & $\begin{array}{l}\text { A entrada de um dado processo é resultado de } \\
\text { outro processo controlado, as saídas de um } \\
\text { processo servem para outros processos } \\
\text { controlados } \\
\text { - Melhorias de qualidade foram atingidas } \\
\text { - Gestores de processos diferentes comunicam } \\
\text { entre si de maneira regular e formalmente. }\end{array}$ \\
\hline 5 & Otimizado & $\begin{array}{l}\text { Melhoria de qualidade e novas oportunidades de } \\
\text { negócio além dos processos. } \\
\text { - Relação entre TI e negócios da organização } \\
\text { - Evidências de inovação nos processos } \\
\text { - Gestão de qualidade e melhoria contínua são } \\
\text { praticadas } \\
\text { - Medição de eficiência }\end{array}$ \\
\hline
\end{tabular}

Tabela 2.1: Tabela de níveis de capacidade CMM. 


\section{Capítulo 3}

\section{Metodologia Adotada}

Neste capítulo serão mostradas as hipóteses para solução da problemática na empresa. Por seguinte uma breve justificativa para uma implementação de um protótipo. Mais adiante o levantamento da realidade, onde foram descritos o sistema de apoio ao ITIL utilizado na empresa e uma modelagem As Is para GI, SD, GM e Gestão de Configurações. Será também discutido uma análise do nível de capacidade das gestões existentes e por fim uma análise das simulações obtidas pelos processos As Is e To Be com o foco na GM.

\subsection{Hipóteses de Solução do Problema}

De forma a podermos adequar os processos ao modelo ITIL ou até melhorar o nível de capacidade dos processos, uma reengenharia do processo pode ser realizada tendo como base as diretivas sugeridas pelo próprio ITIL. Gerando mais interação entre as áreas, que hoje se encontram relativamente individualizadas e uma vez realizada essa reengenharia, seria necessário elaborar um plano de ação para implementá-la na empresa buscando cooperação dos colaboradores e explicitando a importância, as vantagens e a dinamicidade que isso traz para as gestões existentes.

Quanto à automatização dos processos deve-se verificar tarefas repetitivas e simples de forma que seja possível substituir tais tarefas por macros, programas ou sistemas de apoio a decisão. Acreditamos que a partir de um levantamento completo da conjectura atual dos processos internos da empresa e de uma devida documentação pode ser realizada uma análise profunda e compará-las com o framework das melhores práticas apresentadas no modelo ITIL.

A partir desta comparação seria possível verificar o grau de adequação ao modelo atualmente adotado e sugerir novas formas e reestruturações no processo visando a total implementação do modelo, inclusive delimitando a integração entre gerências, de forma a alcançar todos os benefícios que este framework de 
operações provê.

Acrescido à remodelagem e adequação dos processos, há na empresa também certa necessidade de ferramentas de apoio à decisão uma vez que o sistema de apoio ao ITIL, atualmente utilizada, tem um foco em registros isolados e nas minúcias de cada um deles. Desta forma, ficam claros os benefícios de uma ferramenta auxiliar que facilite a realização de tarefas que necessitam de referências cruzadas entre vários registros, desapegada dos detalhes e peculiaridades, fornecendo assim um contexto único, genérico e apropriado para os gerentes e usuários.

Esta referência cruzada incluiria formas de ver RFCs concorrentes, que possuam sistemas impactados similares, distribuição dos chamados em função do tempo e do sistema impactado.

\subsection{Justificativa}

Existem no mercado diversos estudos de caso apontando todos benefícios obtidos pela implementação de um framework de operações. Dentre estes benefícios devem ser destacados novamente a redução de custos operacionais, a maior controlabilidade do ambiente como um todo, o aumento de qualidade dos serviços prestados e um grau de disponibilidade dos ambientes ampliado. Estes benefícios são necessariamente proporcionais ao grau de adequação, respeito e cooperação com o processo implementado [Funke, 2004].

Desta forma, torna-se claro que todo e qualquer esforço para tornar os processos internos da empresa mais adequados ao framework escolhido terão em médio e longo prazo efeitos muito benéficos para imagem da empresa perante os consumidores e para o seu orçamento por obter melhor custo-benefício.

Outra forma de melhorar o processo e reduzir custos é desonerar os funcionários de funções trabalhosas, repetitivas e rotineiras, substituindo-as por formas de execução automatizadas mais eficientes e com melhor custo de conformidade.

\subsection{Levantamento da Realidade}

O trabalho de levantamento de dados foi realizado por meio de entrevistas, documentos, conhecimentos adquiridos na empresa e dados amostrais do CMDB. Nas páginas a seguir serão mostrados os processos As Is para as Gestão de Incidentes, Service Desk, Gestão de Configurações e Gestão de Mudanças. As modelagens foram realizadas utilizando a ferramenta WBI Workbench da IBM versão $4.2 .3 \mathrm{e}$ o documento tutorial da ferramenta (veja [IBM, 2003]).

A empresa utiliza um sistema de apoio o qual automatiza workflows e tarefas, como por exemplo, notificações por e-mail, compartilhamento de documentos, 
rastreamento de Incidentes, RFCs e ICs durante seu ciclo de vida. Todas as áreas levantadas utilizam o mesmo sistema de apoio, cada gestão utiliza seu módulo próprio. O sistema possui um CMDB a qual é compartilhada por todas gerências. Cada gerência possui uma interface diferente das demais e focada para sua área específica.

Na figura 3.1, ilustramos como esse sistema funciona em alto nível. Fora da caixa maior, temos os clientes que podem entrar em contato direto com o SD (por telefone ou utilizando o sistema) ou com a GM (somente utilizando a ferramenta). As duas setas que apontam para sentidos opostos entre os clientes, SD e clientes, mudanças indicam que os clientes podem ter acesso, e recebem retorno por meio de um sub-sistema que envia automaticamente $e$-mails. A GI, por sua vez pode ter acesso ao módulo de Mudanças, no caso de Mudanças imediatas. Obviamente, ambas gerências têm acesso ao CMDB tanto para guardar dados sobre Incidentes e RFCs que foram entrados pelos usuários, quanto para recuperar os dados já gravados no CMDB. Foi colocada uma linha em volta de GI e SD para indicar que na empresa as duas são parte de uma mesma gestão.

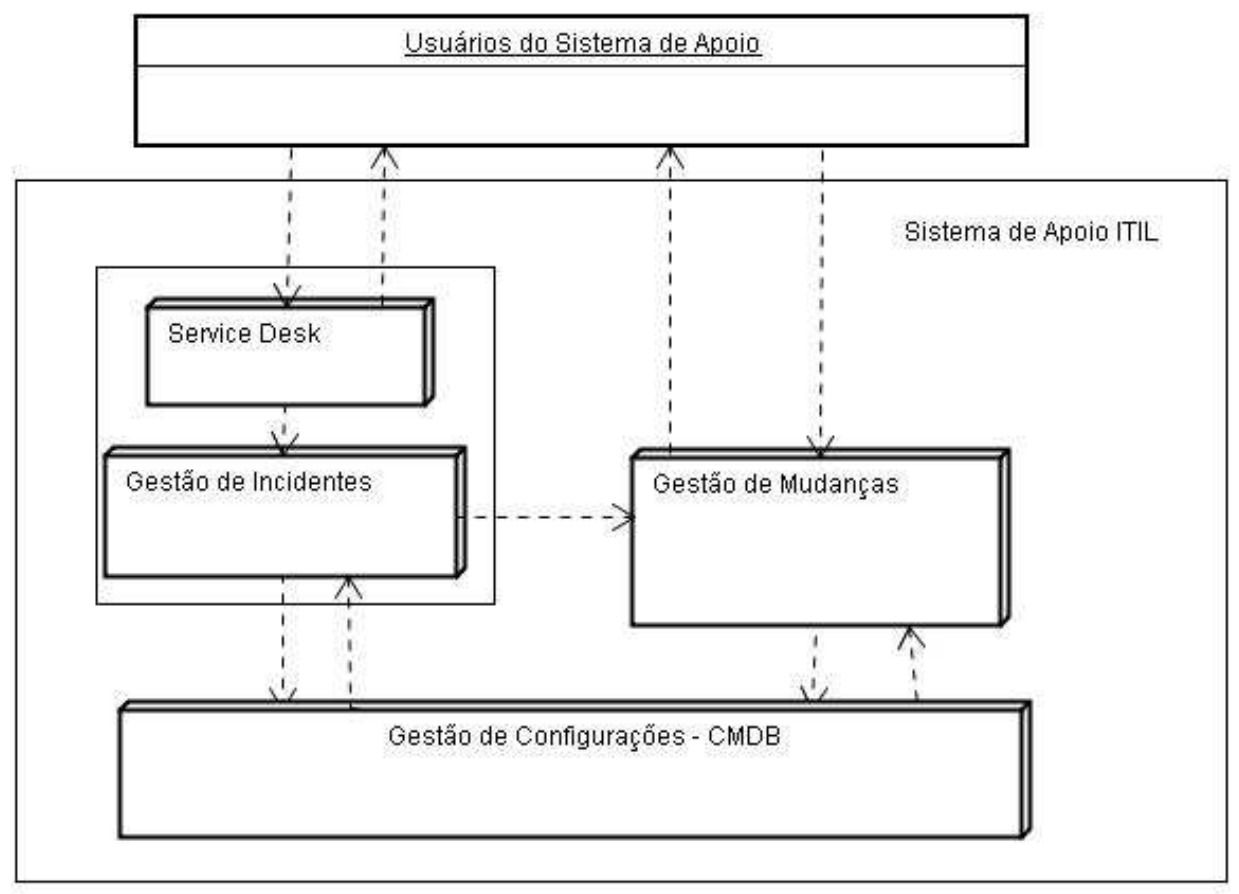

Figura 3.1: Esquema do sistema de apoio utilizado na empresa.

Os processos de SD foram modelados em 2 processos principais. São eles o processo de obtenção de informações pessoais e o registro de Incidentes.

Foram modelados 4 processos relativos à GM. Inicialmente a aprovação, com visão macro, a aprovação realizada pelo coordenador, a aprovação realizada pelo Gestor de Mudanças e por fim a execução. Também foram coletados dados de tempos para RFCs circuladas para uma reunião do CAB. Isso possibilitou simular o estado atual da gerência por meio da ferramenta Workbench, com isso pôde-se obter estimativas para tempos e custos envolvidos. 
Por último, a Gestão de Configuração foi modelada identificando 3 grandes processos. Para início uma visão geral, e os seguintes processos principais. A atualização, o cadastramento e a geração de relatórios sobre ICs.

Não foram coletados dados sobre as outras gerências, pois ficaria fora do escopo e tempo de elaboração deste trabalho uma análise exaustiva de todas gestões já existentes na empresa. Nas figuras seguintes, da figura B.1 a B.18, foram utilizadas cores para representar os atores nas caixas de atividades. A cor verde é indicada para as áreas solicitantes, a cor azul para a equipe da GM, a cor roxa para a equipe de atendentes do SD, preto para indicar diretores, por fim branco para indicar a equipe de técnicos executores.

\subsubsection{Modelagem As Is para Service Desk e Gestão de Incidentes}

O projeto ITIL implantado na empresa aglomera duas gestões em uma só área. São eles o Service Desk e a Gestão de Incidentes. A área está estruturada da seguinte forma. Uma equipe de atendentes realiza recebimento de Incidentes, seguido de documentação e encaminhamento de cada Incidente de um cliente. São aceitos tanto formulários eletrônicos (realizados pelo sistema de apoio) quanto ligações telefônicas. O correio eletrônico não é aceito nesse centro de atendimento, exceto casos especiais os quais são tratados pelos supervisores da equipe. Os atendentes, uma vez documentado e registrado o Incidente, encaminham esse documento eletrônico aos grupos executores. Por sua vez, eles fazem registro da solução do Incidente. Na empresa, o termo chamado é sinônimo de Incidente. O termo Help Desk é também designado para Service Desk.

Na figura B.1 é mostrado o processo inicial de recebimento de chamados. Existem duas formas de se avisar um Incidente, ambas formas já descritas no parágrafo anterior. Cabe ao atendente do SD registrar, categorizar e atribuir uma prioridade ao Incidente. Em casos de Incidentes maiores, o supervisor é notificado imediatamente pelos membros da equipe. Na figura B.2, o processo de resolução é demonstrada. O Incidente pode ser resolvido alí mesmo com o atendente ou pode ser indicado para uma outra equipe técnica. Incidentes menores relativos a informática podem ser resolvidos com o atendente por meio de solução remota. Outros eventos maiores que passam pelo escopo de aplicações específicas, sistema de banco de dados, rede, sistemas operacionais, equipamentos de grande porte e de infra-estrutura são designados para equipes técnicas específicas. A categoria informática é entendida na empresa como eventos inesperados em computadores de mesa, impressoras, teclados, monitores, entre outros.

As figuras B.3 e B.4 mostram um cenário de cadastramento ou atualização de dados pessoais de um funcionário no CMDB. Uma ligação telefônica inicia o processo a qual é recebida por um atendente do SD. O atendente passa por um roteiro de atendimento, em caso de novo usuário é realizado essa inclusão. Caso seja atualização, os novos dados são passados e salvos no cadastro. Tarefas 
relativas a cadastramento também podem ser realizadas pelo sistema de apoio (veja figura B.5), tanto para os usuários quanto para terceiros (por exemplo, novos funcionários na empresa). Um problema corrente é a desatualização desses dados. Esses dados são importantes, pois é por meio deles que é possível saber onde esse funcionário se localiza, quais equipes ele pertence, quais papéis são desempenhados, e como contactar esse cliente caso seja necessário. Fica evidente a falta de integração entre um sistema de gestão de pessoas e o CMDB. Com um problema desse tipo, o SD pode ter dificuldades em atender um cliente, ou até outras áreas como GM e GI que necessitam desses dados.

\subsubsection{Modelagem As Is para Gestão de Mudanças}

Nesta gestão, o processo de Mudanças foi modelado em 5 partes. Podemos enumerar:

1. Visão geral de aprovações ao longo do processo

2. Aprovação realizada pelos coordenadores

3. Workflow de Mudanças emergenciais.

4. Processo de Mudanças programadas

5. Processo de implantação das RFCs.

As figuras B.6 e B.7 ilustram o processo de aprovação de GMUD (sigla de designação interna na empresa para RFC). O processo se inicia com a criação e emissão de uma GMUD por um colaborador no sistema de apoio chamado Remedy. Esse colaborador é geralmente uma profissional da área de TI, em outras vezes é o líder de projeto ou técnicos que mantém a infra-estrutura. Esta GMUD é então sujeita à aprovação do coordenador deste colaborador. Se aprovada, a RFC é repassada à área de Gestão de Mudanças que poderá ou não aprovar a solicitação. Essa aprovação é realizada de acordo com uma análise de impactos, consistência das atividades, tempo disponível para negociação e alinhamento prévio com área técnica. Uma vez aprovada pela Gestão de Mudanças é encaminhada à execução, executada e homologada (ciclo de revisão da RFC). Caso a homologação não seja bem sucedida é registrado o roll-back no sistema de apoio. Essa atividade de roll-back recomenda aos técnicos executores um procedimento de retorno a um estado anterior à implementação da RFC. As solicitações tratadas pela Equipe de Mudanças pode ser de 2 tipos. A emergencial e a programada. A primeira recebe aprovação adicional pelo gerente ou diretor da área requisitante. Já as programadas são analisadas pelo CAB e não necessitam aprovação da alta gerência. Toda RFC reprovada volta para seu solicitante. A seguir serão explicitadas as caixas da figura B.6, aprovação pelos solicitantes, aprovação pela Gestor de Mudanças e a execução de RFC aprovadas (caixas verde, azul e branco, respectivamente). 
Nas figuras B.8 e B.9 são mostrados procedimentos de aprovação realizados pelo coordenador. Caso a RFC não seja do tipo programada, o assunto é escalado para seu gerente ou diretoria decidir a aprovação. A aprovação do coordenador é registrada na RFC por meio do sistema de apoio. Já a aprovação do gerente do coordenador é realizado por um e-mail enviado ao Gestor de Mudanças. Por fim, essa aprovação gerencial recebida pela equipe de Gestão de Mudanças é anexada no histórico da RFC.

As figuras B.10 e B.11 mostram os procedimentos emergenciais. Na figura B.10, a tarefa de contactar as áreas impactadas e áreas executoras podem levar um tempo maior caso a RFC seja complexa. Entretanto, o tempo de aprovação pelo Gestor de Mudanças é reduzido devido a emergencialidade. A aprovação ou não da GMUD requer uma negociação conjunta entre solicitante, áreas impactadas e executoras, sendo comum ocorrer ajustes ao longo do processo. Cabe ao Gestor de Mudanças realizar as tarefas de contactar as áreas, ajustar a Mudança (alterar dados na RFC) e final aprovação. A aprovação do Gestor de Mudanças e do aprovador emergencial (papel geralmente designado ao coordenador, figura B.11) finalmente encaminham a RFC para execução. Os técnicos executores e as áreas impactadas são notificados automaticamente pelo sistema de apoio por meio de um e-mail com dados mais importantes da RFC planejada.

A figura B.12 mostra as tarefas de RFCs programadas. Elas são analisadas e discutidas pelo $\mathrm{CAB}$ e aprovadas somente no consenso geral de haver sucesso de implantação. Cabe ao Gestor de Mudanças preparar, planejar, moderar e conduzir essa reunião. A execução da RFC aprovada é também notificada às áreas impactadas e executoras via e-mail. Vale ressaltar que durante esse processo, embora haja um tempo maior para aprovação, o volume de solicitações é muito intenso. Isso determina o ritmo da reunião, o que pode diminuir a qualidade de serviços da Gestão de Mudanças, além de tornar a reunião longa e exaustiva.

Na figura B.13 são explicitadas tarefas da fase de implantação da RFC. São tomadas como métricas os tempos de execução para cada passo de implantação de uma Mudança. Essas métricas avaliam a discrepância entre o tempo planejado e o tempo realmente despendido. Ao fim da execução, a documentação eletrônica é atualizada com esses registros. O solicitante é informado da finalização da RFC automaticamente por e-mail.

Foram coletados dados de tempos as quais possibilitaram uma simulação de custos e tempo médio para RFCs. Esses dados foram incluídos no modelo As Is da ferramenta Workbench o qual possibilitou uma estimativa mais próxima da realidade. Foi tomado um período de janeiro a maio de 2006, totalizando 489 RFCs programadas e 356 RFCs emergenciais. Foi medido o tempo médio decorrido entre a criação de uma RFC e a sua aprovação final para execução. Segue a tabela 3.1 indicando os resultados obtidos.

A GM conta com o suporte de uma equipe de desenvolvimento, focada na manutenção e evolução do sistema de apoio. O módulo que a equipe da GM utiliza está em constante evolução e correção. Foram desenvolvidas soluções para questões 


\begin{tabular}{llc} 
Tipo de RFC & Quantidade & Tempo gasto \\
\hline Emergencial & 489 & 17 horas \\
Programada & 356 & 4,5 dias \\
\hline Total & 845 &
\end{tabular}

Tabela 3.1: Quantidade de RFCs por tipo e tempo médio gasto.

de usabilidade, correção de falhas, funcionalidades inoperantes, evolução de funcionalidades, melhoria nas notificações do sistema, crítica de dados para RFCs. Estão sendo implementadas pela equipe de desenvolvimento soluções de notificação via celular (short message service, SMS), inserção de novos tipos de mudanças (as pré-aprovadas que são estabelecidas pela GM e não pelo solicitante), relatórios gerenciais, interfaceamento entre GM e Configuração, entre outros. Esses são alguns exemplos de alterações que estarão por vir ao ambiente produtivo.

A figura 3.2 mostra a dinâmica da empresa entre o período de janeiro de 2005 a junho de 2006. O período de tempo de amostragem é bem maior se compararmos ao período da figura 1.1. Os primeiros 9 meses, entre janeiro e agosto de 2005, o comportamento é justificado conforme a análise discutida na página 17. Os demais meses seguem uma tendência relativamente diferente dos meses anteriores, onde existem vales de RFCs programadas os quais se referem a intervenções no ambiente produtivo pela diretoria de TI, ou seja, foram inibidos um grande número de RFCs que não eram prioridade. Em novembro de 2005, devido às férias coletivas e período de vendas para natal, houve apenas aprovação de RFCs consideradas importantes pela diretoria. Nesse final de 2005, o volume de emergenciais foi altamente controlado por uma equipe de consultoria que realizou uma filtragem de RFCs junto à GM. Já em maio de 2006, houve outra intervenção da diretoria. Isso ocorreu devido a necessidade da área de negócios em evitar prejuízos advindos da indisponibilidade dos serviços suportados pela TI. Novamente, foram realizadas apenas RFCs necessárias para correção de falhas do ambiente produtivo, lançamento de promoções, entre outros.

\subsubsection{Modelagem As Is para Gestão de Configurações}

A Gestão de Configurações possui uma equipe com o foco em atualizar o CMDB e gerar relatórios para as outras áreas. No CMDB constam muitas informações inconsistentes com a realidade o que torna a atualização uma tarefa duradoura e difícil de alcançar.

Na figura B.14 é mostrado a visão alto nível dos processos mais básicos da gestão. São elas a atualização do CMDB e a geração de relatórios. As figuras B.15 e B.16 mostram as tarefas de geração de relatórios. Esses relatórios são lidos por gerentes, ou coordenadores das equipes. Eles tem por objetivo detectar ICs que demonstram maior freqüência de falhas ou detectar inconsistências entre os dados e o ambiente real. Essa revisão é um tipo de técnica de controle de qualidade que 


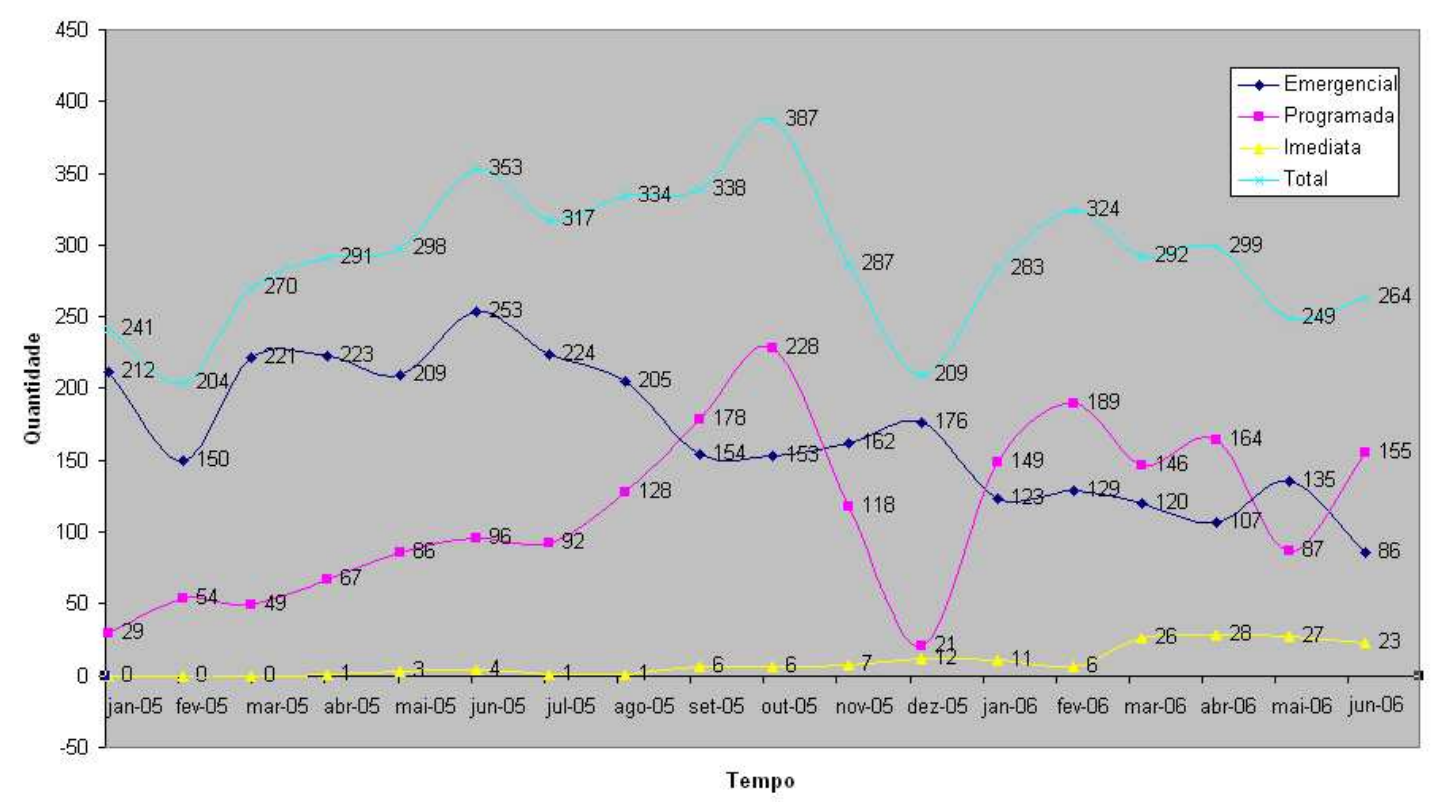

Figura 3.2: Registro de evolução de Mudanças separados por tipos. Fonte: CMDB da empresa pesquisada.

os auditores utilizam. Quanto melhor a consistência do CMDB melhor serão os dados disponibilizados para as outras áreas cliente.

Tanto na figura B.17 quanto B.18 o maior gargalo do processo se encontra na obtenção de informações a respeito dos ICs. Dependem da disposição e tempo de resposta de outras equipes técnicas em realizar essa tarefa. Por ser uma tarefa altamente manual, torna a atualização do CMDB um processo ineficiente e abaixo da velocidade ideal. 


\subsection{Análise da Realidade e Adequabilidade ao Modelo ITIL}

Neste seção serão feitas análises dos processos verificando gargalos de processo, apontando deficiências comparando o modelo teórico e por fim avaliar a viabilidade das gerências.

\subsubsection{Análise de Capacidade Sobre as Gestões Existentes na Empresa}

De acordo com os níveis de capacidade apresentados na seção 2.3.3, página 51 inclusive a tabela 2.1, as gestões implementadas na empresa podem ser avaliadas segundo os níveis CMM.

Para o SD e a GI, certamente não teríamos nível de capacidade ausente, pois as atividades são suportadas por processos. O nível inicial também é atingido, observou-se que existe uma documentação, definição de tarefas e atividades, embora muitas vezes não demonstrem consistência. A partir daqui, para os níveis de capacidade superiores, as gestões agregam apenas algumas características apresentadas. No nível de controle percebe-se que processos são bem definidos, entendidos e seguidos, existe uma razoável comunicação, embora nem todos quesitos de qualidade são entendidos e apropriadamente medidos. No nível integração percebe-se o contato com Gestão de Mudanças (trâmite de um Incidente que origina uma Mudança imediata), Configuração (acesso ao CMDB), inclusive há integração com uma área de monitoração de sistemas na empresa (o sistema de apoio permite geração automática de Incidentes, caso ocorram alarmes originados dos sistemas de monitoração). Por fim, a otimização dos sistemas é presente, devido o esforço de melhoria nos processos, evidência de inovação, evolução no sistema de apoio, gestão de qualidade. Até o nível de controle, pode-se observar que a gestão consegue se enquadrar. Os níveis superiores (controle, integração, otimização), embora não totalmente atingidos apresentam aspectos existentes na gestão.

A Gestão de Configurações segue um nível de capacidade parecido, embora existam fatores externos que influenciam o desempenho desta. Observa-se a aderência dos 3 primeiros níveis, exceto controle, integração e otimização. No controle, a atualização do CMDB depende de pessoas, o que torna o processo lento e passível de erros. A falta de disciplina no controle dos ativos pelos clientes internos e não pela equipe de configuração implica em uma falta de controle em todos quesitos definidos deste nível de capacidade. Isso se justifica pela desorganização, falta de noções sobre o modelo ITIL, pela falta de ferramentas que auxiliam o reconhecimento automático de ativos. Para os níveis de capacidade integração e otimização, nem todos quesitos foram atingidos, entretanto algumas questões como melhorias e evidências de inovação são presentes na gestão. Pode-se citar por exemplo, melhorias de otimização interna do CMDB, implementação de 
interface web para consultas rápidas ao $\mathrm{CMDB}$, interface web com catálogo de hardware e localização física em data center para a Equipe de Configurações.

A GM segue também níveis de capacidade semelhante às gestões anteriormente mencionadas. Observa-se que os objetivos são atingidos somente até o nível de capacidade controlado. O único quesito duvidoso nesse nível é a medição de resultados. Existe atualmente uma dificuldade em obter métricas confiáveis na fase de implementação de uma RFC. Essas métricas são baseadas na disciplina dos executores, daí a alta ocorrência de medições inconsistentes. Atualmente a gestão está em fase de reorganização de seus indicadores, portanto, seus quesitos de qualidades estão sendo revistos. A integração segue algumas características, portanto não totalmente aderidas. Por exemplo, está em curso o ajuste de integração entre Configurações e Mudanças. Nessa integração, uma RFC não atualiza adequadamente um IC caso esse último seja novo na base. Devido o alto volume de RFCs submetidas, pode-se ter uma noção de quantas oportunidades de atualização o CMDB perde.

A tabela 3.2 mostra resumidamente os níveis de capacidade de cada gestão implementada na empresa. Estão marcados com "X" o nível atingido pelas gestões. O símbolo "O" indica que traços do nível são atingidos, mas não plenamente. Níveis de capacidade entre 0 e 5 foram definidos conforme tabela 2.1.

\begin{tabular}{lcccccc} 
Níveis de Capacidade & 0 & 1 & 2 & 3 & 4 & 5 \\
\hline Gestões Avaliadas & & & & & & \\
Service Desk & X & X & X & O & O & O \\
Gestão de Incidentes & X & X & X & O & O & O \\
Gestão de Configuração & X & X & X & X & O & O \\
Gestão de Mudanças & X & X & X & X & O & O \\
\hline
\end{tabular}

Tabela 3.2: Níveis de capacidade atingidos por cada gestão.

\subsubsection{Processo Gestão de Mudanças - Visão Geral}

De acordo com a modelagem realizada sobre o processo de Mudanças, o tempo de trabalho real sobre as RFCs são muito menores que o tempo total do processo. Isso se deve a um longo período de latência, que pode ser atribuído à tão desejada antecedência do planejamento pregada pelo modelo ITIL o que faz com que a maioria das Mudanças sejam solicitadas muito antes da data prevista de finalização da mesma. Quanto a adequação do processo macro às melhores práticas do modelo, percebe-se que o processo é suficientemente adequado neste nível de detalhamento.

Contrastando os dados da tabela 3.1 e a figura 1.1, verifica-se que o número de RFCs programadas superam as emergenciais, estatística que contraria o panorama da figura 1.1, referente a um período de 1 ano anterior. Tal fato é justificado por duas razões. Primeiro, o envolvimento da diretoria em reprovar solicitações 
emergenciais desnecessárias e segundo lugar, a elaboração de um calendário com as janelas apropriadas para manutenções do ambiente de produção. Esse cronograma que deixou claro aos solicitantes quando e em que período as RFC podem ser submetidas.

\subsubsection{Processo de Gestão de Mudanças - Aprovação do Coordenador}

Este nível corresponde ao primeiro crivo enunciado pelo ITIL. Difere do framework, pois este crivo é dado em função do tipo de Mudança e não meramente em função da relevância da mesma. Por esse motivo e devido a uma não observância criteriosa por parte dos coordenadores dos solicitantes é possível que, no caso da adoção do modelo por uma larga fatia das áreas de negócio da empresa, ocorra um sério overhead para os gerentes, que terão que analisar cada solicitação uma a uma exercendo eles o papel que os coordenadores não exercem devidamente.

\subsubsection{Aprovação pela Gestão de Mudanças}

Podemos enunciar alguns problemas encontrados na atividade de aprovação pelo Gestor de Mudanças:

- Não há ajuste de todas RFCs antes do Comitê de Mudanças, nem negociação com as áreas executoras para resolução de assuntos técnicos.

- Não há interação entre a Gestão de Mudanças e as áreas antes e durante o desenvolvimento dos projetos.

- O Gerente de Mudanças nem sempre possui autoridade necessária para a devida atuação em seu papel.

- Não há ainda um processo bem definido e atuante no acompanhamento de cada manutenção.

- Não há um respeito e cobrança do registro no sistema de apoio a decisão o que resulta num descrédito e na incapacidade de obter medidas concretas de desempenho individual de cada área.

- Ainda não está implementada a interface entre Mudanças e Configurações. Com isso, muitas alterações de ambiente devidamente registradas com a RFC não são repassadas ao CMDB o que o torna inconsistente e inconfiável. Além disso, os níveis de segurança do ambiente produtivo são afetados, uma vez que os ICs não precisam estar cadastrados para serem utilizados em uma RFC. 
- Não há um padrão ou critério definido para escolha dos ICs de cada atividade da RFC. Por vezes é escolhido o serviço, por vezes o servidor envolvido, por vezes o software impactado, o que torna o rastreamento e histórico de manutenções algo sem sentido e impassível de ser realizado.

\subsubsection{Execução de Mudanças}

O processo aqui descrito é extremamente simples devido a grande variabilidade que este pode ter. Porém toda e qualquer atividade de uma RFC pode ser descrita desta forma. O maior problema que é verificado neste processo é o descaso dos colaboradores com a devido registro da atividade, executando de fato o registro de início de execução antes do mesmo e o registro de finalização assim que a atividade é finalizada. Devido a esta inconsistência, não é possível utilizar o sistema de apoio para realizar o acompanhamento satisfatório e os acionamentos das áreas envolvidas na ordem prevista pelo planejamento acarretando um overhead desnecessário ao solicitante que necessita fazer pessoalmente este papel.

A falta de um registro confiável gera problemas de métricas para apresentação de resultados e planejamentos de futuros RFCs. Com isso, impede maior nível de capacidade no processo da GM.

Outro ponto importante é a realização de testes antes da execução de uma mudança. A recomendação feita pelo documento ITIL é que sejam realizados testes antes que a mudança ocorra realmente. Isso não quer dizer que todas mudanças devam passar por testes, entretanto, a ferramenta de apoio não força o solicitante a questionar o fato do artefato ter sido testado ou não.

\subsubsection{Análise do Processo de Mudanças As Is}

Dados coletados durante a pesquisa permitiram a elaboração de uma simulação no processo da GM. Foram especificadas as atividades do processo, os papéis, as ferramentas de auxílio envolvidas e os atores na ferramenta. De acordo com os dados extraídos do CMDB (amostragem de RFCs da tabela 3.1 e dados da figura 3.2), foram estimadas probabilidades no programa de simulação para ocorrência de eventos possíveis. Por exemplo, a probabilidade de certa RCF ser programada ou emergencial, aprovada pelo coordenador, CAB, Gestor de Mudanças, aprovador emergencial, entre outros. A simulação gerou uma amostragem de 5 RFCs (Tarefas A, B, C, D, E) demonstradas na tabela 3.1, a duração total do processo para uma RFC (DT) em dias, a duração real da RFC (DR) em dias, e o custo associado a cada $\mathrm{RFC}$ em reais.

Como resultados obtidos, pôde-se visualizar o tempo despendido em uma RFC e o tempo real despendido sem interrupções. Os custos de cada RFC foram obtidos por estimação do valor por hora de trabalho dos profissionais envolvidos no processo. Segue na tabela 3.3 os resultados obtidos. 


\begin{tabular}{llllll} 
Tarefa & Data de início & Data fim & DT & DR & Custo \\
\hline A & $5 / 6 / 2006$ 8h & $6 / 6 / 2006$ 11h45min & 1,47 & 0,60 & 54,79 \\
B & $5 / 6 / 2006$ 8h10min & $6 / 6 / 2006$ 15h35min & 1,80 & 0,47 & 36,04 \\
C & $5 / 6 / 2006$ 8h20min & $6 / 6 / 2006$ 08h45min & 2,05 & 0,60 & 54,79 \\
D & $5 / 6 / 2006$ 8h30min & $6 / 6 / 2006$ 09h45min & 2,16 & 0,60 & 54,79 \\
E & $5 / 6 / 2006$ 8h40min & $6 / 6 / 200610 h 45 m i n$ & 2,26 & 0,60 & 54,79 \\
\hline Média & & & 1,95 & 0,57 & 51,04
\end{tabular}

Tabela 3.3: Resultados da simulação As Is para o processo de mudanças.

Na figura 3.2, verifica-se que o volume de solicitações ao longo do ano é variável, porém o número médio de RFCs por mês é relativamente alto. Nessa amostragem foram aprovadas em média 291 RFCs por mês, segundo a figura 3.2. Pode-se inferir o número que por semana, são aprovadas aproximadamente 67 RFCs. Os efeitos sazonais verificados nessa figura se devem a regras da diretoria, férias coletivas, feriados nacionais, entre outros. Verifica-se uma tendência diferenciada com maior realização de RFCs programadas (período entre janeiro a abril de 2006, onde não ocorrem cortes). As RFCs programadas são avaliadas pelas CABs. Diante essa tendência, podemos inferir também que essa sazonalidade não afeta severamente as simulações realizadas. A influência dessa sazonalidade na simulação está no fato de que quanto menos RFCs programadas, menor será a economia de gastos oferecida pela proposta do modelo To $B e$.

\subsection{Modelagem To $\mathrm{Be}$}

A modelagem realizada nesta seção compreende em uma solução para um gargalo verificado durante a realização das CABs no processo de Mudanças. Na figura B.12, foi verificado como gargalo a tarefa de aprovação de Mudanças durante o Comitê. Como previamente mencionado, o volume de RFCs é alto, e por isso a necessidade de um pré-processamento. As tarefas sugeridas estão circuladas por uma retângulo na figura 3.3. As figuras 3.3 e 3.4 mostram o processo de RFCs programadas com modificações.

Na figura 3.3, ao ser submetida uma RFC, os coordenadores das equipes de execução seriam responsáveis por utilizar o sistema pré-comitê, registrar suas decisões para serem reportadas à equipe de Gestão de Mudanças. A ferramenta gera um relatório de ajustes a serem realizados para todas RFCs que constam algum tipo de comentário. Seguindo o processo, na figura 3.4, as caixas em azul marcam as tarefas relativas a Equipe de Mudanças.

O esforço do pré-processamento nas RFCs programadas pode diminuir utilizando um sistema de apoio automatizado. No caso, o sistema pré-comitê. O volume de RFCs não resolvidas (pendentes aprovação pelo comitê) pode diminuir, pois o pessoal técnico tem acesso fácil aos pedidos de Mudanças podendo verificar 


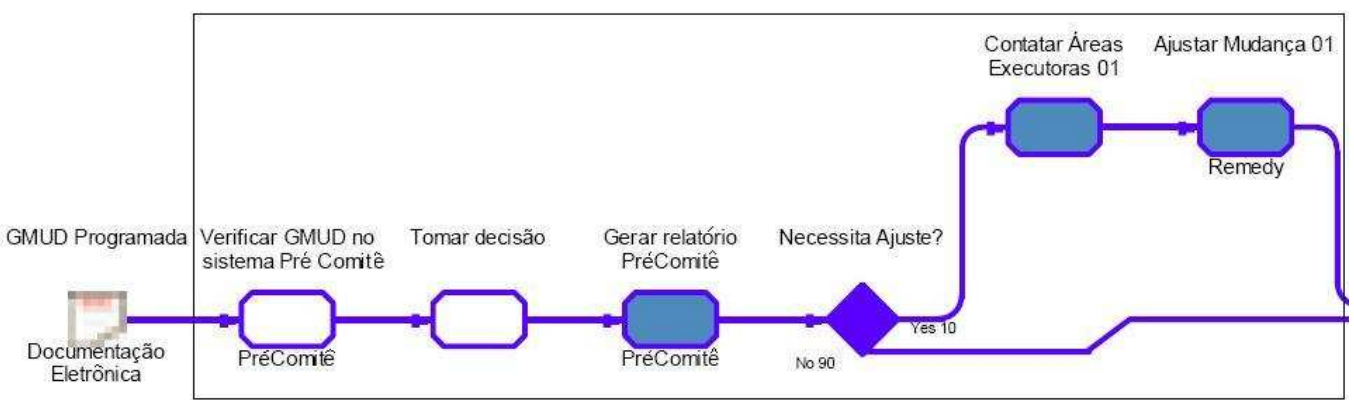

Figura 3.3: Modelagem To Be realizada na aprovação de RFCs pela GM. Continua na figura 3.4

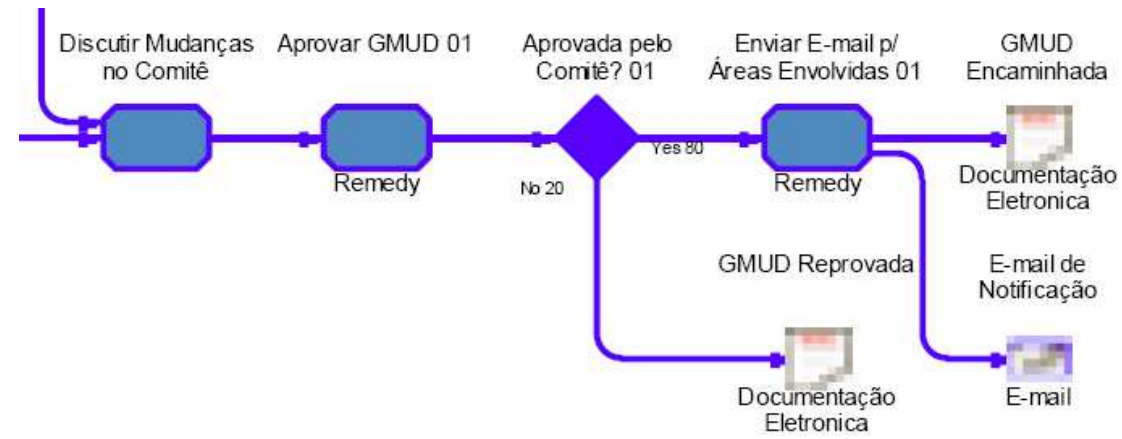

Figura 3.4: Modelagem To Be, fim do processo das RFCs programadas.

globalmente as Requisições de Mudança, e não individualmente, como o sistema de apoio atualmente permite.

As simulações obtidas do modelo modificado foram obtidas da mesma forma como mencionada anteriormente. A tabela 3.4 mostra os resultados obtidos para a nova configuração de tarefas. Os 5 casos de RFCs foram qualificados pelas datas de início e fim, a duração total do processo para uma RFC (DT) em dias, a duração real da RFC (DR) em dias, e o custo associado a cada RFC em reais.

\begin{tabular}{llllll} 
Tarefa & Data de início & Data fim & DT & DR & Custo \\
\hline $\mathrm{A}$ & $5 / 6 / 2006$ 8h & $6 / 6 / 2006$ 14h15min & 1,66 & 0,65 & 42,81 \\
$\mathrm{~B}$ & $5 / 6 / 2006$ 8h10min & $6 / 6 / 2006$ 15h15min & 1,76 & 0,65 & 42,81 \\
$\mathrm{C}$ & $5 / 6 / 2006$ 8h20min & $6 / 6 / 2006$ 16h15min & 1,86 & 0,65 & 42,81 \\
$\mathrm{D}$ & $5 / 6 / 2006$ 8h30min & $6 / 6 / 2006$ 08h15min & 1,97 & 0,65 & 42,81 \\
$\mathrm{E}$ & $5 / 6 / 2006$ 8h40min & $6 / 6 / 2006$ 09h15min & 2,07 & 0,65 & 42,81 \\
\hline Média & & & 1,86 & 0,65 & 42,81
\end{tabular}

Tabela 3.4: Resultados da simulação To Be para o processo de mudanças.

Comparando as simulações As Is e To Be nas tabelas 3.3 e 3.4, podemos verificar alterações nos valores médios de duração do processo, duração real despendida em uma RFC, e o seu custo. Houve diminuição na duração total de um processo, 
pois foi possível resolver o gargalo do processo de aprovação durante uma CAB. Em oposição à diminuição percebida, o tempo real despendido em cada RFC aumentou, devido a inserção de novas tarefas para a equipe de Gestão de Mudanças. Por fim, o custo de cada RFC foi diminuida pois os recursos despendidos na realização da CAB foram otimizados. Uma informação que um coordenador anunciava somente em tempo de $\mathrm{CAB}$ passou a ser comunicada previamente, com isso um melhor aproveitamento durante as reuniões. Por exemplo, o custo de uma reunião da alta gerência é significativo e ainda mais se realizem reuniões muito longas, o custo de um processo que depende dessa atividade pode se tornar também significativo. A tabela 3.5 demonstra o comparativo entre os resultados médios obtidos.

\begin{tabular}{ll} 
Métrica & Diferença entre As Is e To Be(em \%) \\
\hline Duração Total & 4,62 (diminuição) \\
Duração Real & 14,04 (aumento) \\
Custo & 16,12 (diminuição) \\
\hline
\end{tabular}

Tabela 3.5: Comparativo de resultados entre os modelos To Be e As Is. 


\section{Capítulo 4}

\section{Os Protótipos}

Neste capítulo serão apresentados os dois protótipos implementados neste trabalho. Ao longo das seções, serão comentadas as especificações de requisitos dos protótipos, logo após uma modelagem demostrando o workflow do funcionamento interno dos programas. Por fim, uma discussão sobre detalhes de implementação no desenvolvimento dos protótipos.

\subsection{Especificação de Requisitos do Notificador de Pendências}

A empresa estudada adota um software de e-mail da IBM chamado Lotus Notes. Os colaboradores dessa empresa utilizam diariamente esse programa, sendo que nesse software existe um sub-sistema de notificação chamado de Lotus Sametime. Esse sub-sistema funciona como um programa messenger. Quando o usuário se identifica, além de ter acesso às suas mensagens, pode trocar mensagens instantâneas com aqueles que estiverem disponíveis no diretório de colaboradores. Com isso é possível uma comunicação rápida e informal entre os funcionários.

Além desse programa, a empresa adota um sistema de apoio o qual a gestão de mudanças utiliza durante seu expediente. Todas RFCs circulam por um fluxo de trabalho, com estados definidos e bem determinados. Os estados foram descritos nas modelagens As Is. Por exemplo, quando uma RFC é executada completamente, seu estado passa para o processo de revisão. Daí, é necessário que o solicitante verifique sua RFC e certifique-se de que os objetivos foram alcançados. Devido o grande volume de RFCs, falta de hábito pelo solicitante em acessar o sistema de apoio, muitas RFCs ficam esquecidas o que deteriora a eficiência e qualidade do processo de mudanças.

No início da implantação do projeto ITIL na empresa, o volume de RFCs não era expressivo. Neste período inicial, a equipe de gestão de mudanças conseguia manter um controle razoável de todas solicitações. Porém, com a adoção do 
projeto por toda a empresa, o volume tornou-se significativo, e então, a tarefa que antes era realizada manualmente tornou-se praticamente inviável.

Uma das grandes limitações que foram encontradas no processo de mudanças da empresa estudada foi a dificuldade de acompanhamento do desenvolvimento individual de cada RFC. Isso ocorre devido à grande quantidade de solicitações e da não existência de um colaborador ou área responsável por esta atividade.

Devido ao caráter simples e mecânico que esta atividade requer, tornou-se claro que optar por uma solução automática de notificação aos responsáveis seria algo útil. Essa solução poderia ser viável e de baixo custo se comparado à opção da contratação de um ou mais colaboradores ou, por exemplo, alocar atendentes do SD, para realizar esta função.

Para resolver esse problema foi criado um programa que implementa uma notificação automática de pendências utilizando o instant messenger.

O programa é um script que realiza automaticamente a notificação via Instant Messenger do Lotus Notes (Sametime). O usuário é notificado sobre suas pendências no workflow de mudanças, evitando que estas fiquem esquecidas ou desapercebidas atrasando o processo de mudanças como um todo.

O programa é um plug-in do GAIM (protocolo de mensagens instantâneas multiplataforma) que recebe como entrada um arquivo texto. Esse arquivo pode ser atualizado diariamente com todas as pendências e tem como saída a comunicação destas pendências aos responsáveis no momento que estes realizem o login no messenger.

O programa notifica ao iniciador da RFC todas requisições que estão sob sua responsabilidade e que não estão em dia com o cronograma esperado. Para cada tipo de estado de uma $\mathrm{RFC}$, o iniciador recebe uma mensagem diferente. O usuário deve ser notificado sobre a não execução de atividades, a não realização do processo de revisão de uma Mudança, e a não confirmação sobre o encerramento da RFC.

\subsection{Especificação de Requisitos do Sistema Pré- Comitê}

A ferramenta tem a função de exibir todas as atividades de um grupo determinado e permitir a interação do usuário (dentro de um escopo delimitado, que deve necessariamente estar contido nos privilégios a ele concedidos pela empresa), permitindo à equipe de Gestão de Mudanças tomar atitudes preliminares a partir de relatório(s) gerado(s) com as entradas dos usuários.

Para tal, faz-se necessário que a ferramenta possua as seguintes funcionalidades: 
- Na validação do usuário, a autenticação no sistema Pré-Comitê deve utilizar o cadastro existente no CMDB do sistema de sistema de apoio utilizado na empresa.

- No controle de acesso, deve haver verificação de pertinência do usuário ao grupo selecionado, evitando que usuários possuam acesso às áreas não permitidas pelo sistema principal.

- Quanto ao super-usuário, o sistema Pré-Comitê deve verificar se o usuário pertence ao grupo "GMUD" e, caso pertença, permita-lhe visualizar todo e qualquer grupo, além da opção "Ver todos".

- Quanto a exibição apenas de atividades pertinentes, o sistema deve reduzir a exibição das atividades apenas ao conjunto daquelas que tenham sido designadas para o grupo executor selecionado.

- Quanto a tomada de decisão, o sistema deve permitir que o usuário selecione uma das opções de decisão padrão ("OK", "Recurso já alocado neste horário", "Horário incompatível com a atividade", "Há dúvidas quanto à execução"). Este conjunto limitado de decisões foi selecionado para que, com o menor número de opções, englobasse todas as incompatibilidades mais comuns durante as discussões de RFCs.

- Quanto a solicitação de ajuste na RFC, o sistema deve permitir ao usuário a solicitação de algum ajuste na atividade ou mudança.

- Quanto a solicitação de ajuste na RFC, esta solicitação deve se dar por meio de texto livre devido ao caráter subjetivo deste campo.

- Quanto ao armazenamento de usuários, todas as entradas dos usuários devem ser armazenadas para consulta futura.

\subsection{Workflow do Notificador de Pendências}

As figuras 4.1 e 4.2 mostram o funcionamento do programa. A cada usuário conhecido que se loga no sistema mensageiro, é lido um arquivo com a lista de pendências e dependendo do caso, são disparadas diferentes mensagens automáticas. Mais detalhes de implementação na próxima seção, veja seção 4.5.

\subsection{Workflow do Sistema Pré-Comitê}

De acordo com os requisitos citados em 4.2, seguem nas figuras 4.3, 4.4, $4.5 \mathrm{um}$ diagrama de workflow do sistema pré-comitê utilizando a ferramenta Workbench. $\mathrm{Na}$ seção 4.6, serão explicadas as figuras 4.3, 4.4, 4.5. 


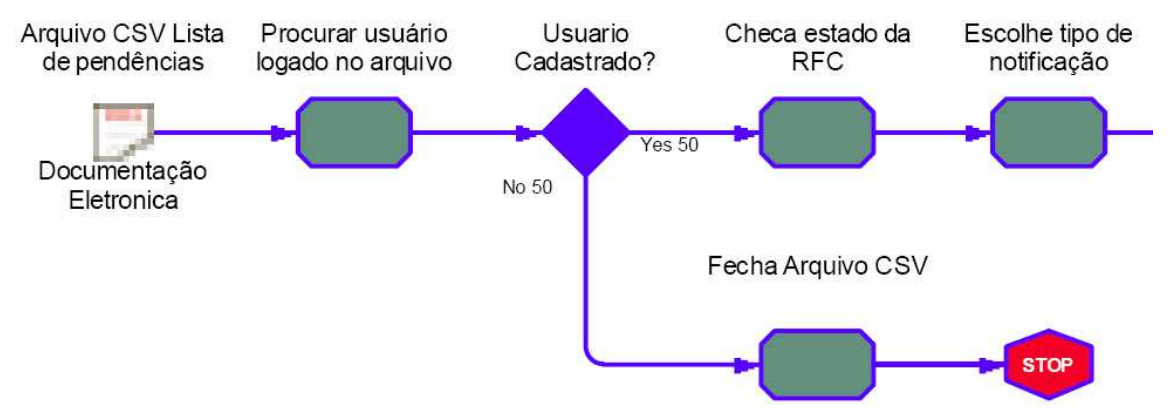

Figura 4.1: Fluxograma de funcionamento do Notificador de Pendências. Continua na figura 4.2.

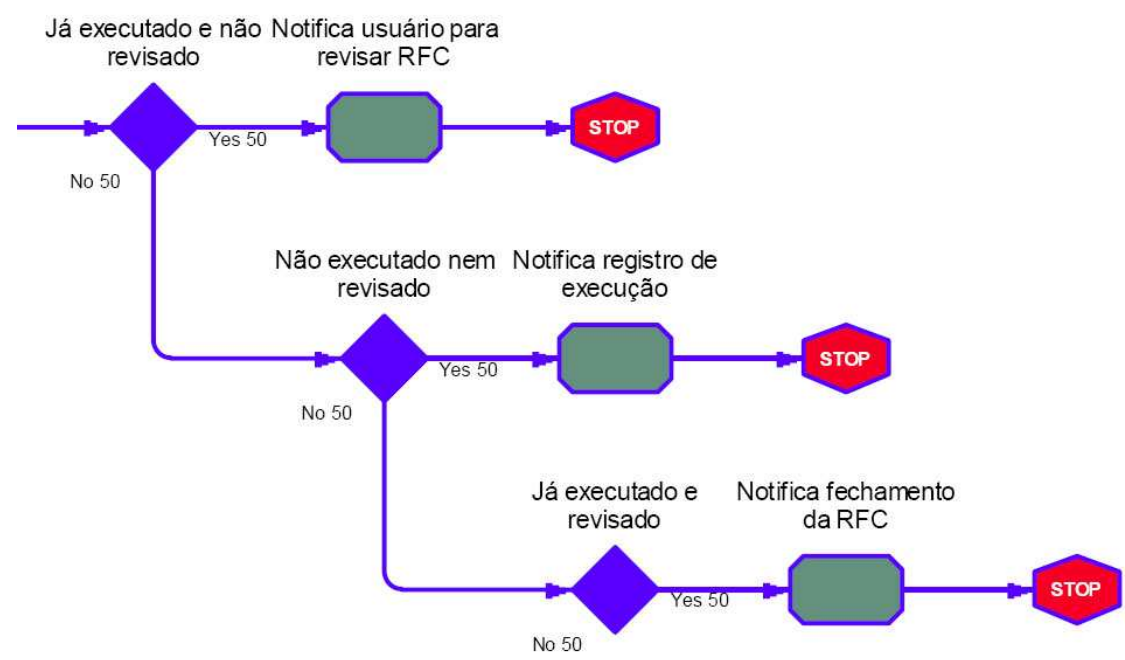

Figura 4.2: Parte final do fluxograma de funcionamento do Notificador de Pendências.

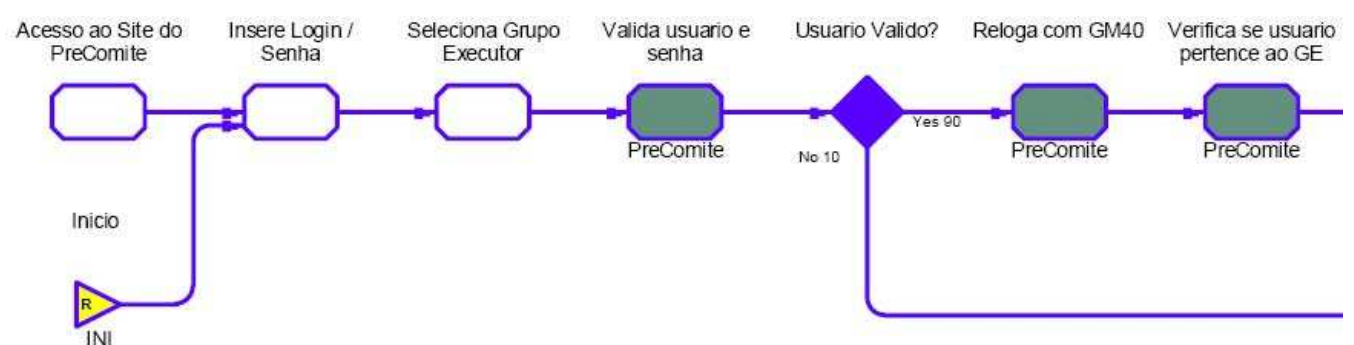

Figura 4.3: Workflow do Sistema Pré-Comitê. Continua na figura 4.4. 


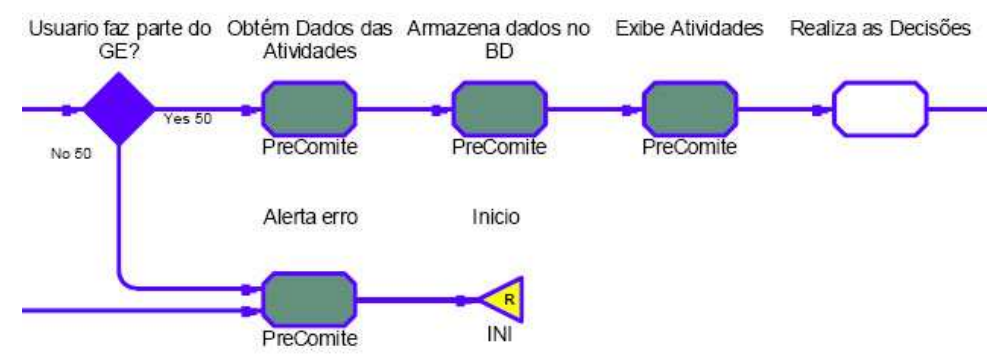

Figura 4.4: Continuação do Workflow para Sistema Pré-Comitê. Continua na figura 4.5 .

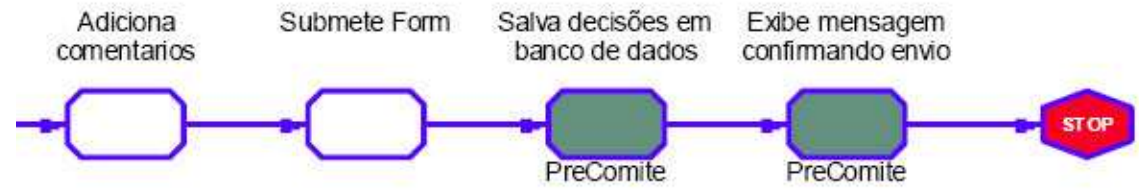

Figura 4.5: Parte final do Workflow no Sistema Pré-Comitê. 


\subsection{Desenvolvimento do Notificador de Pendências}

Para a elaboração do script do programa, foi utilizada a documentação do cliente GAIM [GAIM, 2006], foi selecionado um protocolo para uma plataforma opensource, multi-plataforma (portável) de maneira que seja utilizável em qualquer máquina.

Esta plataforma é composta do Instant Messenger GAIM, o plugin de ativação do protocolo Mean While (que permite a comunicação com os mensageiros Sametime do Lotus Notes) e um plugin a ser desenvolvido.

Além destes elementos, ainda será necessária uma atualização manual do registro de pendências através da realização de uma exportação dados do sistema de apoio no início do expediente.

Por ser um plug-in, é necessário que o GAIM tenha suporte à linguagem de programação escolhida. Dentre as opções, o PERL era a linguagem de maior simplicidade e maior documentação, inclusive com exemplos dos quais pôde ser retirado o esqueleto do plug-in desenvolvido.

Sobre o algoritmo utilizado, quando um usuário cadastrado na lista de contatos do servidor autentica no Sametime, ele gera um evento que dispara a execução do plug-in. O plug-in extrai, por meio de divisões em caracteres especiais, a matrícula do usuário que autenticou. Em seguida, ele faz uma pesquisa no arquivo de texto com a relação de RFCs pendentes e, ao encontrar alguma pendência, dispara uma mensagem instantânea para o usuário solicitando que o mesmo tome as medidas necessárias.

O código fonte se encontra no apêndice C.1 deste documento.

\subsection{Desenvolvimento do Sistema Pré-Comitê}

Para o desenvolvimento da aplicação do Pré-Comitê foram feitas as seguintes opções de projeto:

- A linguagem de programação escolhida foi o PHP (PHP: Hypertext Preprocessor) devido ao caráter de desenvolvimento para a web, o qual garante o acesso de qualquer usuário ao sistema. Outro motivo muito forte para a escolha da linguagem PHP foi a facilidade de programação e de integração com bancos de dados ODBC e MySQL

- Para realizar a persistência dos dados na implementação do sistema PréComitê foi escolhido o banco de dados MySQL pela fácil integração com o PHP e pelo custo zero. 
Quanto a plataforma de desenvolvimento, para o desenvolvimento da aplicação foram utilizados as seguintes ferramentas:

- 1 desktop na função de servidor PHP + Banco de Dados ( Apache 2.0.58 + PHP 4.4.2 + MySQL 5.0 Community Edition )

- IDEs (Integrated Development Environment) utilizadas: PHP Designer 2006 e PHPEclipse

- Ferramentas de apoio: Filezilla Server (Servidor FTP), Novell NetDrive (Mapeamento local de Compartilhamento FTP), Microsoft Access 2003 (Conexão ODBC com o MySQL e geração automática de relatórios).

Quanto aos relatórios gerados pelo sistema Pré-Comite, o sistema se comporta da seguinte forma:

- O relatório de entradas de usuários pode ser gerado de duas formas. $\mathrm{Na}$ forma completa, ele apresenta todas as atividades que foram visualizadas pelos usuários. Em contraponto, na forma resumida o relatório exibe apenas aquelas atividades que tenham tido alguma interação com o usuário (possui uma decisão ou ajuste cadastrado). Em ambos casos, apenas as atividades que ainda não tenham sido marcadas no banco de dados como efetivadas são exibidas. Desta forma, pretende-se diferenciar as que já foram apresentadas ao comitê das que não o foram.

Sobre o algoritmo utilizado, veja as figuras 4.3, 4.4 e 4.5. Segue abaixo um explicativo geral passo-a-passo.

O algoritmo do programa segue o processo decisório descrito nas figuras 4.3, 4.4 e 4.5. Quando um usuário realiza um acesso ao servidor web, este exibe uma página de informações gerais sobre o sistema (index.php) na qual são exibidos um campo de texto para inserção da autenticação utilizado no sistema de apoio, uma campo de senha para a senha do sistema de apoio e um drop down no qual o usuário seleciona o grupo executor ao qual pertence.

Após clicar em "Entrar" o usuário é redirecionado à página principal (spc.php) onde seu $\log$ in e senha são validados. Em seguida, é verificada a pertinência do usuário ao grupo escolhido. Se alguma das etapas anteriores acusar algum erro um alerta é exibido e o usuário é redirecionado à página inicial para nova tentativa de login. Se, por outro lado, nenhum erro seja encontrado o log in/senha é armazenado durante a sessão.

Uma vez validado, as RFCs e as respectivas atividades do grupo executor são pesquisadas no banco de dados do CMDB, parte dos seus dados armazenados no banco de dados MySQL à parte do CMDB, e elas são então apresentadas ao usuário solicitando-lhe que entre com suas decisões e com as sugestões de ajustes que julgar necessários. 
Se o usuário optar por fazer algum ajuste, ser-lhe-á apresentada uma caixa (implementada com DHTML) com uma página pedindo para ele entrar com o ajuste (sugestao.php). Enviando a sugestão, a caixa DHTML é remetida à página de armazenamento de ajustes (sugestao-db.php) onde o registro da RFC no MySQL será atualizado e uma mensagem confirmando o envio da sugestão será apresentada.

Depois de realizadas todas as decisões convenientes, o usuário envia o formulário e é redirecionado para a página $s p c-d b . p h p$ que atualizará os dados das atividades para os quais ele cadastrou decisões.

O sistema assume que cada decisão é suprema e portanto, não permite ao usuário posteriormente alterar as mesmas. Isso foi decidido para evitar quaisquer inconsistências de relatórios gerados com os dados do banco. Contudo ajustes podem ser adicionados, editados a todo tempo. 


\section{Capítulo 5}

\section{Análise dos Resultados}

Neste capítulo serão avaliadas as ferramentas produzidas. Nas seções serão comentadas as dificuldades de implementação enfrentadas ao longo do desenvolvimento, os limites detectados nas ferramentas, e melhorias que poderiam ser alcançadas para os protótipos. Será também apresentada as telas do Sistema Pré-Comitê.

\subsection{Notificador de Pendências}

O protótipo da forma como está codificado se restringe a notificar o solicitante da mudança o estado e a ação que ele deve tomar, incluindo o contato com as áreas envolvidas, solicitando a conclusão das atividades junto às áreas executoras.

Em um segundo momento essa interface via solicitante poderia ser retirada adicionandose apenas uma tabela de grupos aos quais cada usuário pertence, o que propiciaria que o próprio script mandasse a mensagem solicitando a execução diretamente aos executores, não necessitando mais da interferência do solicitante.

Outra melhoria passível de ser feita em futuros projetos seria a implementação de uma interface ODBC em tempo real com o banco de dados do sistema de apoio, o que permitiria a verificação em tempo real das pendências via consultas SQL e a eliminação da necessidade de uma exportação manual de dados.

Por fim, uma terceira melhoria seria a implementação de um timeout, mecanismo que permite que o script seja executado não somente no login mas rotineiramente (por exemplo, uma vez a cada meia hora) quando notificaria as atuais pendências novamente. Esta, contudo, estaria condicionada à implementação da interface ODBC pois, caso contrário, enviaria notificações de atividades possivelmente erradas.

Foram encontradas algumas dificuldades na implementação do notificador de pendências. Para que o projeto consiga obter resultados, é necessária a utilização do mensageiro instantâneo por todos os envolvidos no processo de Gestão de Mu- 
danças, o que não ocorre atualmente e além disso, o Sametime depende de uma aprovação formal para uso no ambiente de trabalho.

\subsection{Sistema Pré-Comitê}

O protótipo está atualmente executando em um computador pessoal, e portanto estará mais vulnerável, caso a aplicação entre em produção deste modo. O passo seguinte seria transpor o sistema em uma plataforma de produção mais confiável, com um próprio banco de dados interligado ao CMDB. A aceitação dos usuário foi em geral satisfatória, exceto alguns usuários que gostariam de ter uma visão diferente daquela que foi implementada no sistema.

Uma melhoria que poderia ser realizada é a integração do banco de dados do sistema diretamente ao CMDB, uma vez que existe a recomendação da documentação ITIL em sempre ter uma base de configuração única e central. O motivo para esta prática é relativo ao esforço de manter uma base única a manter um conjunto de CMDBs pulverizados em vários locais.

Algumas dificuldades encontradas foram em como lançar o protótipo para produção e realmente reforçar todos participantes da CAB em utilizar a ferramenta disponibilizada. Seria talvez possível integrar a ferramenta no sistema de apoio utilizado atualmente na empresa.

As figuras 5.1, 5.2, 5.3, 5.4, 5.5 foram capturas das telas do sistema Pré-Comitê implementado.

Na figura 5.1, pode-se ver a tela de autenticação do sistema, onde o usuário pode realizar o seu log in. É realizada uma busca no CMDB, comparando a senha entrada com a aquela existente na base de dados.

Na figura 5.2, o usuário pode ler as RFCs designadas para sua equipe técnica. Uma RFC é composta por várias atividades (listadas nas linhas na parte de baixo da tela), e ativando o botão de decisão, pode-se escolher uma opção de decisão e salvá-la. O termo "atividade" é definido na empresa como uma tarefa de planejamento durante a implementação de uma mudança. Adicionalmente, na figura 5.3, o usuário pode inserir uma descrição textual livre de sua proposta de ajustes para aquela RFC exibida na tela. Para guardar as sugestões no banco de dados do sistema, o usuário deve clicar no botão "Enviar Sugestão" após inserir o texto.

A ação realizada pelo usuário (veja figura 5.4) para salvar as decisões são guardadas no banco de dados do sistema e é exibido ao usuário uma mensagem de retorno. Logo após, na figura 5.5 é realizada a finalização e o log off no sistema Pré-Comitê. 


\section{GMUD}

mudanças operacionais de TI

\section{Bem-Vindo ao Sistema Pré-Comitê GMUD}

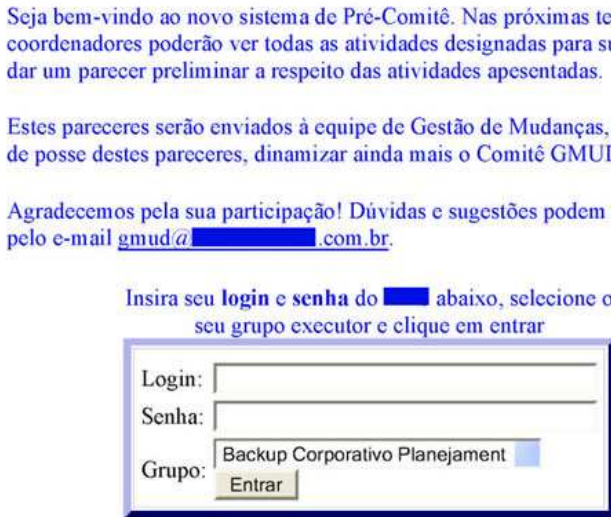

Figura 5.1: Tela de autenticação do sistema Pré-Comitê.

\section{GMUD}

mudanças operacionais de TI

\section{Pre-Comite}

\section{Relatorio}

Relação de GMUDs do proximo comite para o grupo: Backup Corporativo Planejamento

\begin{tabular}{|c|c|c|c|c|c|}
\hline $\begin{array}{l}\text { Numero } \\
\text { Mudanca: }\end{array}$ & \multicolumn{5}{|c|}{ MUD000000006869 } \\
\hline $\begin{array}{l}\text { Descricao } \\
\text { Mudanca: }\end{array}$ & \multicolumn{5}{|c|}{$\begin{array}{l}\text { [TSM] - Migração do TSM Server DFTSMNT do servidor airo-02 para o servidor } \\
\text { DFDF0262 }\end{array}$} \\
\hline $\begin{array}{l}\text { Nome } \\
\text { Solicitante: }\end{array}$ & \multicolumn{5}{|c|}{ E } \\
\hline Criticidade: & \multicolumn{5}{|l|}{ Alta } \\
\hline Data Inicio: & \multicolumn{5}{|c|}{ 10/06/2006 08:00 } \\
\hline Data Fim: & \multicolumn{5}{|c|}{$11 / 06 / 200604: 40$} \\
\hline $\begin{array}{l}\text { Impacto } \\
\text { Previsto: }\end{array}$ & \multicolumn{5}{|c|}{$\begin{array}{l}\text { Durante a manutenção não haverá a realização de backup e restore de arquivos do } \\
\text { Fileserver da não realização de restore de e-mail no servidor } \\
\text { não realização do backup dos archives do banco de dados do } \\
\text { log do sistema fretes no servidor }\end{array}$} \\
\hline Motivo: & \multicolumn{5}{|c|}{ Atualização de versão da aplicação e utilização de hardware novo } \\
\hline \multicolumn{6}{|c|}{ Atividades para o seu grupo: } \\
\hline \multicolumn{2}{|c|}{ Descricao } & $\begin{array}{l}\text { Data } \\
\text { Inicio }\end{array}$ & Data Fim & $\begin{array}{c}\text { IC } \\
\text { Impactado }\end{array}$ & Sua decisao: \\
\hline \multirow{2}{*}{\multicolumn{2}{|c|}{$\begin{array}{l}\text { Desabilitar sessões de } \\
\text { Clientes no TSM Airo_02 }\end{array}$}} & $10 / 06 / 2006$ & $10 / 06 / 2006$ & \multirow{2}{*}{${ }^{6}$ AIRO-02 } & Selecione uma opcao \\
\hline & & $08: 00$ & $08: 10$ & & Sugerir Ajuste \\
\hline \multicolumn{2}{|c|}{ Descricao } & $\begin{array}{l}\text { Data } \\
\text { Inicio }\end{array}$ & Data Fim & $\begin{array}{c}\text { IC } \\
\text { Impactado }\end{array}$ & Sua decisao: \\
\hline \multirow{2}{*}{\multicolumn{2}{|c|}{$\begin{array}{l}\text { Migrar áreas do Disk Pool } \\
\text { para Fita }\end{array}$}} & $110 / 06 / 2006$ & $10 / 06 / 2006$ & \multirow{2}{*}{6 AIRO-02 } & Selecione uma opcao \\
\hline & & $08: 10$ & 09:40 & & Sugerir Ajuste \\
\hline
\end{tabular}

Figura 5.2: Tela principal do sistema Pré-Comitê. 
GMUD

mudancas operacionais de 11 Relatorio Pre-Comite

Relação de GMUDs do proximo comite para o grupo: Backup Corporativo Planejament

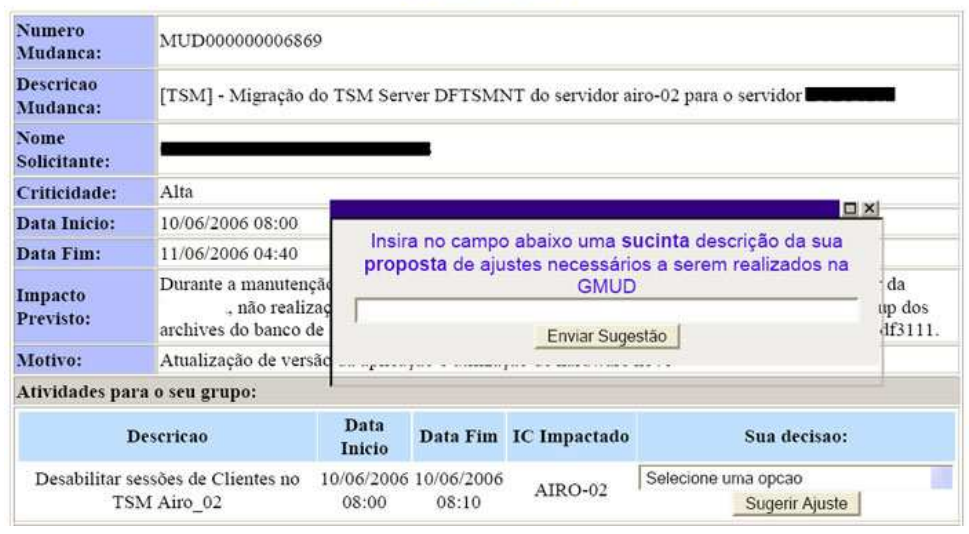

Figura 5.3: Caixa de diálogo para usuário inserir dados.

\title{
mudanças operacionais de II Relatorio Pre-Comite
}

GMUD

Relação de GMUDs do proximo comite para o grupo: Backup Corporativo Planejament

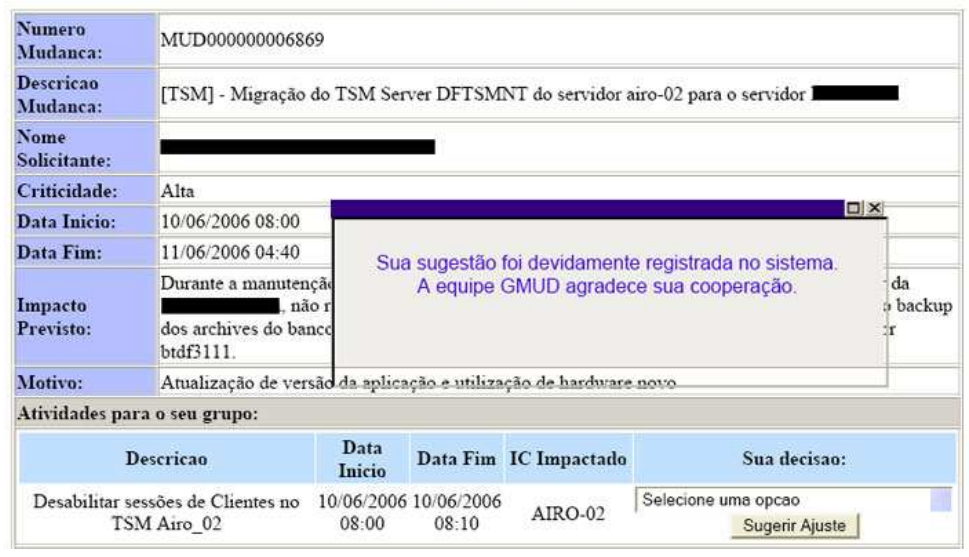

Figura 5.4: Caixa de diálogo para notificar usuário.

\section{GMUD \\ mudancas operacionais de „11 Relatório Pré-Comite}

\author{
Decisões Processadas \\ Muito Obrigado por coolaborar no processo de mudanças Operacionais de TI. \\ Esperamos que esta ferramenta tenha sido útil para você! \\ Atenciosamente, \\ Equipe de Gestão de Mudanças- GMUD
}

Figura 5.5: Tela de finalização do sistema. 


\subsection{Integração do Protótipo no Ambiente Pro- dutivo}

O protótipo, uma vez pronto, foi apresentado aos membros da empresa que são responsáveis pela área de Gestão de Mudanças e por eles muito bem recebido. Foi alvo de elogios e sugestões, algumas das quais foram inclusive acatadas e incluídas no código tais como a validação de usuário e o registro da matrícula do mesmo no momento em que ele cadastre alguma decisão.

O protótipo está sendo utilizado em uma máquina desktop da equipe de GM e se encontra ainda em fase de testes, porém com uma boa aceitação ainda que não completa por parte dos usuários (grupos executores), pois o sistema registra que algo entre 3 e 6 grupos executores utilizam-se atualmente da ferramenta para analisar as suas demandas porém há apenas 1 grupo que de fato cadastra suas decisões e os ajustes necessários.

Para que o sistema possa entrar de fato no processo e na política da empresa ele terá alguns desafios. O primeiro será migrar do banco de dados MySQL (escolhido por motivos acadêmicos para o trabalho) para o banco de dados Oracle, padrão de banco de dados para aplicativos em produção da empresa. O segundo será a alocação de um servidor 24 horas por 7 dias para hospedar o sistema e toda a infra-estrutura sob ele (APACHE + PHP4 + Oracle).

Por fim, pode-se dizer que a aceitação está sendo muito grande. Tal fato é indicado pelo número considerável de usuários do sistema, mesmo que este ainda esteja em testes, o que implica que um dos dois principais objetivos do sistema, que era o de assegurar que as pessoas não esperassem o início da reunião do CAB para saber o que lhes havia sido designado. O objetivo foi alcançado antes mesmo do sistema Pré-Comitê oficialmente chegar à produção e ser inserido no processo. Ainda falta contudo outro esforço que é exigir das equipes técnicas, usuárias do sistemas, a realização de tomada de decisão prévias, que contudo só poderá ser atingido uma vez que a fase de testes se encerre. 


\section{Capítulo 6}

\section{Conclusões e Trabalhos Futuros}

Os objetivos principais deste trabalho foram atingidos no sentido da realização do estudo do modelo ITIL e sua adequabilidade no ambiente real. As simulações, estimativas, avaliações e previsões realizadas ao longo deste trabalho auxiliaram a atingir esses objetivos e conseguiu-se obter ganhos factíveis e verossímios com alterações simples e evidentes. O estudo de caso revelou-se muito importante como fonte de melhorias a serem implementadas no processo de mudanças. A modelagem de processos foi essencial na detecção de pontos de gargalo, elaboração de sugestão de melhorias e simulações que possibilitaram motivar a implementação de um proposta de melhoria. A motivação foi materializada nas evidências das demonstrações de ganho em produtividade, redução de custos e conseqüentemente a localização em um processo sobre onde concentrar esforços para implementar melhorias.

Percebeu-se claramente que o tema abordado neste trabalho é de caráter muito recente e não conta com um acervo suficientemente amplo de textos científicos e bibliografia em língua portuguesa. O assunto sobre modelagem de processos é pouco abordado em periódicos, livros da área de computação, pesquisas acadêmicas, entre outros. Conclui-se que esta área é ainda recente e conseqüentemente seu conhecimento está sendo consolidado. A gestão de TI é assunto pouco abordado no âmbito acadêmico, entretanto é tema comum e recorrente em revistas especializadas em TI e administração. Quanto ao modelo ITIL, percebeu-se o fato da documentação original conter lacunas no conhecimento descrito pelo framework proposto. Não são descritas fórmulas prontas de implementação, mas sim boas práticas de TI que podem ser realizadas de diferentes formas, com diferentes tecnologias, e estratégias de implementação. Mais ainda, não foi encontrado um trabalho que descrevesse a interação entre métodos de engenharia de software aliado ao ITIL, de forma precisa e detalhada.

Durante a pesquisa realizada na empresa, verificou-se pelo menos duas dificuldades no levantamento da realidade. Primeiro foi como abordar outras equipes de outras gestões para que fossem realizadas as modelagens de processos. Os documentos formais encontrados pouco explicaram como as tarefas realmente são 
realizadas na Gestão de Configuração, SD e GI. Em segundo, uma dificuldade técnica foi quanto aos programas desenvolvidos e sua interação com o CMDB. O sistema Pré-Comitê pode acessar o CMDB, e devido sua importância, não foram realizados protótipos que alterassem ou gravassem dados diretamente no CMDB. Devido o risco de produzir programas que afetassem o ambiente produtivo, foram utilizados bancos de dados separados. Os programas implementados não poderiam concorrer com ferramentas já existentes para as gestões, objetivando evitar ao máximo danos e prejuízos possíveis.

Quanto aos frameworks de qualidade, verificou-se que o CMM é um dos mais notórios modelos de qualidade adotados por empresas e setor acadêmico. O CMM aliado ao ITIL foi verificado como uma boa técnica de avaliação de capacidade das gerências. Apartir dessa avaliação, é possível a elaboração de uma proposta de melhoria geral do modelo ITIL adotado na organização, levando em conta os estágios de capacidade de cada unidade de gestão e a priorização dessas melhorias. Adicionalmente, percebeu-se a incompatibilidade de coexistência entre gestões com alto nível e baixo nível de capacidade.

A proposta de melhoria adotada pela implementação do sistema pré-comitê tornou palpável a necessidade de transparência para a Gestão de Mudanças. Um sistema de apoio que não satisfaz as necessidades de seus clientes, como visto neste trabalho, descompromete sua utilização e coloca em risco os investimentos realizados. O sistema pré-comitê possibilitou uma visão geral de todas RFCs de uma CAB, aumentando o nível de satisfação dos clientes. O processo decisório que consumia recursos durante uma $\mathrm{CAB}$ foi amenizada com a redução estimada dos custos. O sistema implementado possibilitou tomadas de decisões mais rápidas, condução de CABs mais proativas (participação efetiva de seus membros) e possivelmente realização de CABs menos extensas. Nota-se que essa é uma área de muitas oportunidades a serem pesquisadas (veja no anexo D um breve ensaio para sistematização da modelagem de processos).

Para trabalhos futuros, com relação a GM, verificou-se a necessidade de um sistema web para agendamentos e publicação de cronogramas futuros de RFCs aprovadas, melhorando ainda mais a visibilidade das RFCs. Além disso, a questão da integração entre gestões, uma avaliação mais profunda nos processos das demais gestões poderiam auxiliar para visionar sistemas e ferramentas que venham a suprir necessidades entre sistema de apoio e usuários. Conforme este trabalho, verificou-se um desequilíbrio que as gestões existentes na empresa podem passar devido a ausência de tratamento eficaz em Problemas e Liberações.

Por fim, como forma de melhoria do modelo, seria de extrema relevância para próximos trabalhos uma modelagem detalhada nos processos de todas gestões existentes na empresa. Diante disso, compará-lo a um modelo completo o qual segue rigorosamente as recomendações de [Berkhout et al., 2000]. Por meio de um planejamento consistente, adotar um conjunto de melhorias por passos (até chegar ao modelo completo), visando não só uma gestão mas o conjunto delas. 


\section{Referências Bibliográficas}

Australian Technology Business Magazine (2003). Licensed to itil. http://www.zdnet.com.au/insight/soa/Licensed_to_ITIL/0, 39023731 , 20274714,00.htm. Acessado em 15 de Janeiro de 2006.

Bartlett, J., Hinley, D., Johnson, B., Johnston, D., Keeling, C., Lloyd, V., MacDonald, I., Mather, J., McLaughlin, G., Rudd, C., Wheeldon, D., and Young, R. (2001). Best Practices in Service Delivery. Stationary Office, United Kingdom, 1st edition. ISBN 0-11-330017-4.

Berkhout, M., Johnson, R. H. B., Lacy, S., Lloyd, V., Page, D., van Goethem, M., van den Bent, H., and Welter, G. (2000). Best Practices in Service Support. The Stationary Office, United Kingdom, 1st edition. ISBN 0-11-330015-8.

Cruz, T. (2000). Workflow: A tecnologia que vai revolucionar processos. Atlas, São Paulo. 2a edição. ISBN 852242618X.

Curtis, B., Kellner, M. I., and Over, J. (1992). Process modeling. Communications of The ACM, 35(9):75-90. http://portal.acm.org/ citation. cfm? $i d=130994$. 130998\&dl=GUIDE\&dl=ACM\&idx=130994\&part = periodical\&WantType=periodical\&title=Communications $\% 20$ of $\% 20$ the $\%$ 20ACM. Acessado em 23 de Junho de 2006.

Edison Electric Institute (2001). Definition of terms when discussing internet hotels. http://www.eei.org/industry_issues/retail_services_and_ delivery/Internet_Hotels/definitions/. Acessado em 29 de Julho de 2006.

Feher, P., Szabo, Z., and Klimko, G. (2004). A knowledge-based perspective of it service management. In Remenyi, D., editor, Fith European Conference on Knowledge Management, chapter 1.3, pages 331-332. Trinity College Dublin, Paris, France.

Ferreira, R. G. (2006). Modelagem de processos aplicada na gestão de um ambiente real de ti. Universidade de Brasília.

Funke, M. (2004). Itil, o lema da ti é servir bem. www.itsmf .com.br/noticias/ Materia-ITIL-IH.pdf. Acessado em 6 de Junho de 2006.

GAIM (2006). A multi-protocol instant messaging client. http://gaim. sourceforge.net/documentation.php. Acessado em 12 de Janeiro de 2006. 
IBM (2003). Ibm wbi workbench tutorial guide 4.2.4. System documentation, IBM Corporation. http://www.cstr.ed.ac.uk/projects/festival/ manual-1.3.0/. Acessado em 15 de Janeiro de 2006.

Leite, L. V. (2003). Estudo e aplicação do psp no desenvolvimento de suporte ao processo. http://www.cic.unb.br/docentes/fernando/matdidatico/ apostilas/completo/ProjetoPSP.pdf. Acessado em 24 de Abril de 2006.

Lucca, G. (2005). Uma ferramenta computacional para gestão por processos: Um estudo de caso. Dissertação de mestrado, Universidade Federal de Santa Catarina. http://teses.eps.ufsc.br/Resumo.asp?2631. Acessado em 7 de Junho de 2006.

Mertins, K. and Jochem, R. (1999). Quality-Oriented Design of Business Processes. Springer, New York, 1st edition. ISBN 0792384849.

Niessink, F. and Vliet, H. V. (1998). Towards mature it services. university of netherlands. http://www.serc.nl/people/niessink/publications/ SPIP98-2.Niessink.pdf. Acessado em 8 de Junho de 2006.

OGC (2002). ITIL Application Management. The Stationery Office, London, United Kingdom, 1st edition. ISBN 0113308663.

OGC (2005). Glossary of itil. http://www.get-best-practice.biz/glossary/ ITIL_Glossary.pdf. Acessado em 25 de Maio de 2006.

Phillips, M. (2004). Cmmi version 1.1 tutorial materials. http://www. sei.cmu . edu/cmmi/presentations/euro-sepg-tutorial/index.htm. Acessado em 8 de Junho de 2006.

Pink Elephant (2004). Process maturity white paper. $\quad$ http://www.pinkelephant.com/NR/rdonlyres/ 44BA79E3-798C-4D18-BAE4-EF000F7838BE/0/ITIL_Process_Maturity_ SelfAssessment.pdf. Acessado em 24 de Maio de 2006.

Santos, A. G. (2005). Modelagem de processos de negócio como base para elicitação de requisitos de software. Monografia de graduação, Universidade Federal da Bahia, Salvador - BA. http://twiki.im.ufba.br/pub/Aside/ NossosProjetos/MonografiaFinal.pdf. Acessado em 25 de Maio de 2006.

Sawy, O. A. E. (2001). Redesigning Enterprise Process For E-Business. Mc-Graw Hill, NY, USA. ISBN 0-07-057225-9.

Sharp, A. and McDermott, P. (2001). Workflow Modeling: Tools for Process Improvement and Application Development. Artech House, Norwood, Massachussets, 1st edition. ISBN 1-58053-021-4.

Staa, A. V. (2000). Programação Modular. Campus, Rio de Janeiro. 1a edição. ISBN 85-352-0608-6.

Tachizawa, T. and Scaico, O. (1997). Organização Flexível Qualidade na Gestão por Processos. Atlas, São Paulo. 1a edição. ISBN 8522416044. 
Apêndice A

\section{Figuras de Processos Gerais para Gestão de Mudanças}




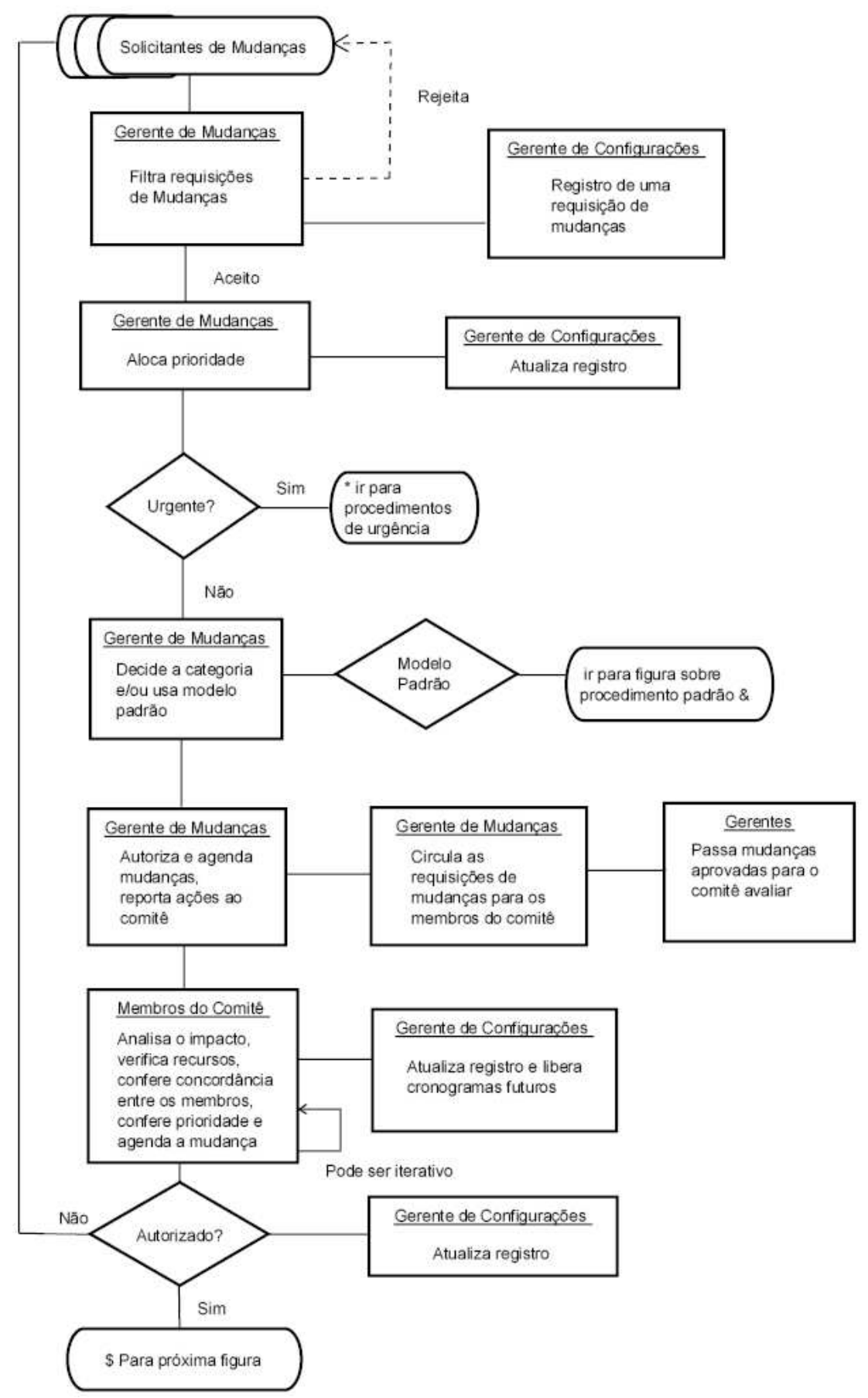

Figura A.1: Uma abordagem para os processos de Gestão de Mudanças. Continua na figura A.2. 


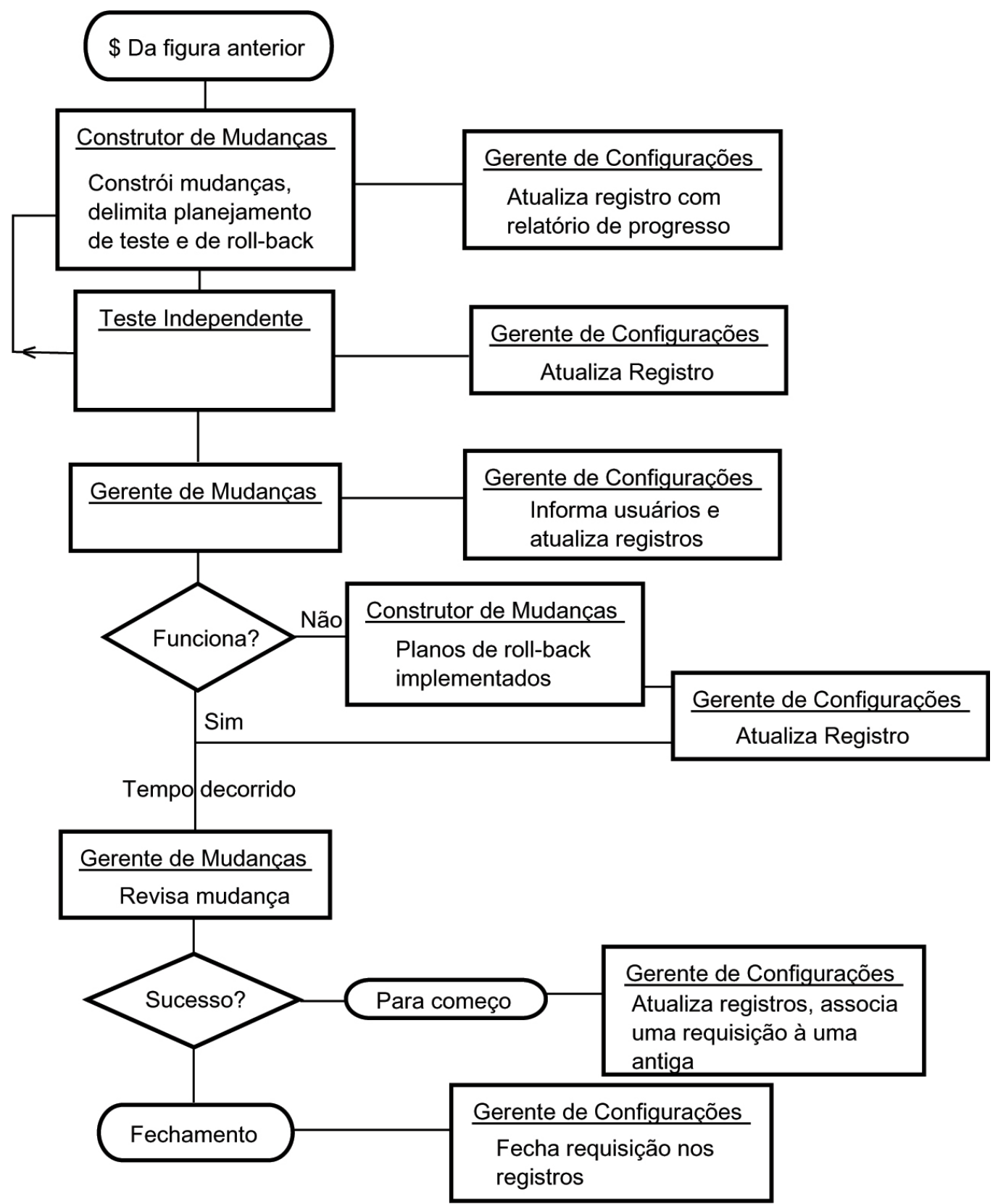

Figura A.2: Uma abordagem para os processos de Gestão de Mudanças. Continua na figura A.3 


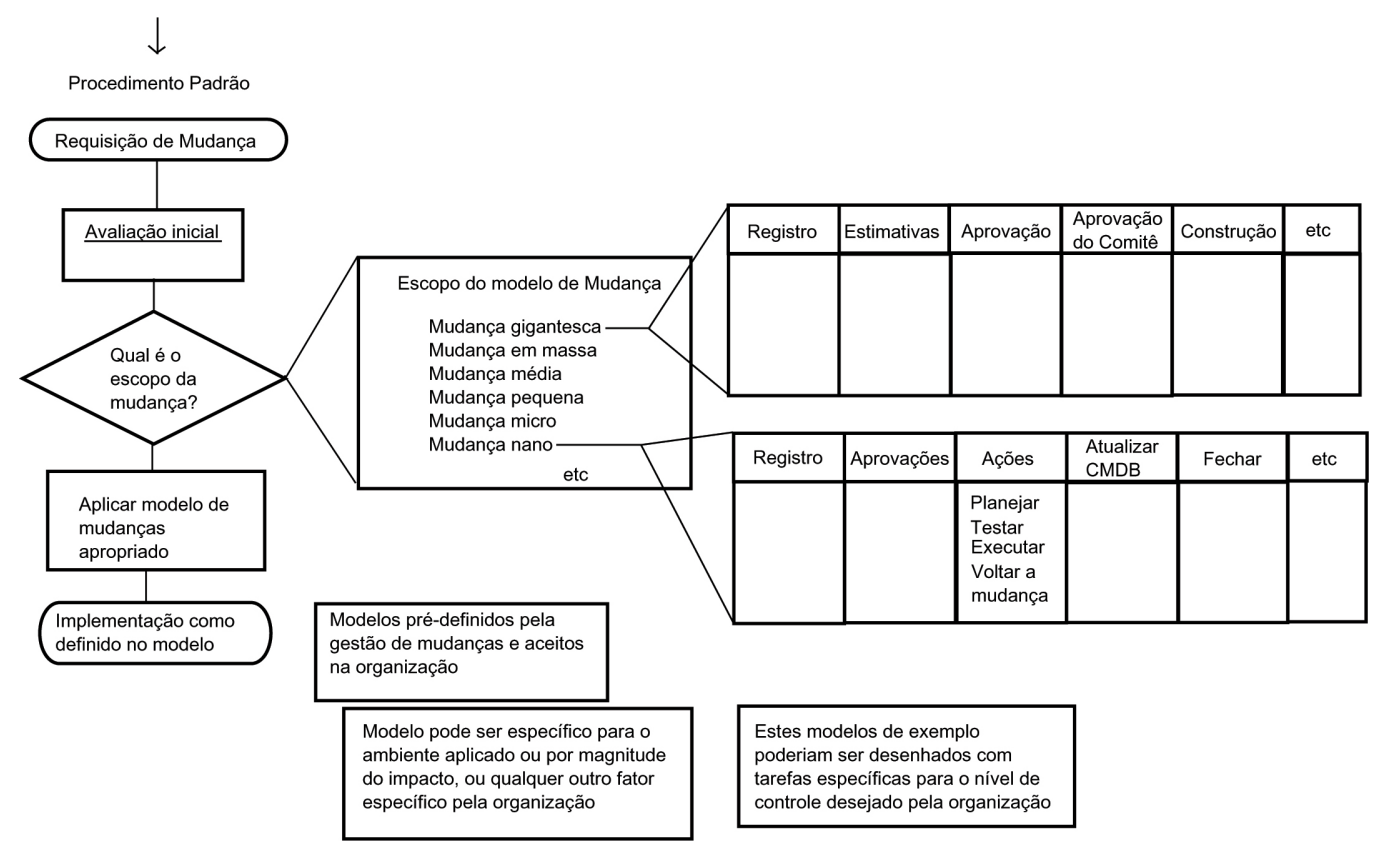

Figura A.3: Uma abordagem para os processos de Gestão de Mudanças. Continua na figura A.4. 


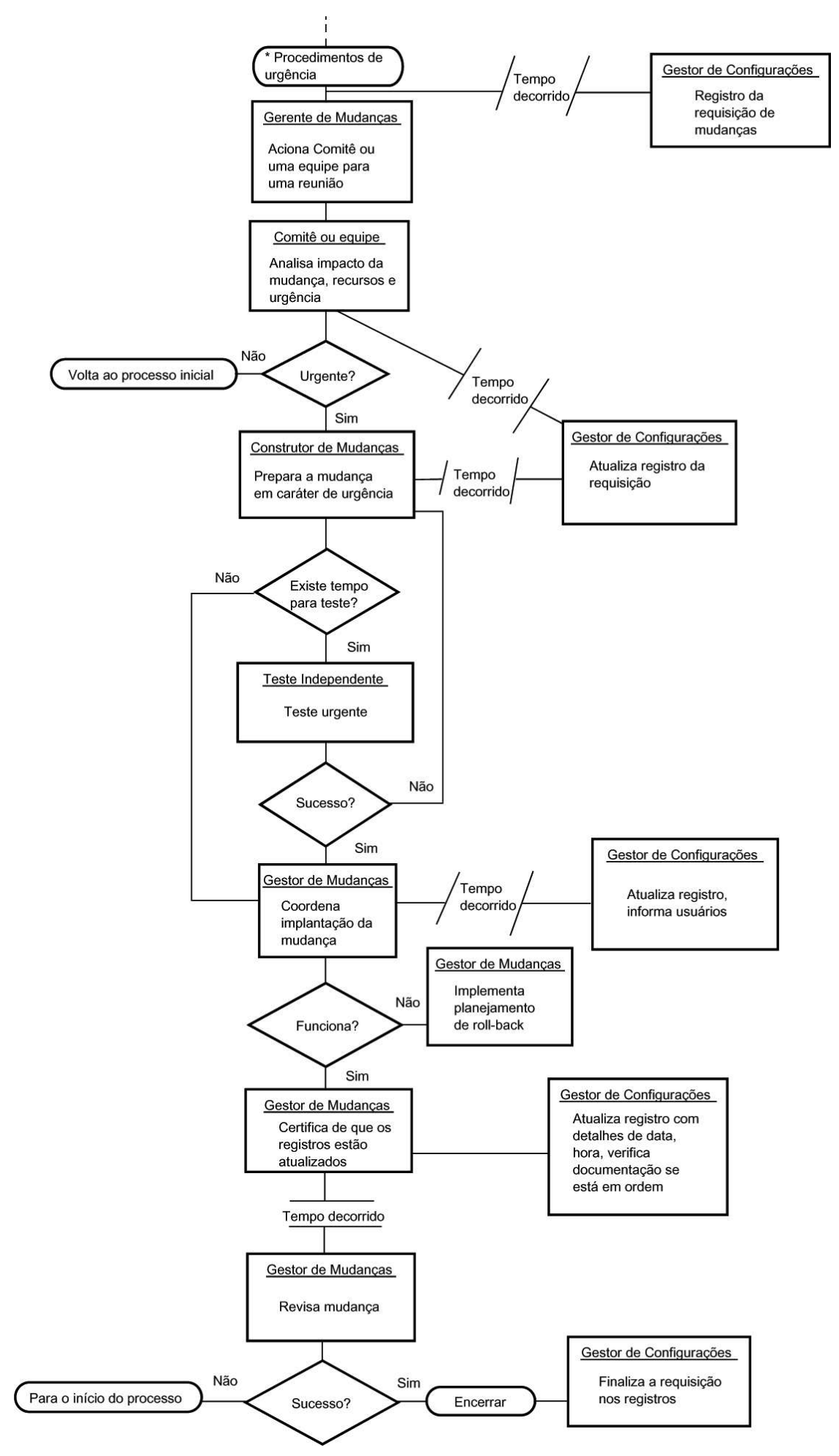

Figura A.4: Procedimentos básicos para Gestão de Mudanças. Procedimentos para Requisição Urgente. 


\section{Apêndice B}

\section{Modelagens Produzidas No Trabalho}

\section{B.1 Modelagem As Is para SD e GI}

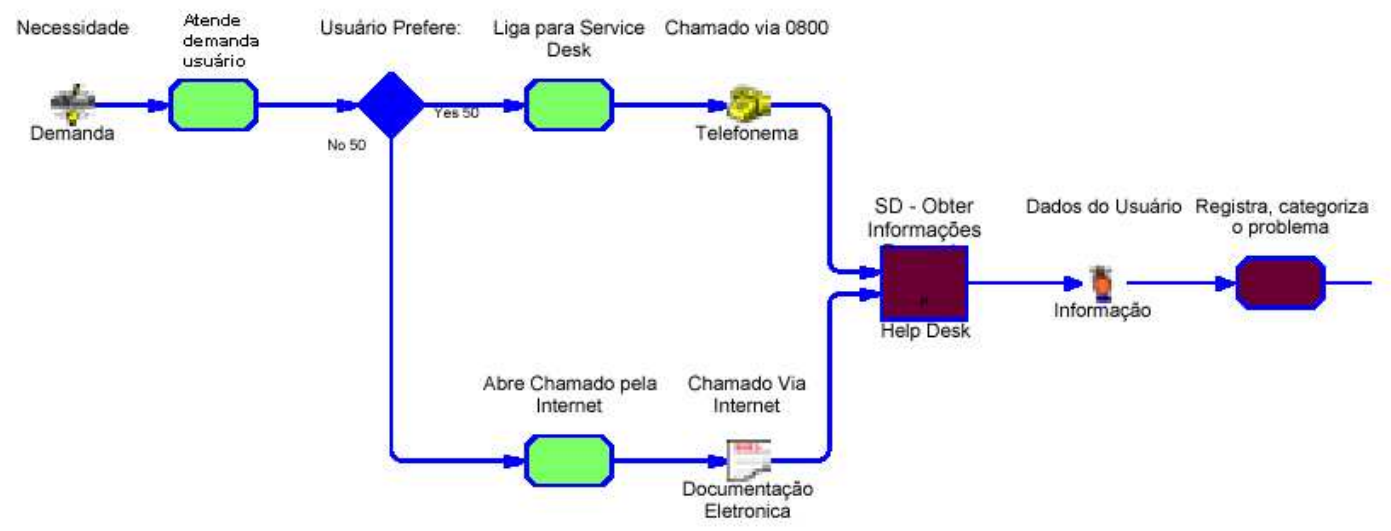

Figura B.1: Processo de recebimento de Incidentes. Continua na figura B.2. 


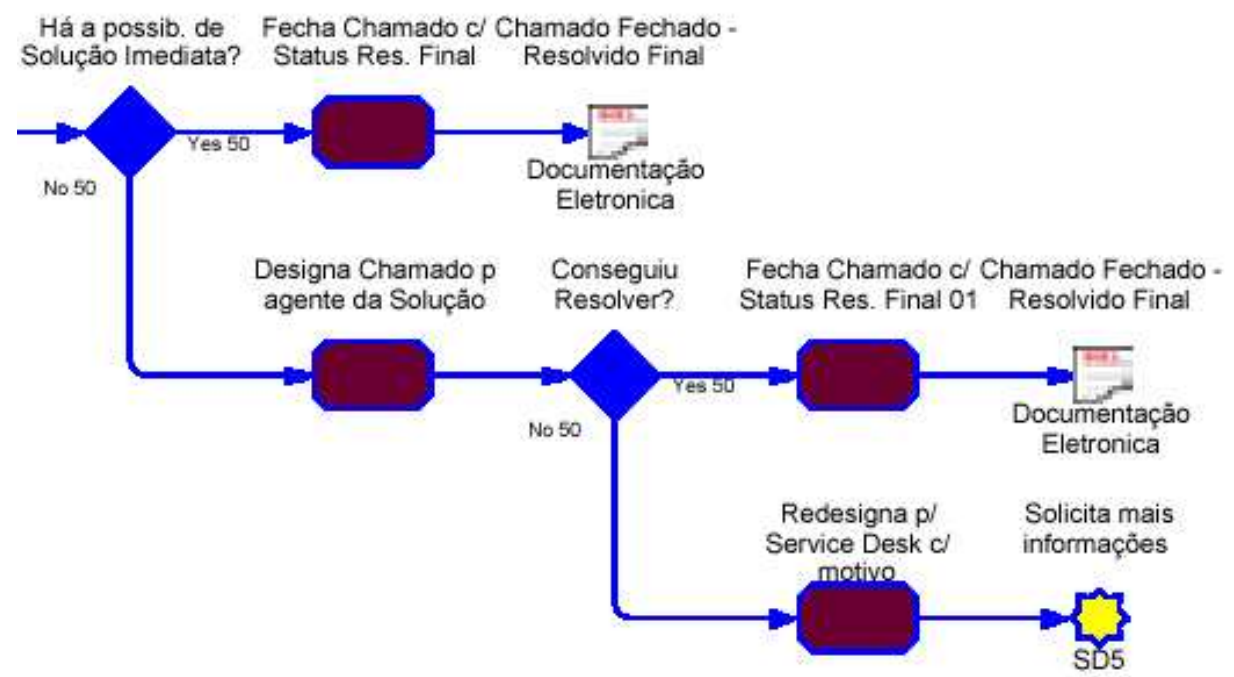

Figura B.2: Recebimento de Incidentes. Parte final do processo.

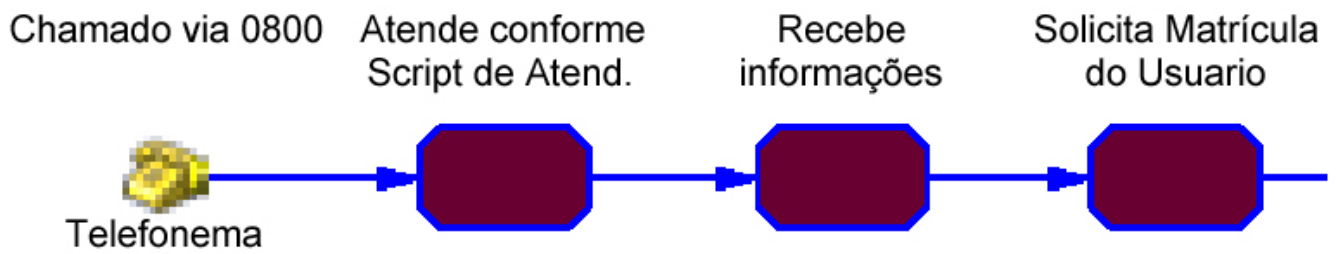

Figura B.3: Processo de obtenção de informações pessoais dos clientes na GI. O processo continua na figura B.4.

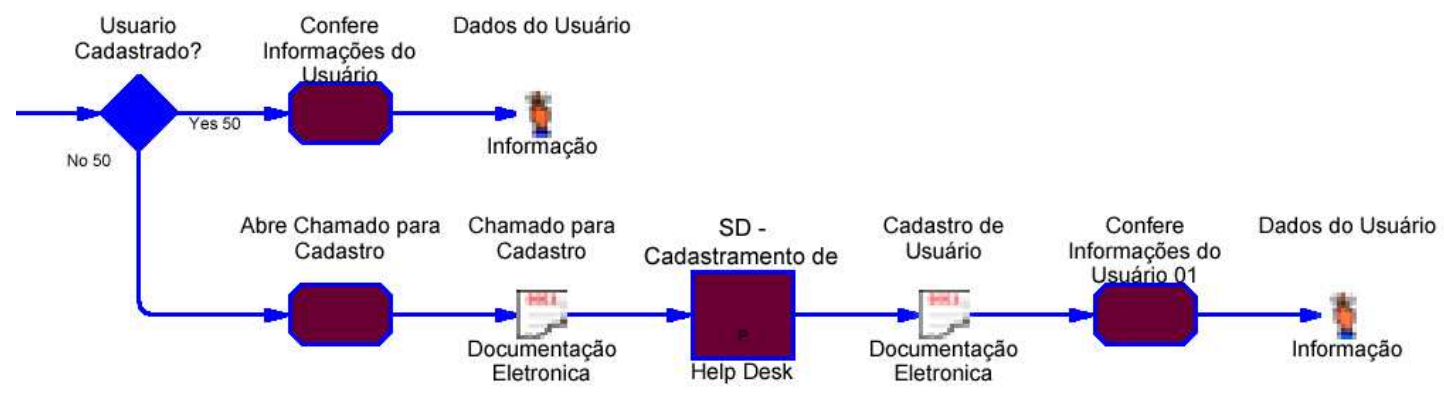

Figura B.4: Processo de obtenção de informações pessoais dos clientes na GI. Processo continua na figura B.5. 


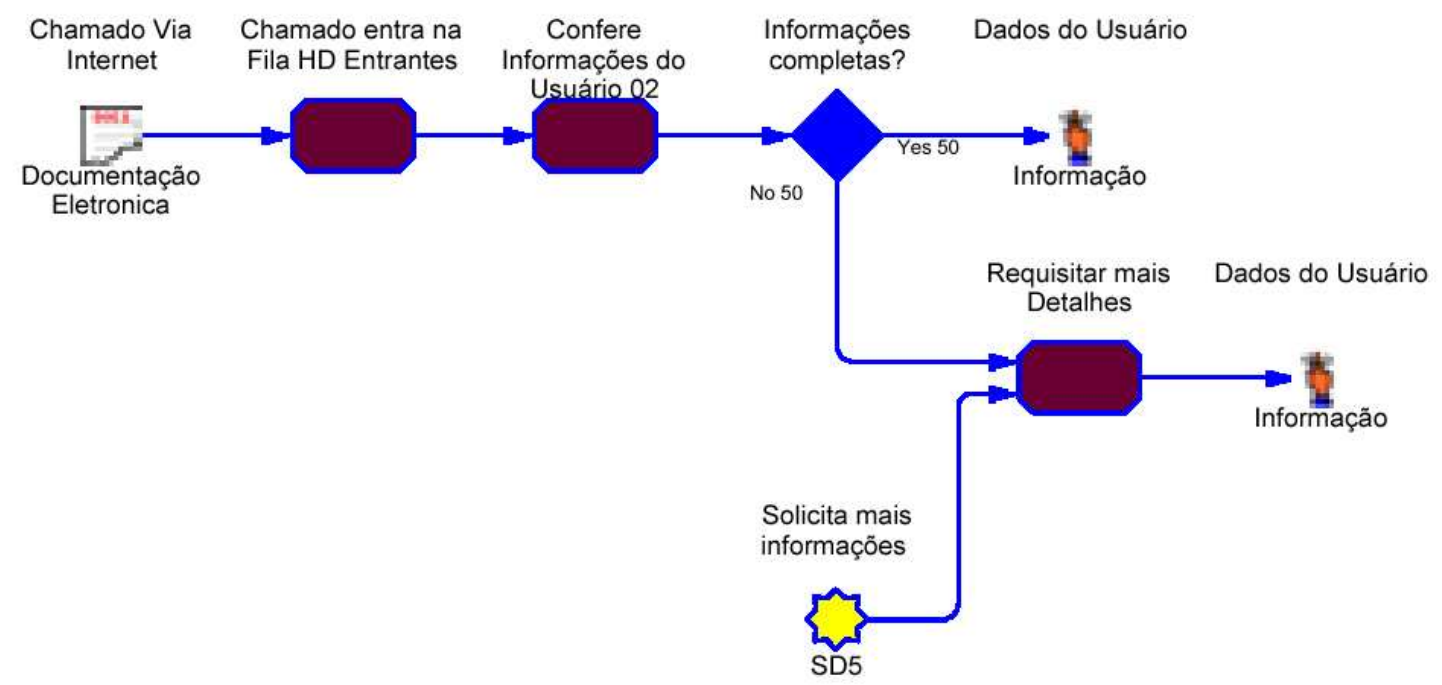

Figura B.5: Processo de obtenção de informações pessoais dos clientes na GI. 


\section{B.2 Modelagem As Is para GM}

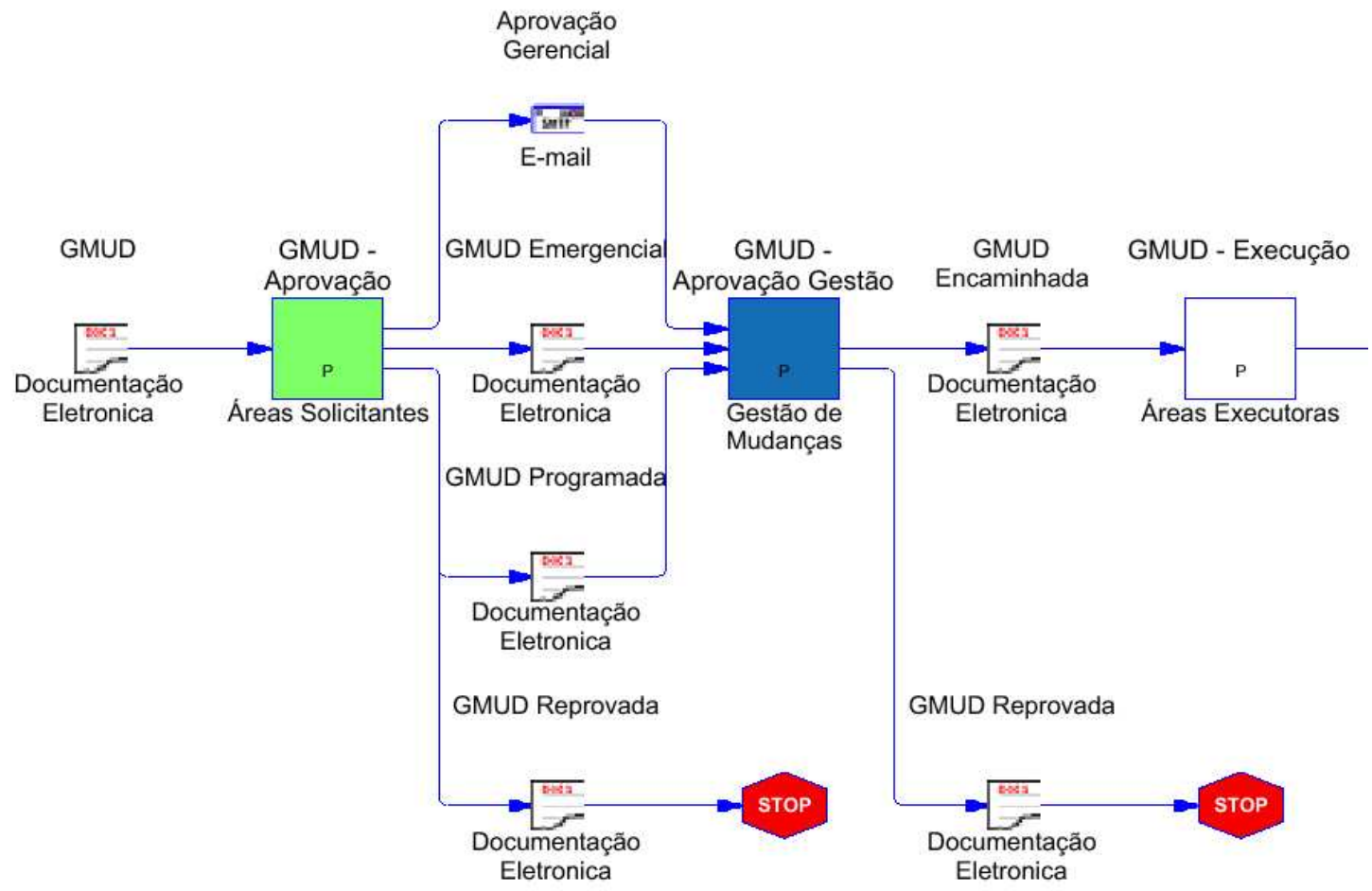

Figura B.6: Gestão de Mudanças no Modelo As Is. Aprovação de RFCs com visão macro. Continua na figura B.7

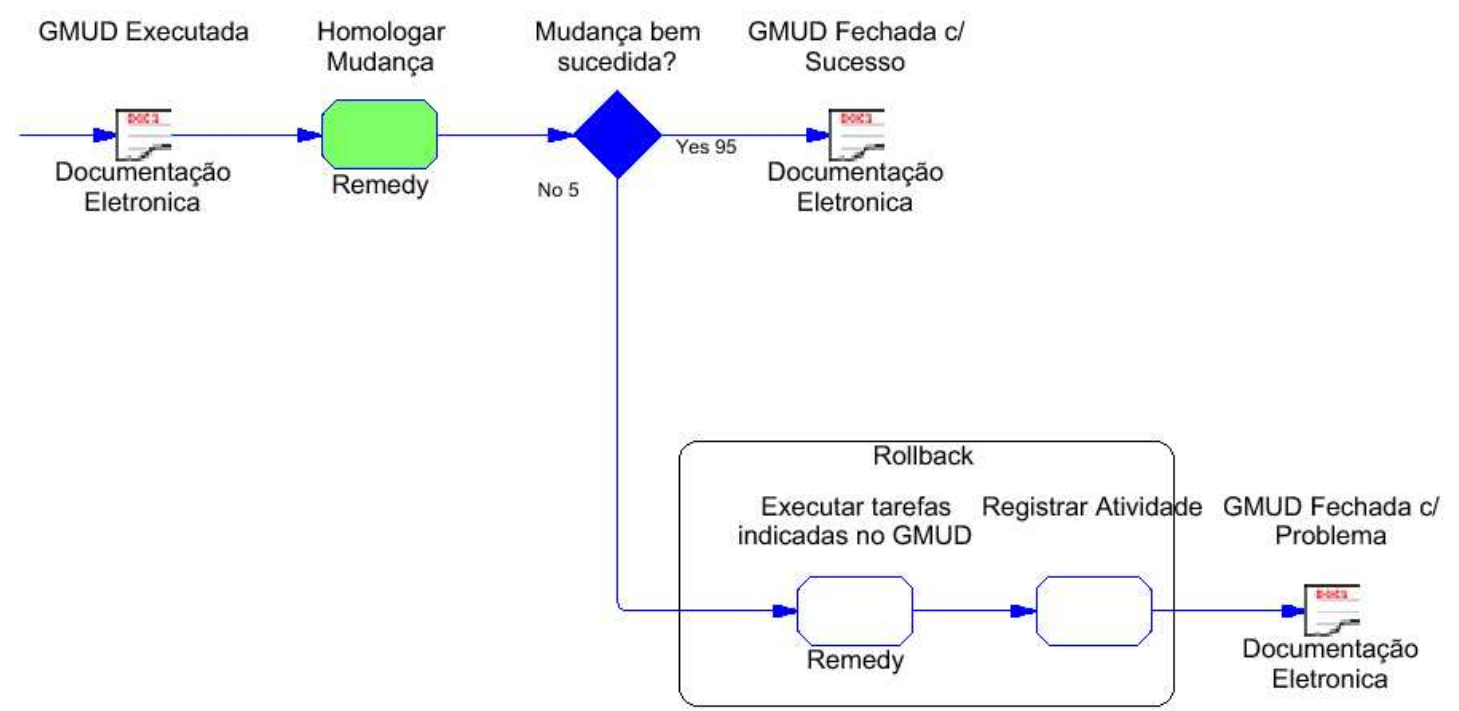

Figura B.7: Gestão de Mudanças - Modelo As Is. Aprovação de RFCs com visão macro. 


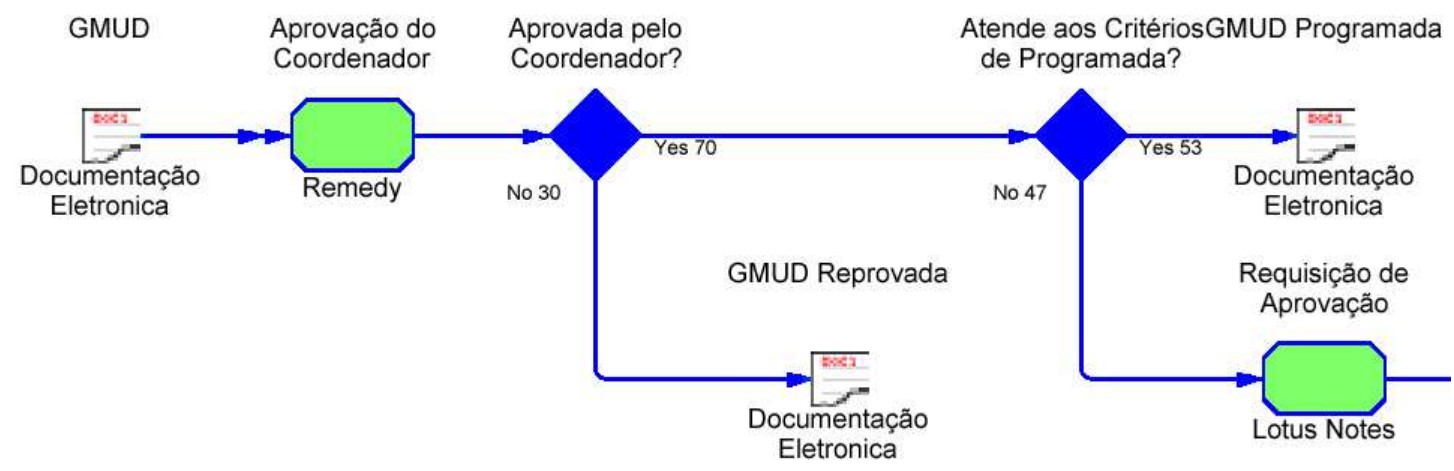

Figura B.8: Gestão de Mudanças no Modelo As Is. Processo de aprovação realizada pelo coordenador. Continua na figura B.9.

\section{GMUD Emergencial}

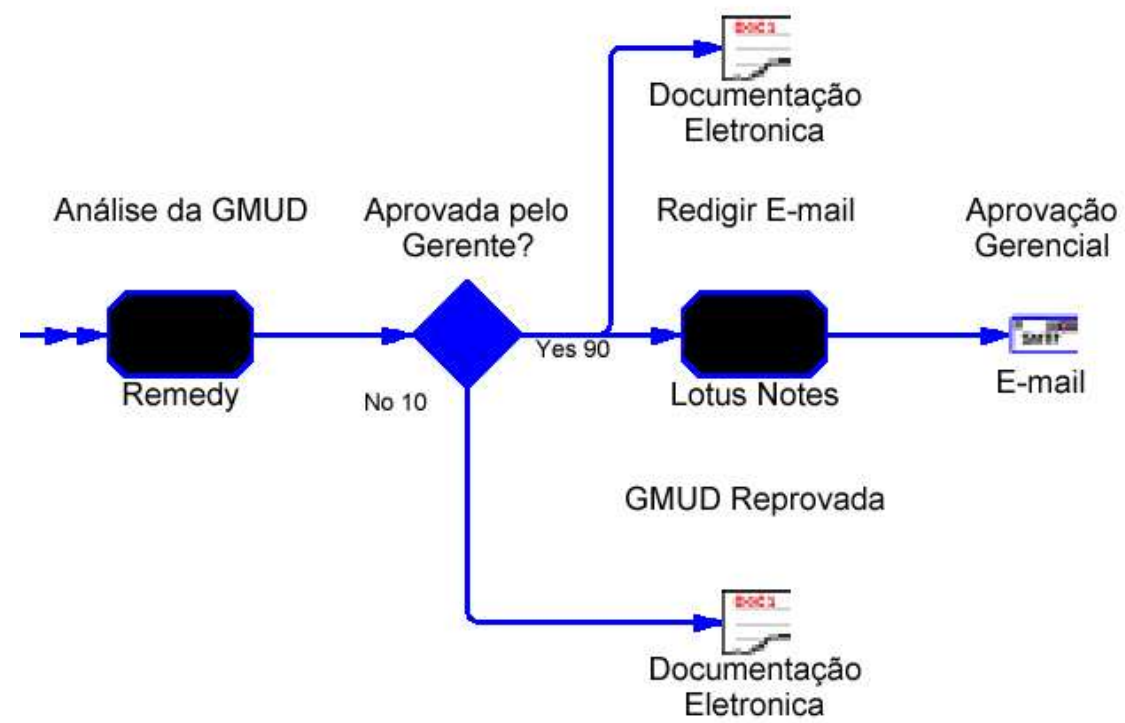

Figura B.9: Gestão de Mudanças. Modelo As Is. Processo de aprovação realizada pelo coordenador.

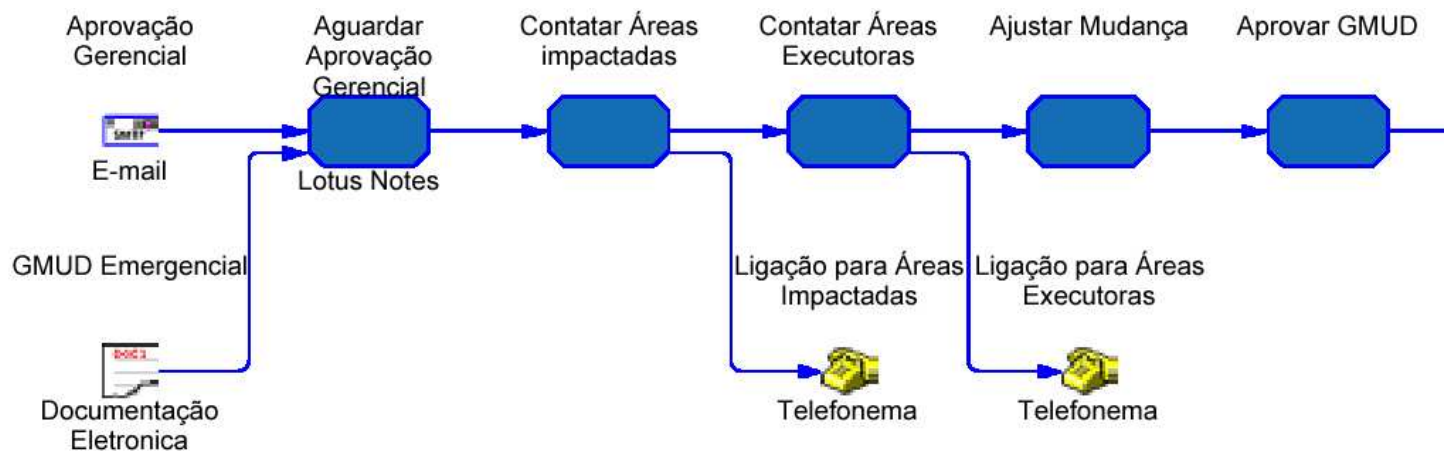

Figura B.10: Gestão de Mudanças no Modelo As Is. Aprovação emergencial, continua na figura B.11. 


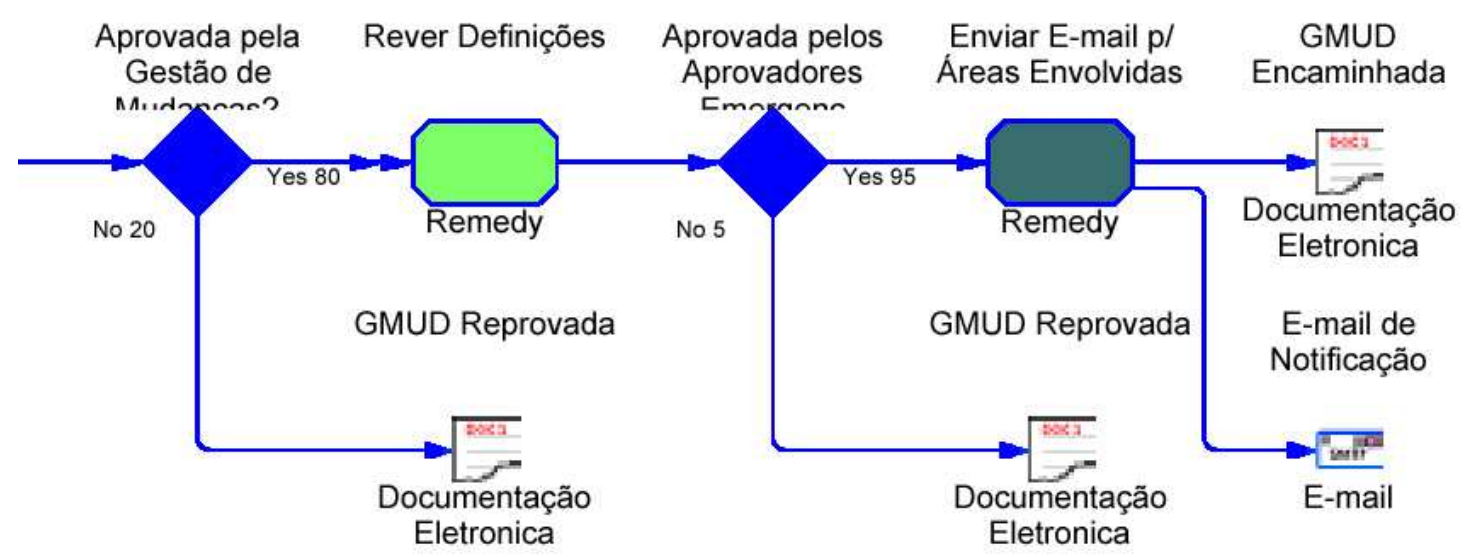

Figura B.11: Gestão de Mudanças no Modelo As Is. Final do processo de aprovação emergencial.

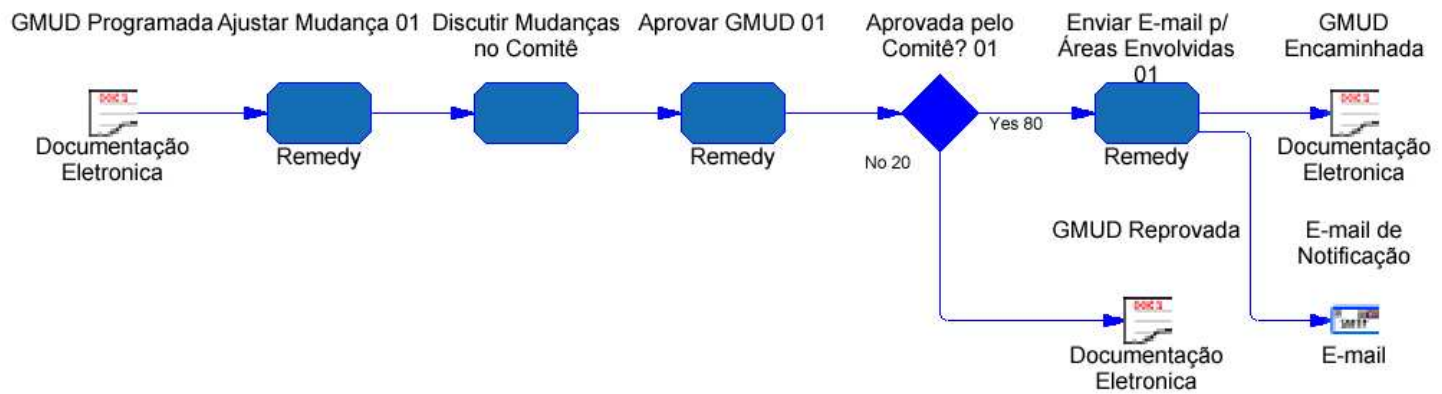

Figura B.12: Gestão de Mudanças. Modelo As Is. Caso de aprovação nas RFCs programadas.

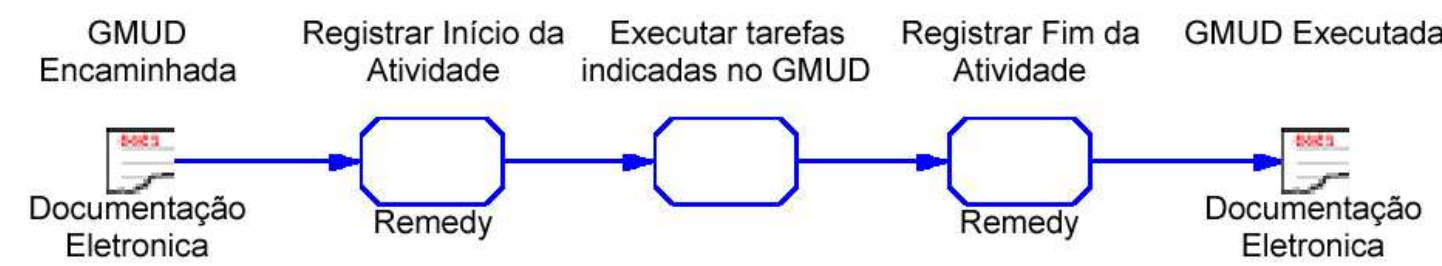

Figura B.13: Gestão de Mudanças no Modelo As Is. Processo de Implantação de RFCs. 


\section{B.3 Modelagem As Is para Gestão de Confi- gurações}

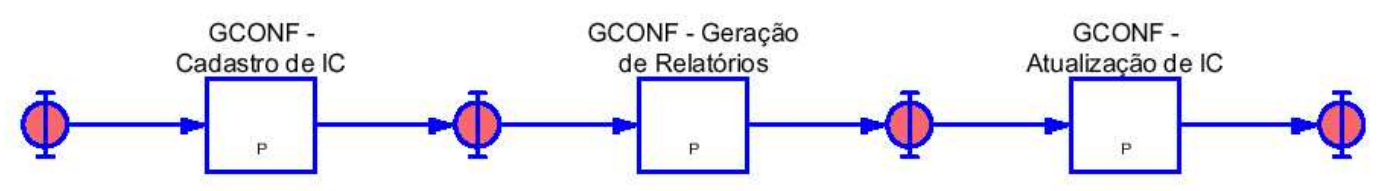

Figura B.14: Visão alto nível da Gestão de Configurações.

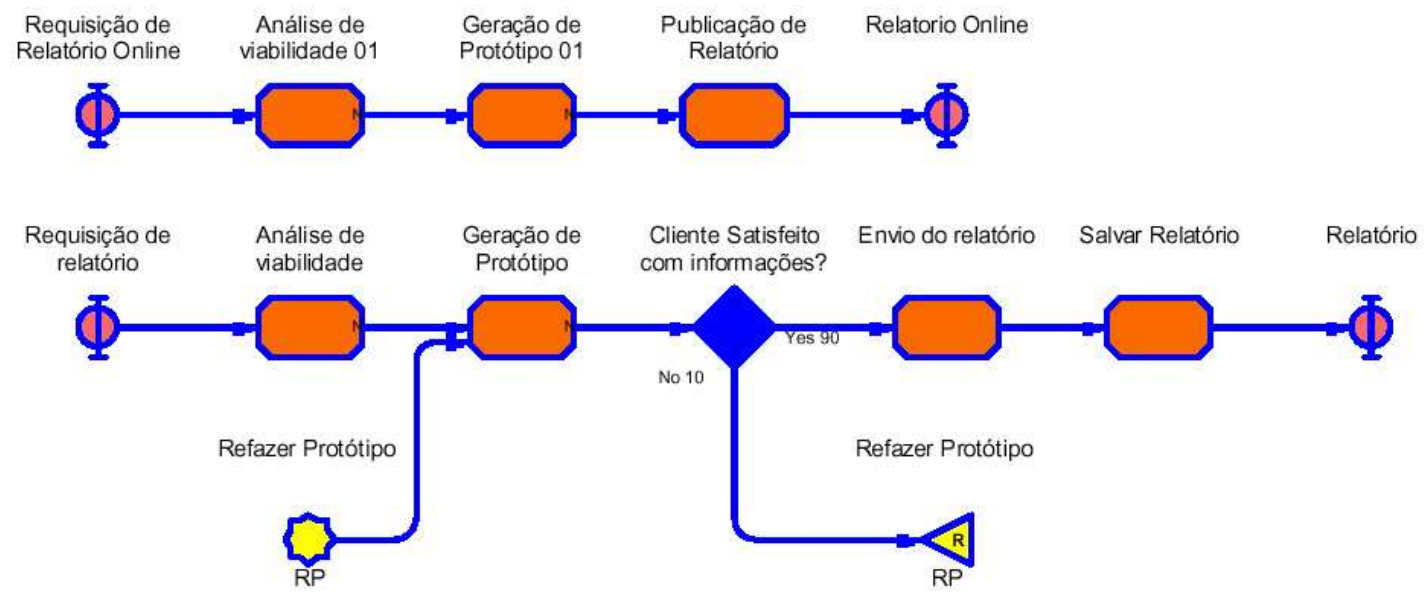

Figura B.15: Processo de geração de relatórios na Gestão de Configurações. Continua na figura B.16.

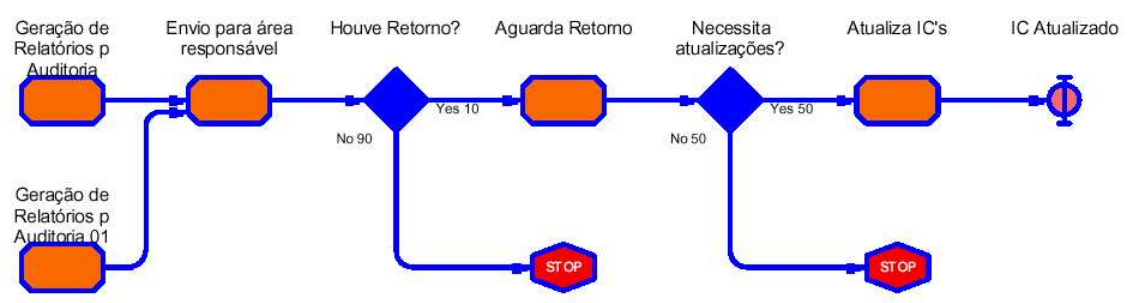

Figura B.16: Processo de geração de relatórios na Gestão de Configurações. Parte final do processo. 


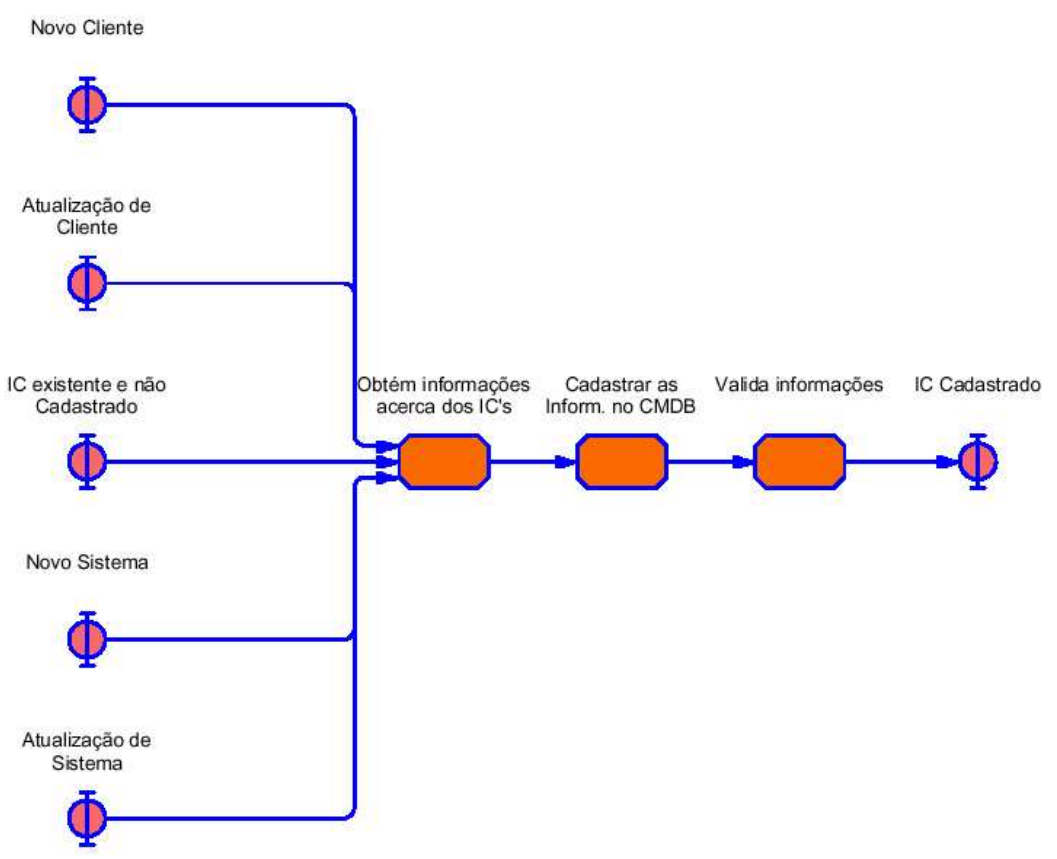

Figura B.17: Processo simplificado de cadastramento para ICs.

IC no deposito entra em Produção

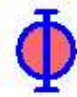

IC sai de produção
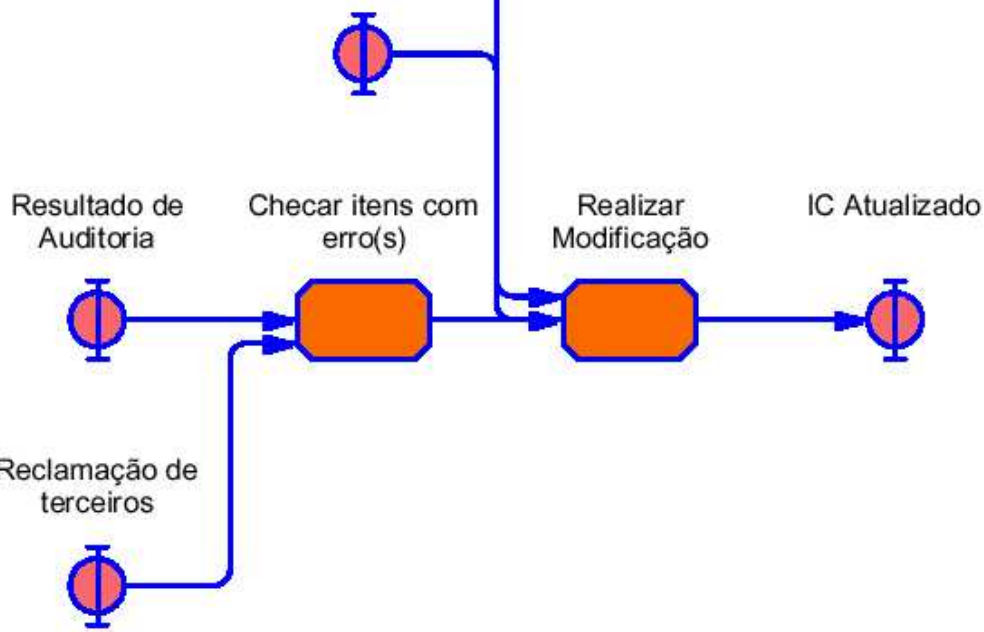

Figura B.18: Processo de atualização no CMDB. 


\section{Apêndice $\mathrm{C}$}

\section{Código Fonte Das Ferramentas Desenvolvidas}

\section{C.1 Sistema Notificador de Pendências}

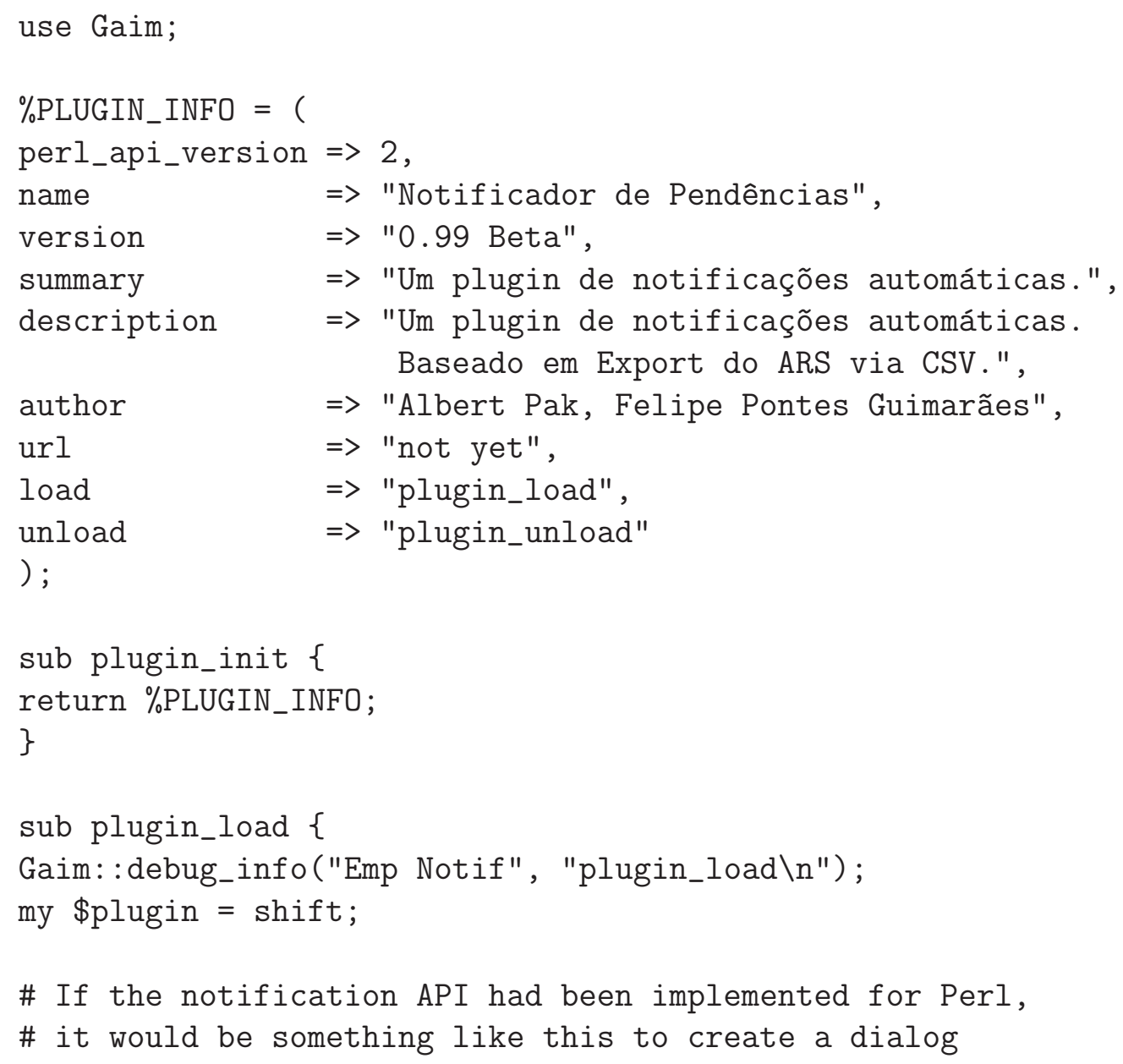


\# Gaim::notify_info(\$plugin, "Example Perl Plugin", "Loaded");

\# If there was a way to set the user Idle, it would be done here

\# Listen for when buddies sign on so we can greet them

Gaim: :signal_connect(Gaim::BuddyList: :handle, "buddy-signed-on", \$plugin, \\&buddy_signed_on_cb, "Verificando suas pendencias...");

\# Add a timer to prompt the user that the plugin has ben loaded

\# for 60 seconds

Gaim: :timeout_add(\$plugin, 60, \\&notify);

\}

sub plugin_unload \{

my \$plugin = shift;

\}

sub buddy_signed_on_cb \{

Gaim: :debug_info("Emp Notif", "In buddy_signed_on_cb $\backslash n$ ");

my (\$buddy, \$data) = $\bigotimes_{-}$;

Gaim::debug_info("Emp Notif", "Lista de Dados: \n

Data is: \$data. \n

Buddy Name is: ".\$buddy->get_name().". In

Buddy Account is: ".\$buddy->get_account().". \n

Buddy Alias is: ".\$buddy->get_alias().". \n");

Gaim: :debug_info("Emp Notif", "Buddy '" . \$buddy->get_alias() . "' signed on. \n");

\# Trecho que verifica se há pendências no arquivo

\# "C:/Exports/Pendencias.csv" para o

\# usuario que se conectou.

\# Primeiramente, pegamos o nome e determinamos quem logou

\# e sua MATR

\$name $=$ \$buddy->get_name ();

\# Abrimos o arquivo e procuramos sua matrícula

\$file = 'Followup.csv'; \# Name the file

open(CSV, \$file); \# Open the file

Olines = <CSV $>$; \# Read it into an array

close(CSV); \# Close the file 


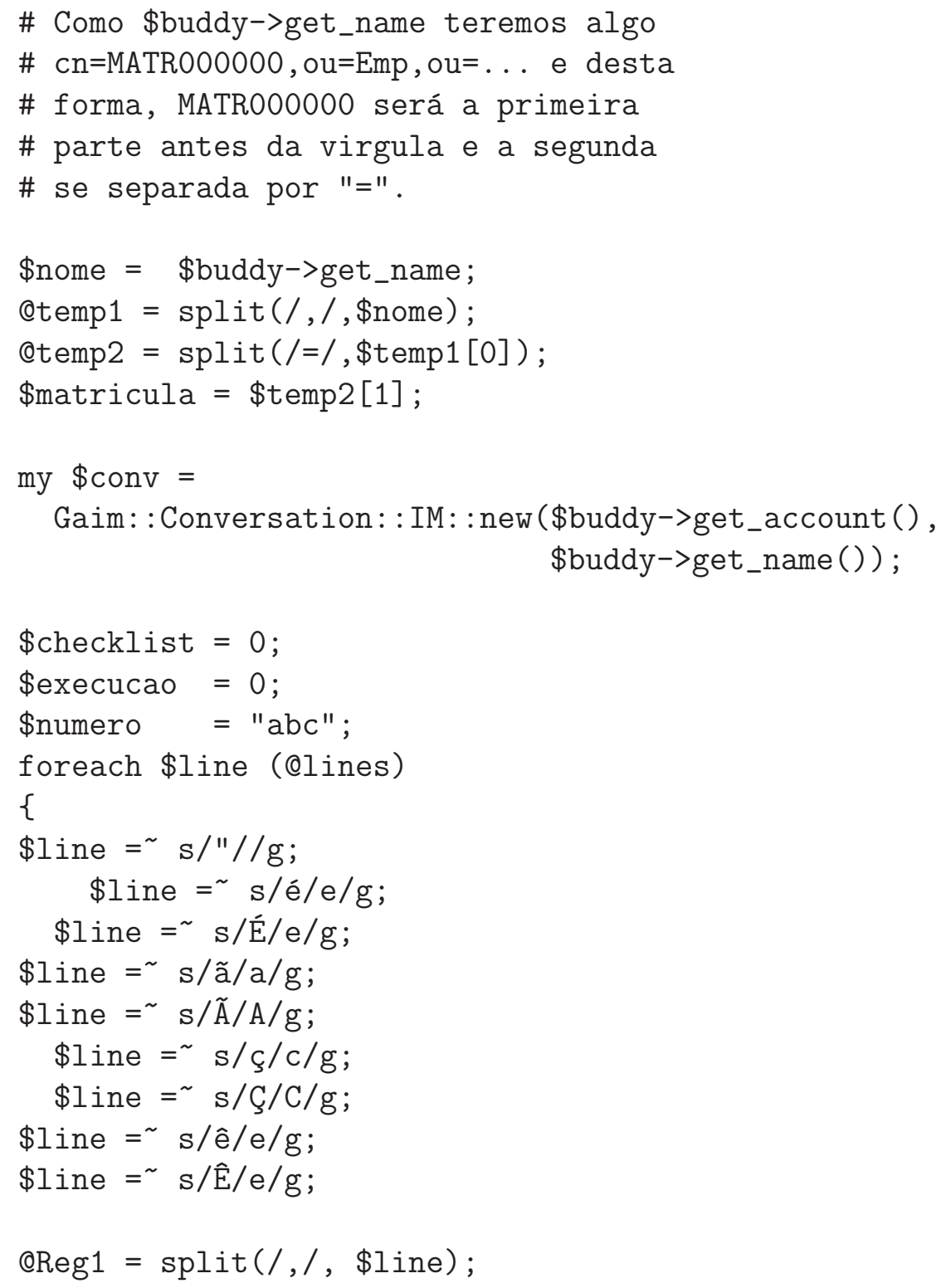




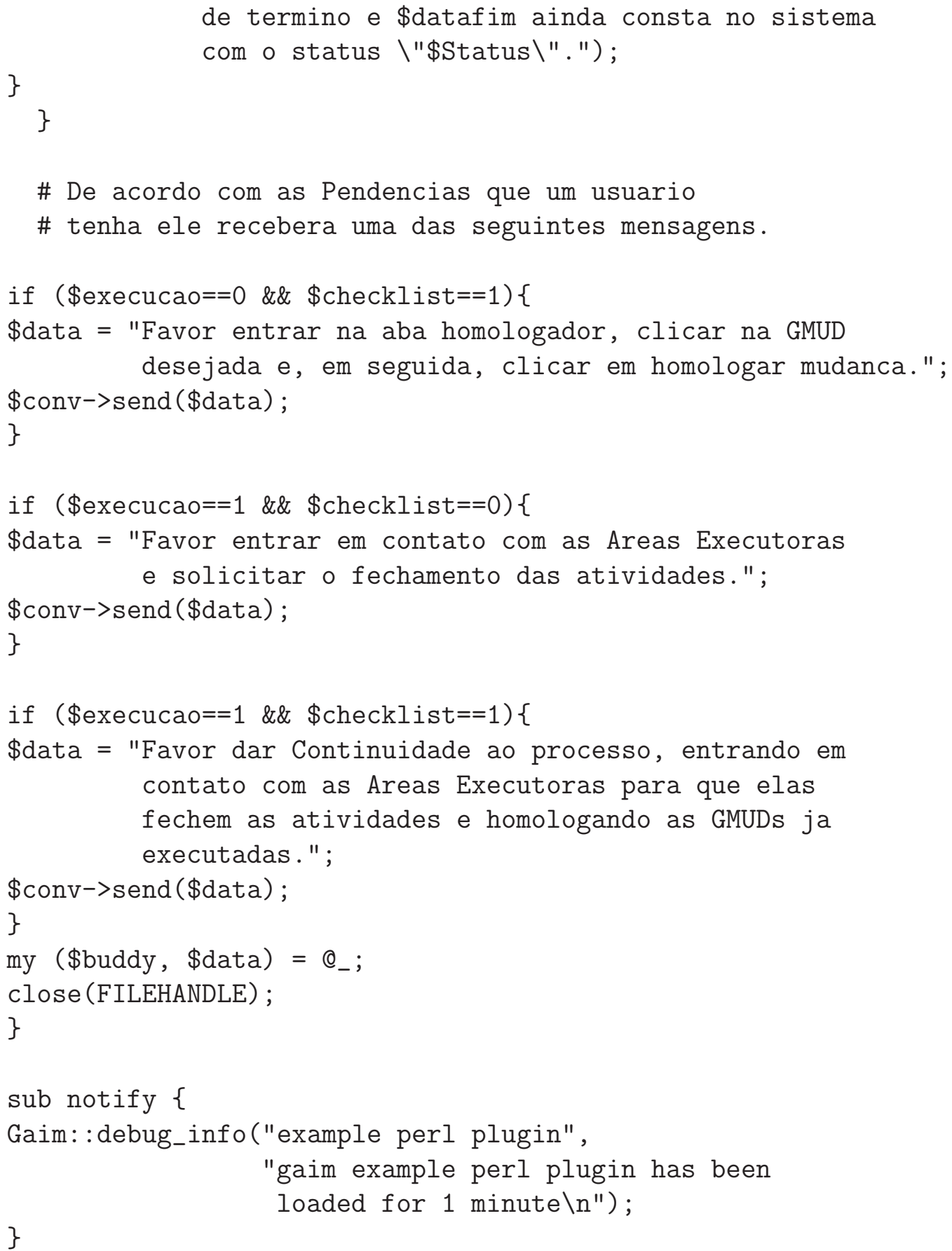




\section{C.2 Sistema Pré-Comitê}

O sistema Pré-Comitê é dividido em 5 arquivos. São eles:

index.php (tela inicial de autenticação)

spc.php (página principal do sistema)

sugestao.php (página para usuário ajustar RFCs)

sugestao-db.php (página onde as sugestões dos usuários são armazenadas)

spc-db.php (página de armazenamento de ajustes)

Segue abaixo o código fonte do sistema desenvolvido.

\section{C.2.1 Arquivo index.php}

Página principal de acesso ao sistema. O usuário se autentica no sistema. Segue o código fonte.

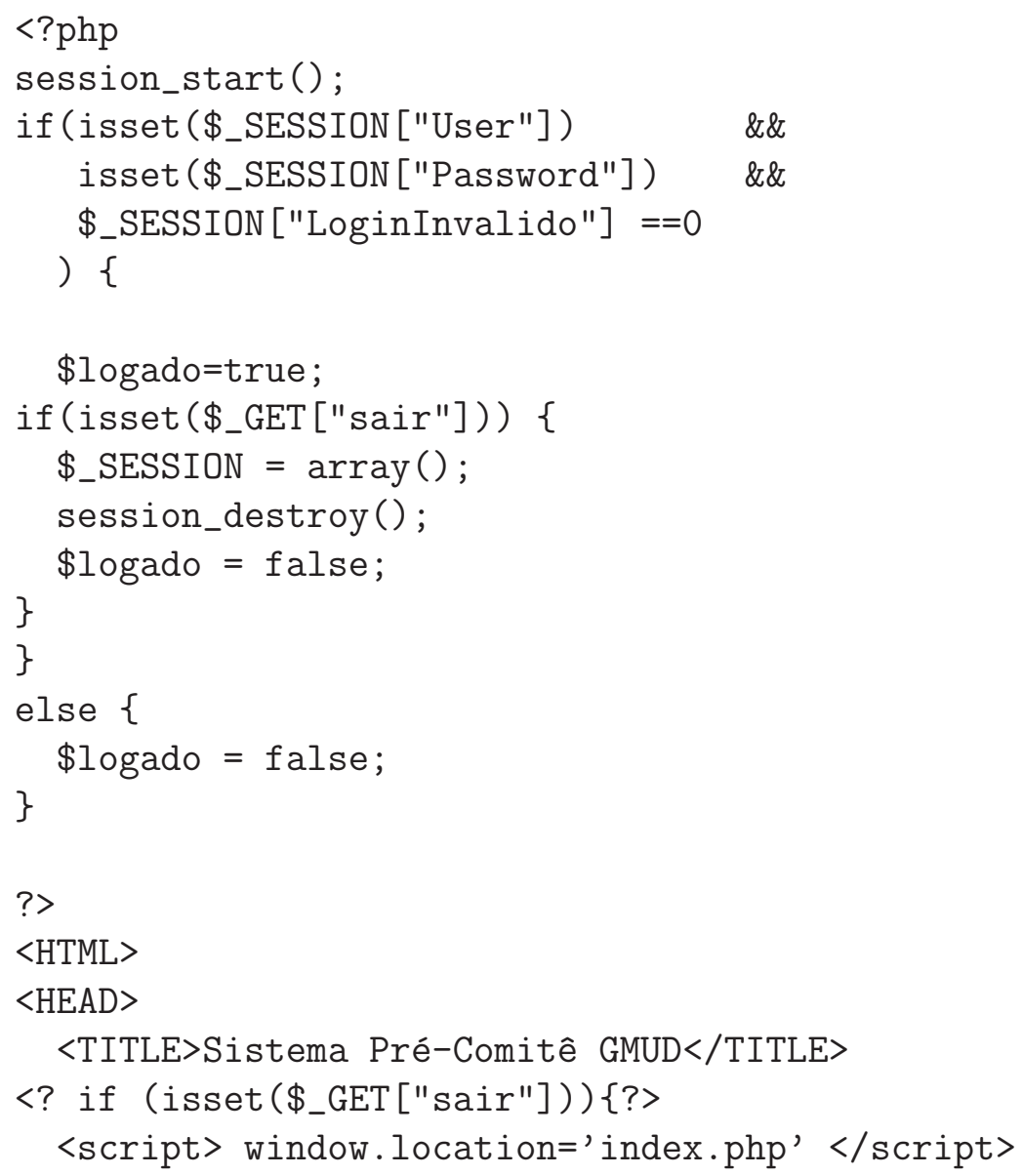




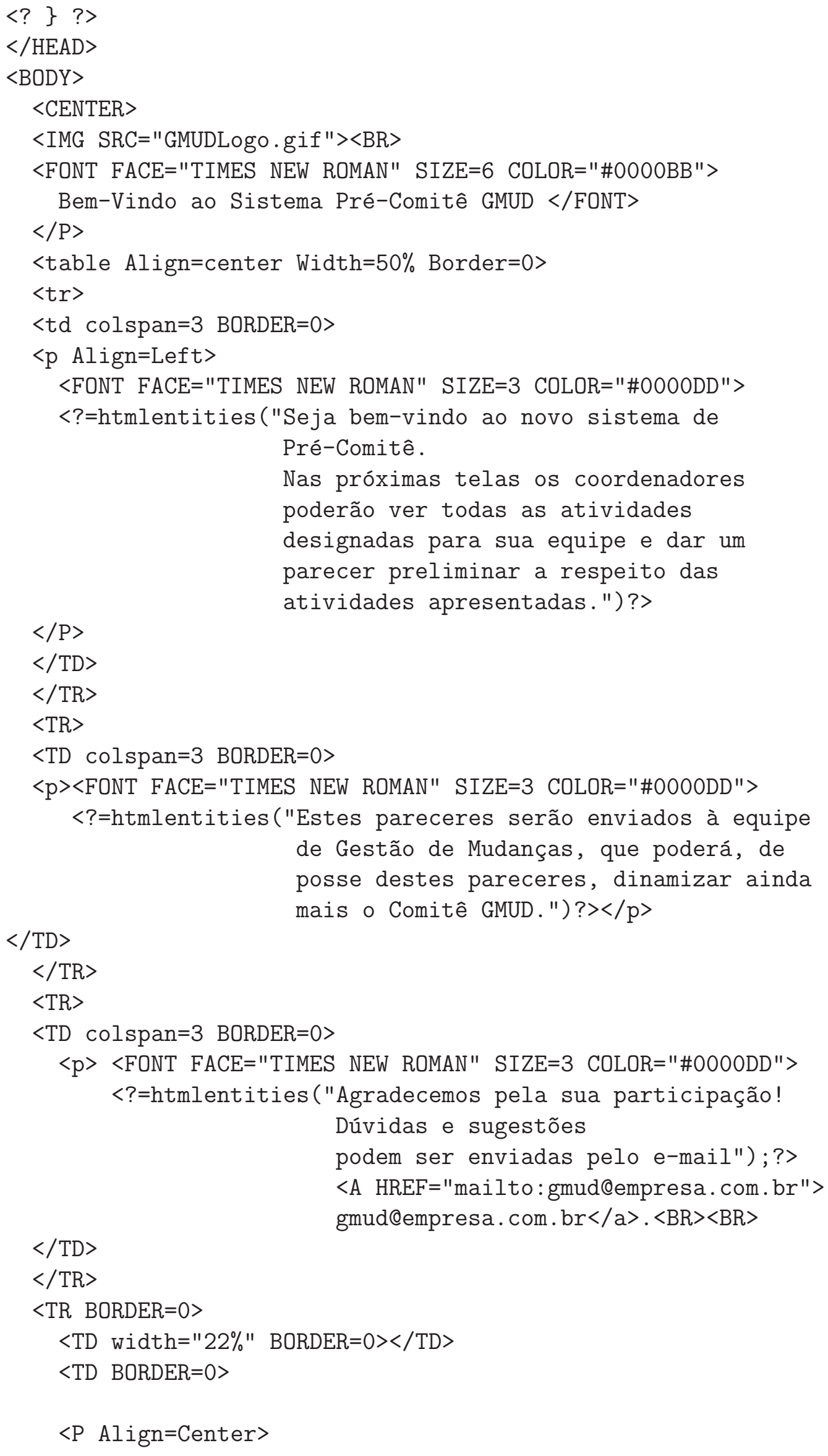


"<TD BORDER=0 $>$ INPUT TYPE=PASSWORD NAME=Senha SIZE=40 ";

if (\$logado)

echo

"DISABLED VALUE=\" ".\$SESSION ["Password"] . "\" "; echo $"></$ TD $>"$.

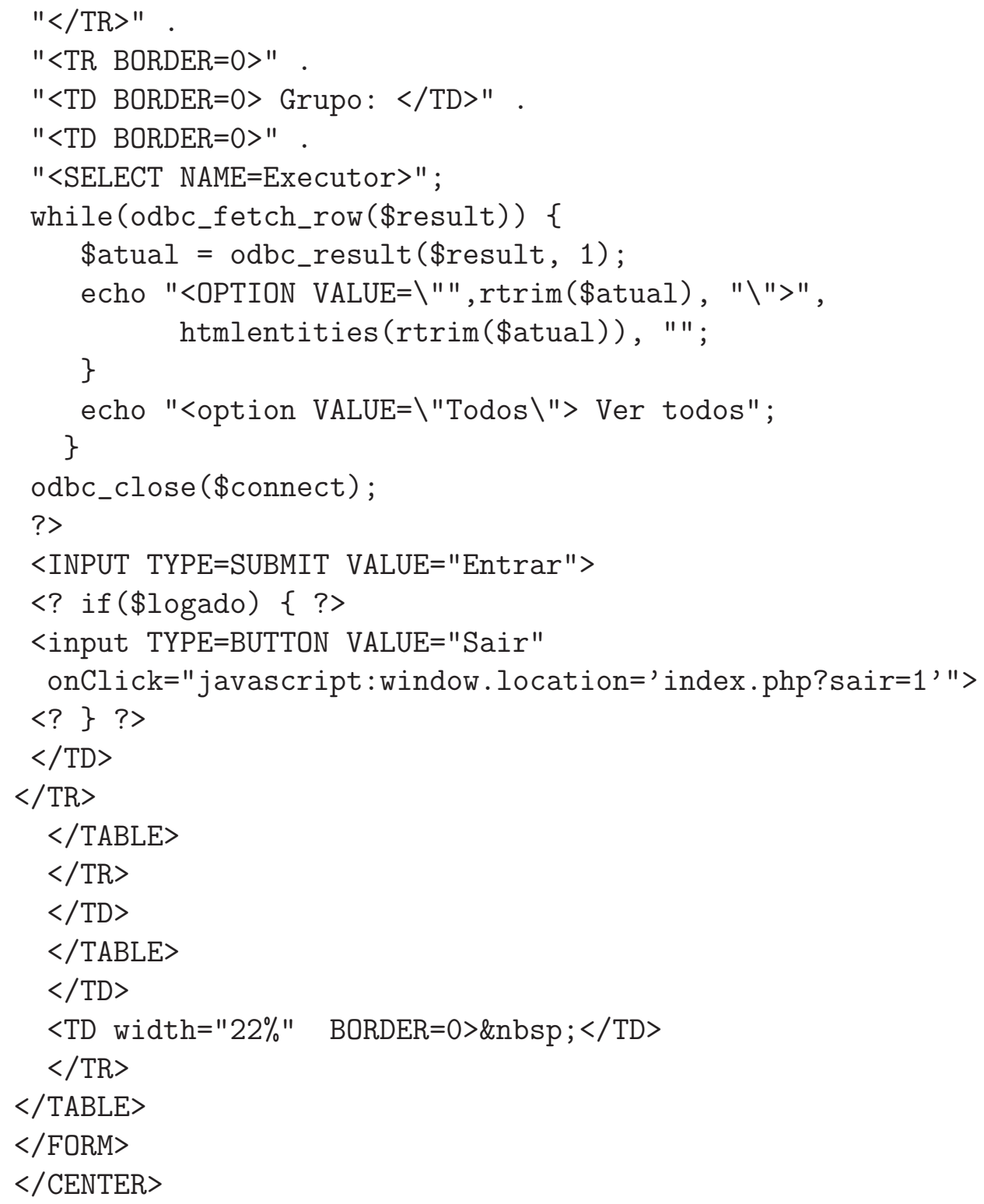




\section{C.2.2 Arquivo spc.php}

Página principal do sistema. Segue o código fonte.

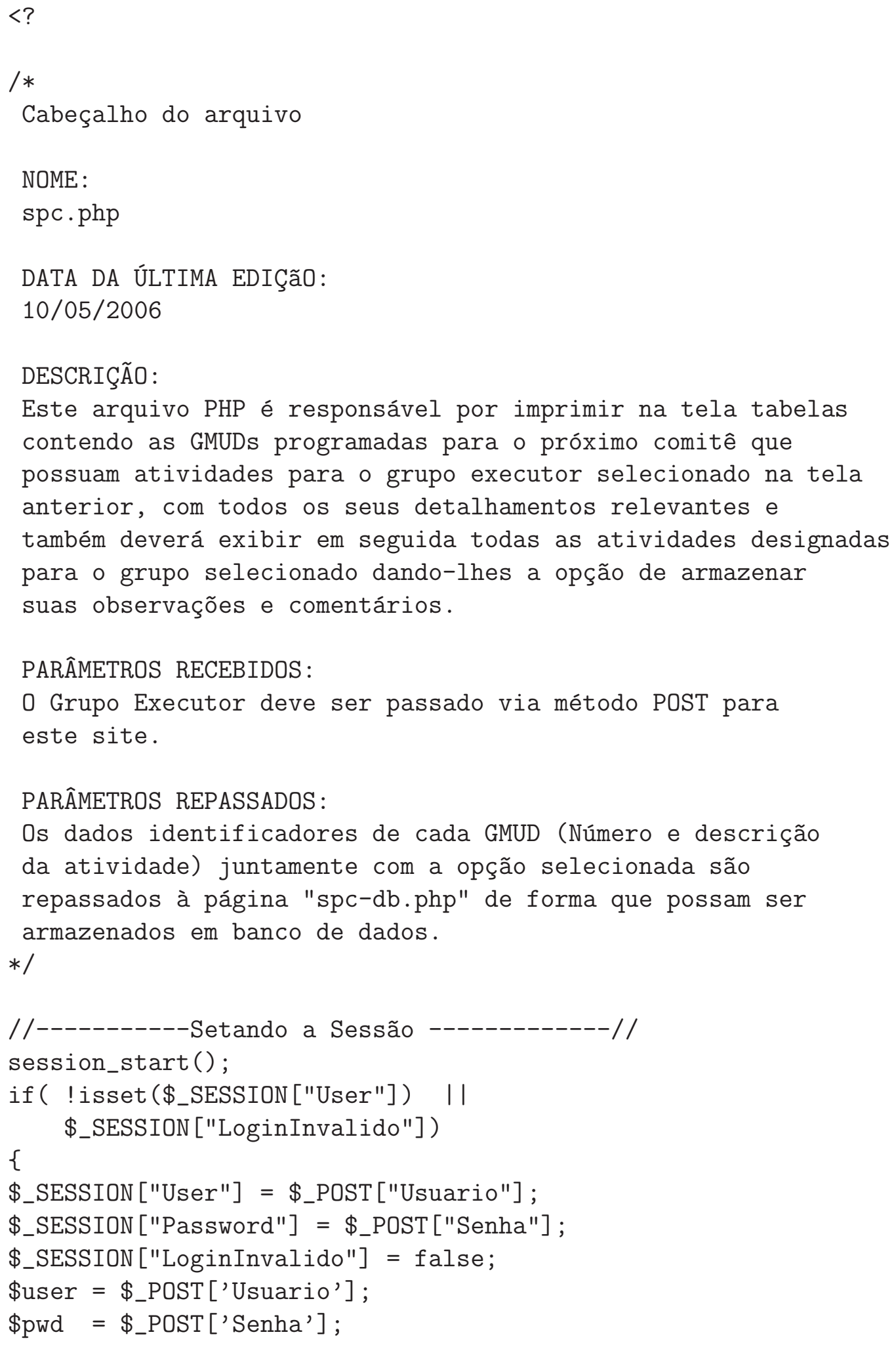




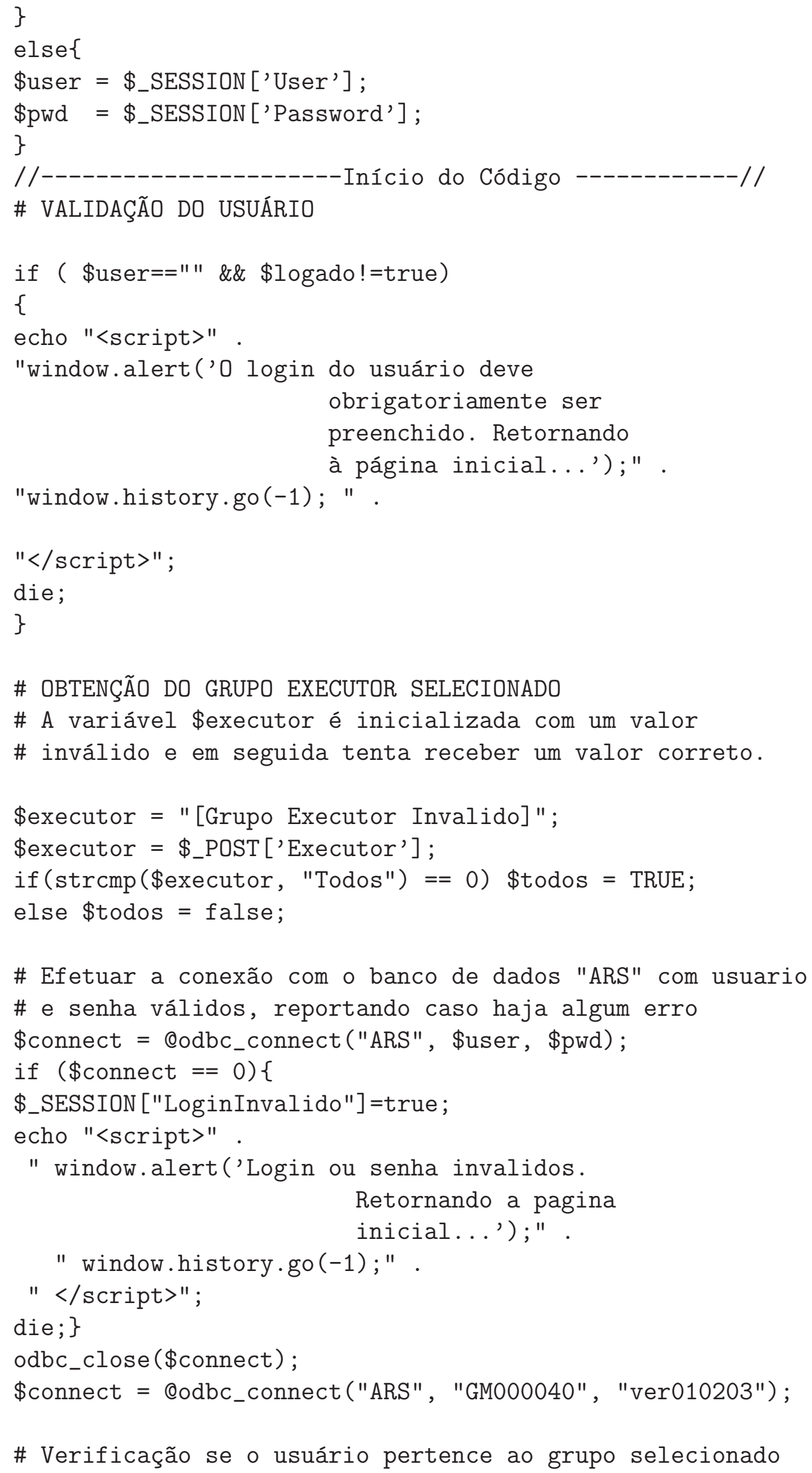




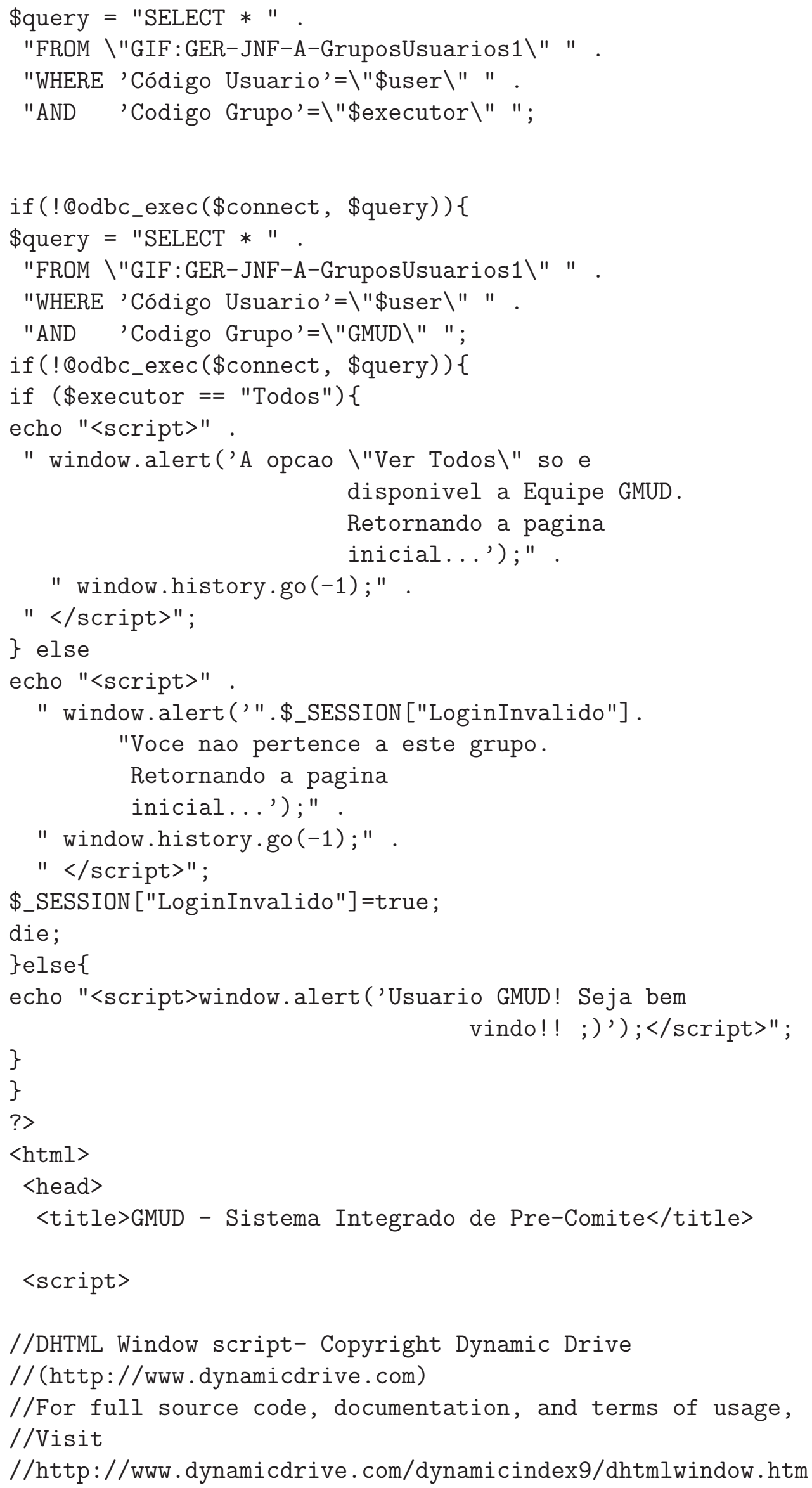

//DHTML Window script- Copyright Dynamic Drive //(http://www.dynamicdrive.com)

//For full source code, documentation, and terms of usage, //Visit

//http://www.dynamicdrive.com/dynamicindex9/dhtmlwindow.htm 


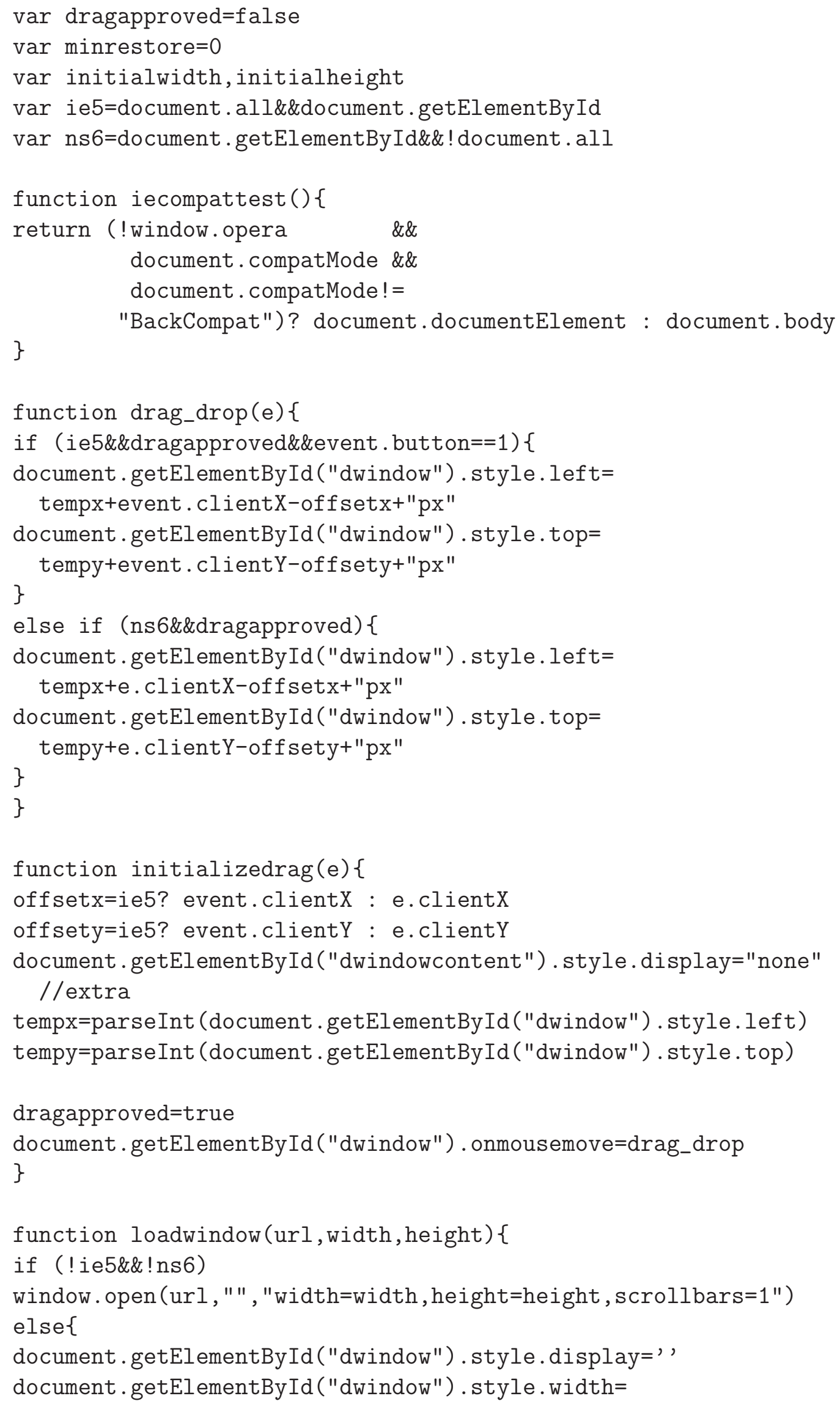




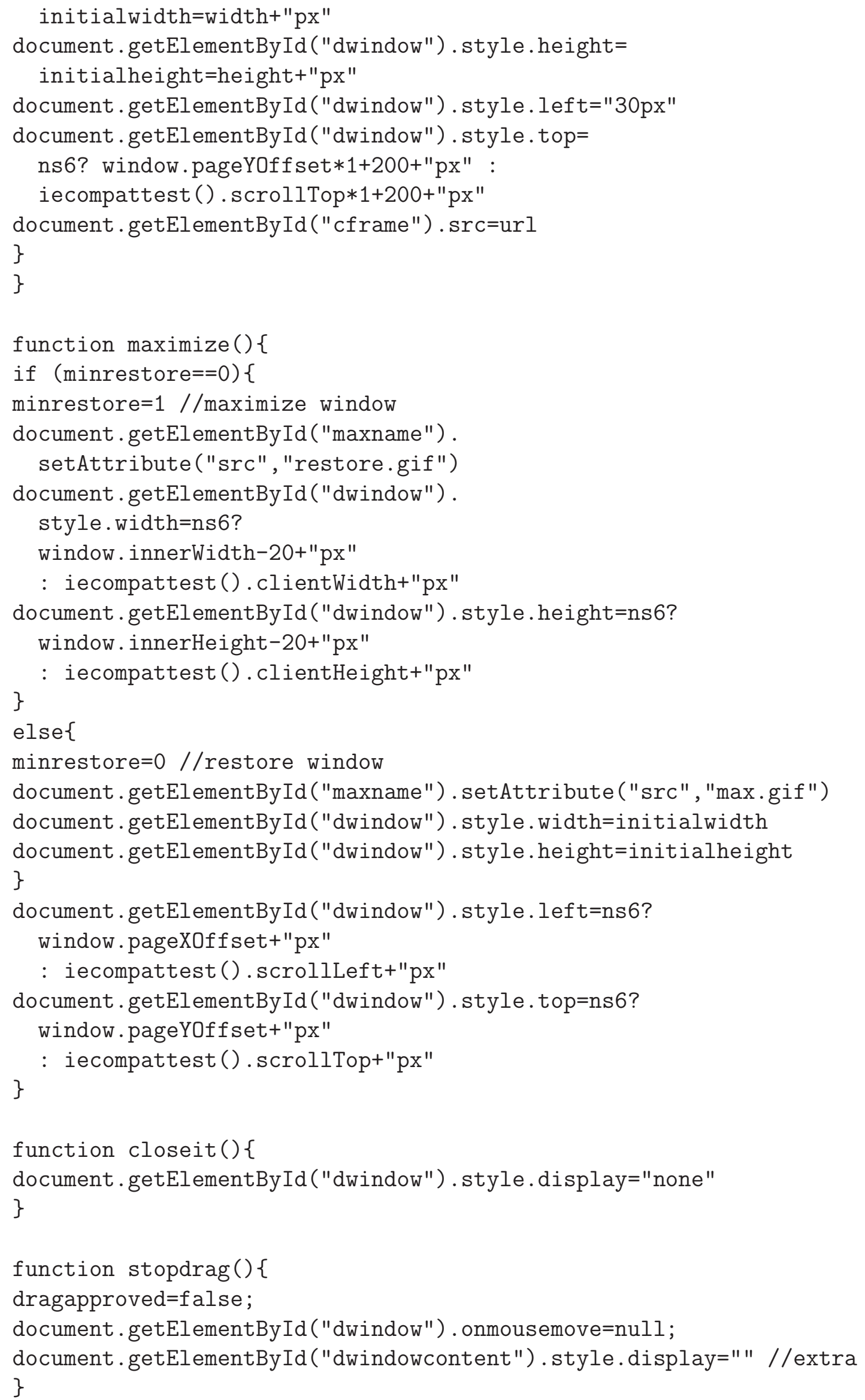




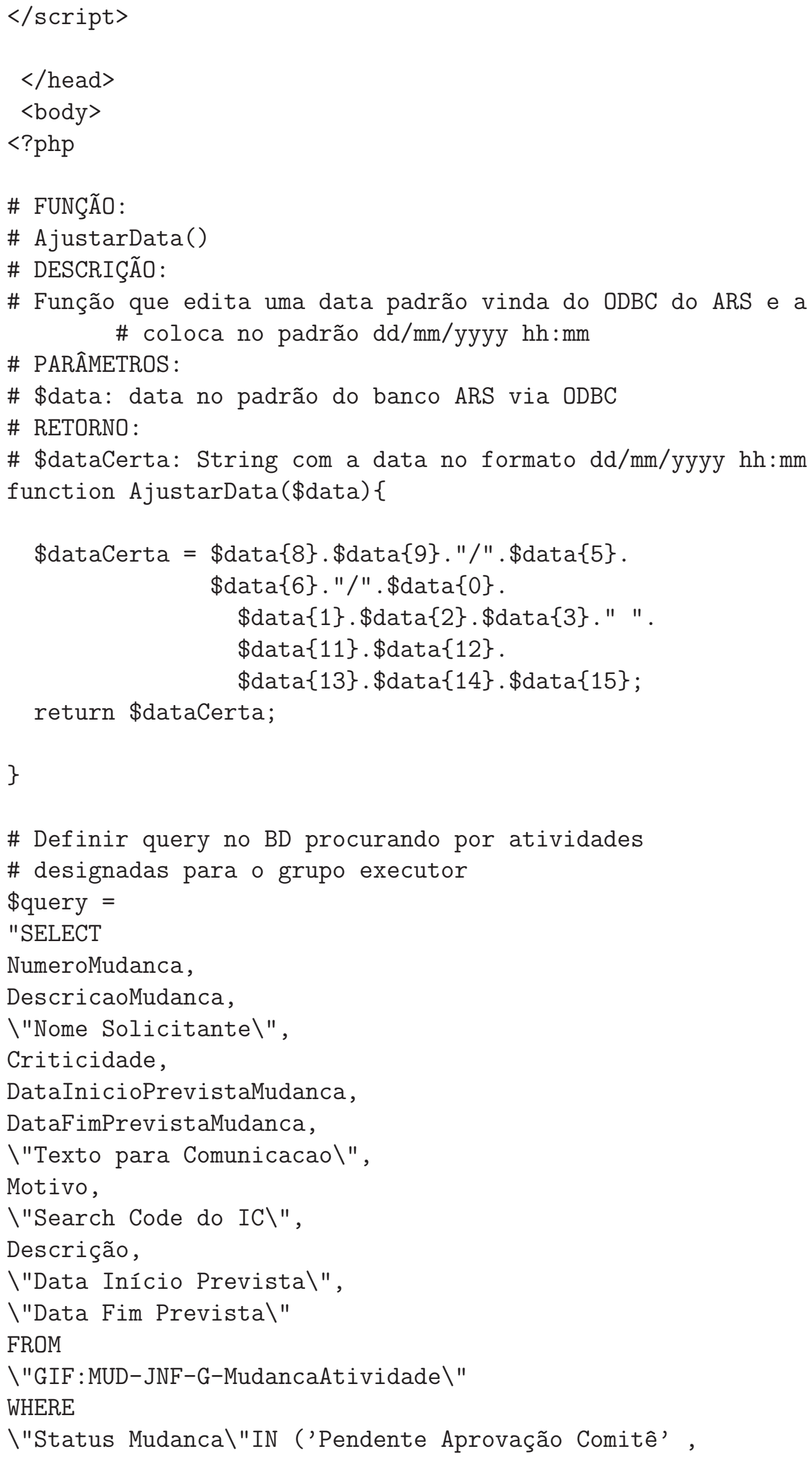


AND TipoMudanca='Programada' ";

'pPendente Convocação Comitê',

'pPendente Conferência Gerente de Mudanças')

if (! \$todos)

\$query = \$query . "AND \"Grupo Responsavel\"='\$executor'";

\$query = \$query . "ORDER BY" .

" DataInicioPrevistaMudanca ASC, NumeroMudanca ASC";

\# Executar a query definida no banco ARS

\$result = odbc_exec (\$connect, \$query);

\# Obter o resultado da query e armazenar no BD do MySQL

//Inicialização de variáveis

$\$ \mathrm{i}=0$;

\$key $=-1$;

\# Conectar no BD MySQL de forma a poder armazenar os

\# dados obtidos

if (!\$todos) mysql_connect("localhost", "gmud", "") or die;

\# Enquanto houverem novos registros no Resultado da Query no ARS while(odbc_fetch_row (\$result)) \{

\# Armazene os valores no MySQL

\$numGmud [\$i] = odbc_result (\$result, 1$)$;

\$descricaoGmud $[\$ i]=$ odbc_result $(\$ r e s u l t, 2)$;

\$solicitante $[\$ i]=$ odbc_result $(\$ r e s u l t, 3)$;

$\$$ crit $[\$ i]=$ odbc_result (\$result, 4);

\$dataInicioGmud [\$i] = odbc_result (\$result, 5);

\$dataFimGmud $[\$ i]=$ odbc_result $(\$ r e s u l t, 6)$;

\$impacto $[\$ i]=$ odbc_result (\$result, 7$)$;

\$motivo $[\$ i]=$ odbc_result (\$result, 8);

\$icImpactado [\$i] = odbc_result (\$result, 9);

\$descricaoAtiv $[\$ i]=$ odbc_result (\$result, 10);

\$dataInicioAtiv [\$i] = odbc_result (\$result, 11);

\$dataFimAtiv $[\$ i]=$ odbc_result (\$result, 12$)$;

\# 0 campo \$ocupado[\$i] indica se o registro já possui uma

\# decisão cadastrada.

\# No caso de um campo recém adicionado isto é

\# necessariamente falso.

\$ocupado $[\$ i]=0$;

\# As atividades abaixo não serão executadas no caso de

\# estar habilitada a opção "Ver Todos"

if (! \$todos) \{

\# Caso seja o primeiro loop, devemos pegar o próximo local

\# de armazenamento, 


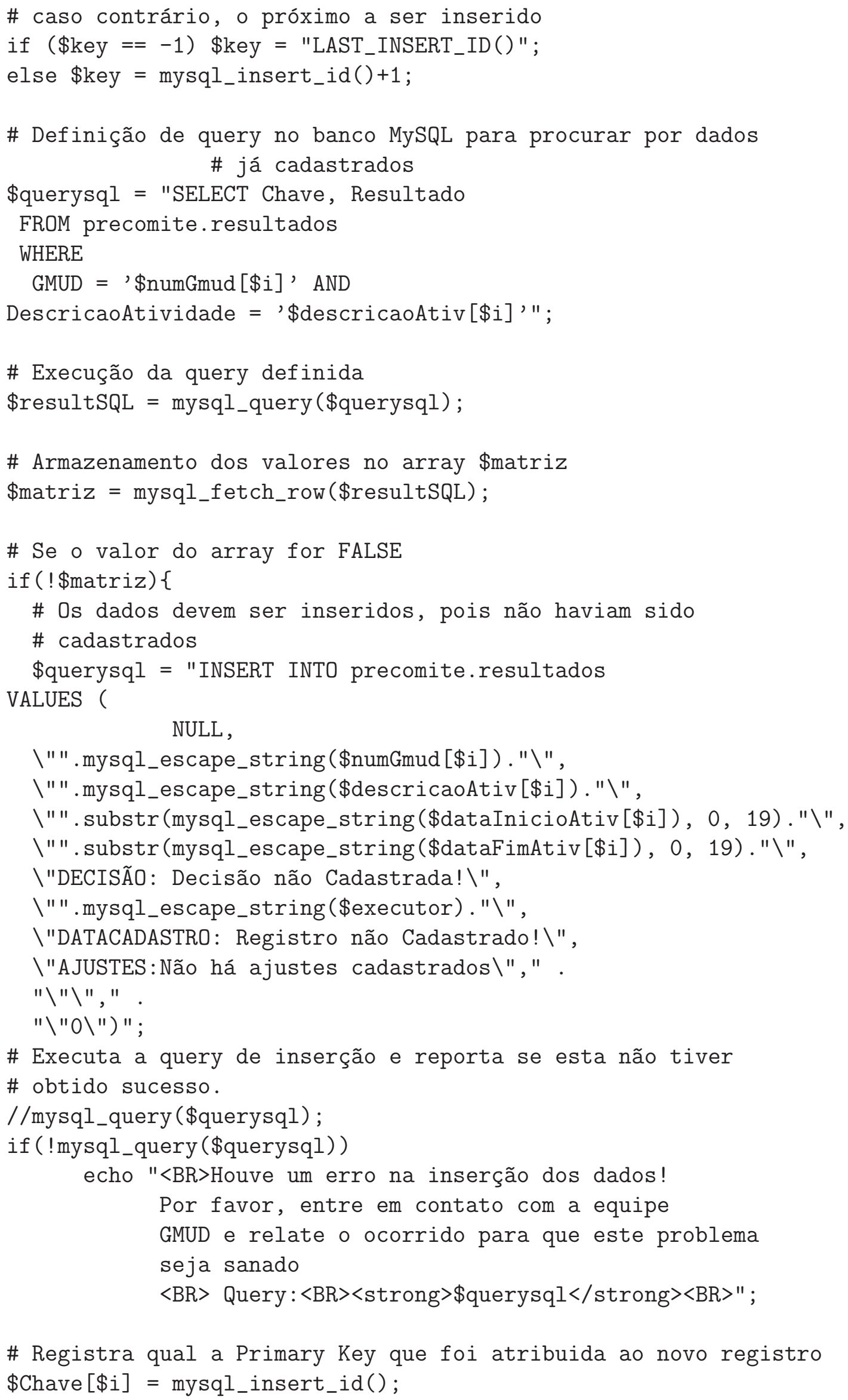




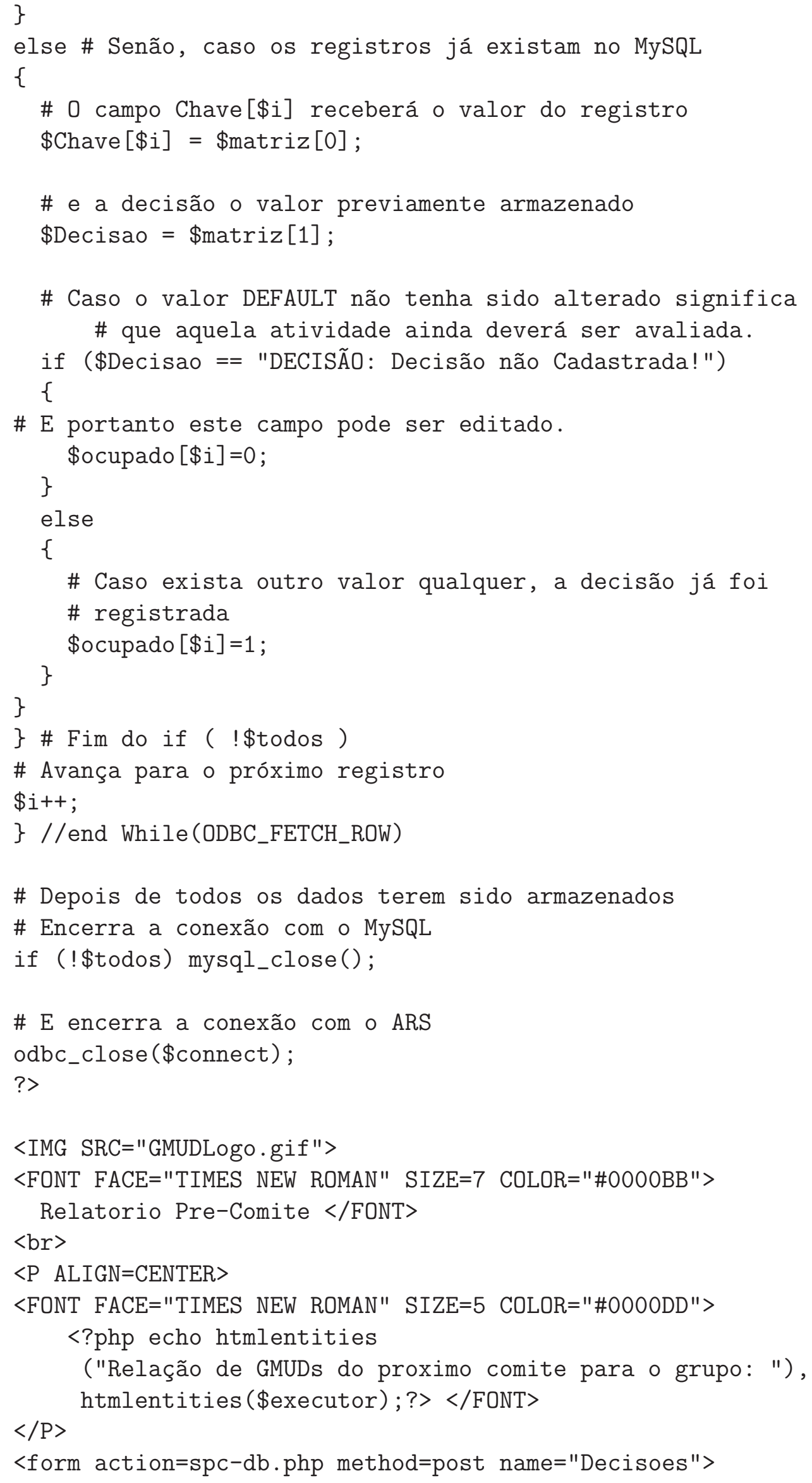




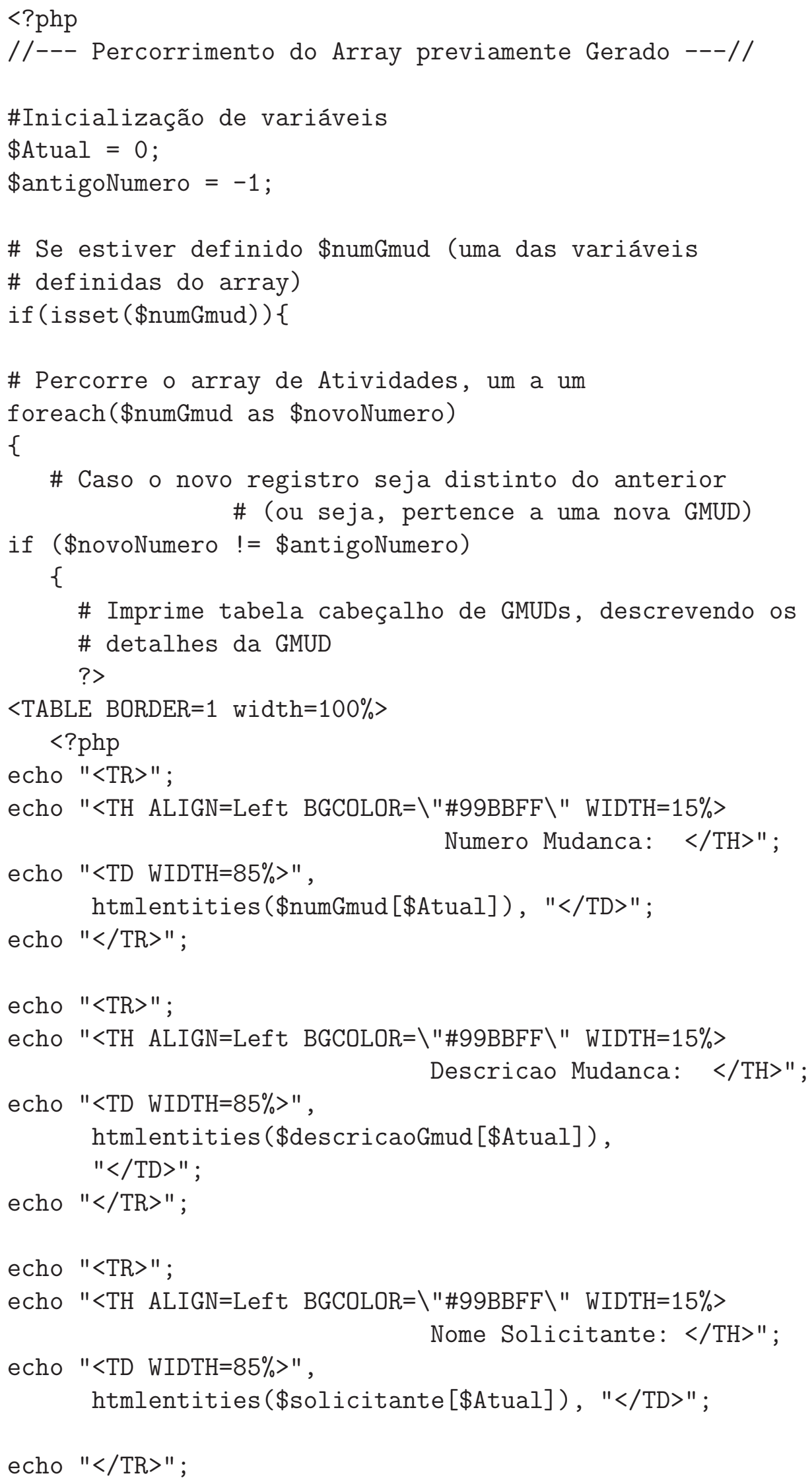




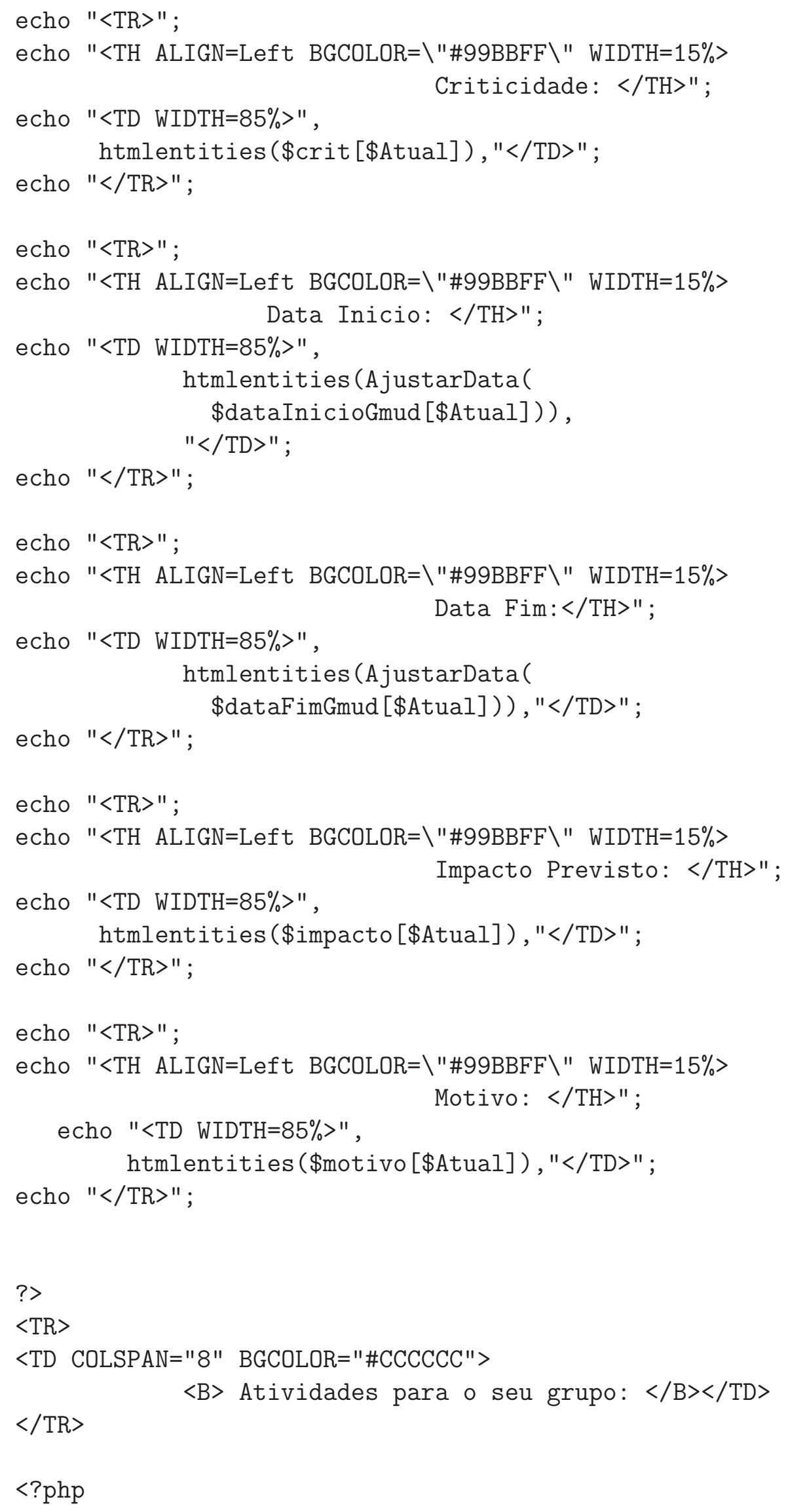


\}

\# Em seguida, imprime, em uma nova linha da tabela principal, \# uma nova tabela contendo a descrição das atividades para o

\# Grupo Executor

?>

$<\mathrm{TR}>$

$<$ TD COLSPAN="8">

$<$ TABLE BORDER $=0$ width $=100 \%>$

$<$ TR BGCOLOR="\#AADDFF" >

$<\mathrm{TH}>$ Descricao $</ \mathrm{TH}>$

$<\mathrm{TH}>$ Data Inicio $</ \mathrm{TH}>$

$<\mathrm{TH}>$ Data Fim $</ \mathrm{TH}>$

$<\mathrm{TH}>$ IC Impactado $</ \mathrm{TH}>$

$<\mathrm{TH}>$ Sua decisao: $\langle/ \mathrm{TH}\rangle$

$</ \mathrm{TR}\rangle$

$<$ ?php

echo "<TR $>$ ";

echo "<TD ALIGN=Center WIDTH=35\% $>$ ", htmlentities (\$descricaoAtiv[\$Atual]) , "</TD>" ;

echo "<TD ALIGN=Center WIDTH=10\%>", htmlentities (AjustarData(

\$dataInicioAtiv [\$Atual]

)) , "</TD>" ;

echo "<TD ALIGN=Center WIDTH=10\% $>$ ", htmlentities (AjustarDatal \$dataFimAtiv[\$Atual] )) , "</TD>" ;

echo "<TD ALIGN=Center WIDTH=15\%>",

htmlentities (\$icImpactado[\$Atual]), "</TD>" ;

\$Atual++;

?>

$<$ TD width $=30 \%>$

$<$ ?php

//--------Teste de Disponibilidade das opções ----------//

\# Primeiramente, verifica-se se o registro já possui

\# decisão cadastrada.

\# Caso alguma decisão tenha sido cadastrada, cria um

\# campo HIDDEN apenas

\# para armazenar o valor, de forma que este possa

\# ser encaminhado

\# à próxima página

if (\$ocupado [\$Atual-1] ==1)

echo "<input type=hidden name= $\backslash$ "Decisao",

\$Atual, "\" value=\"Previamente Cadastrado\">"; 


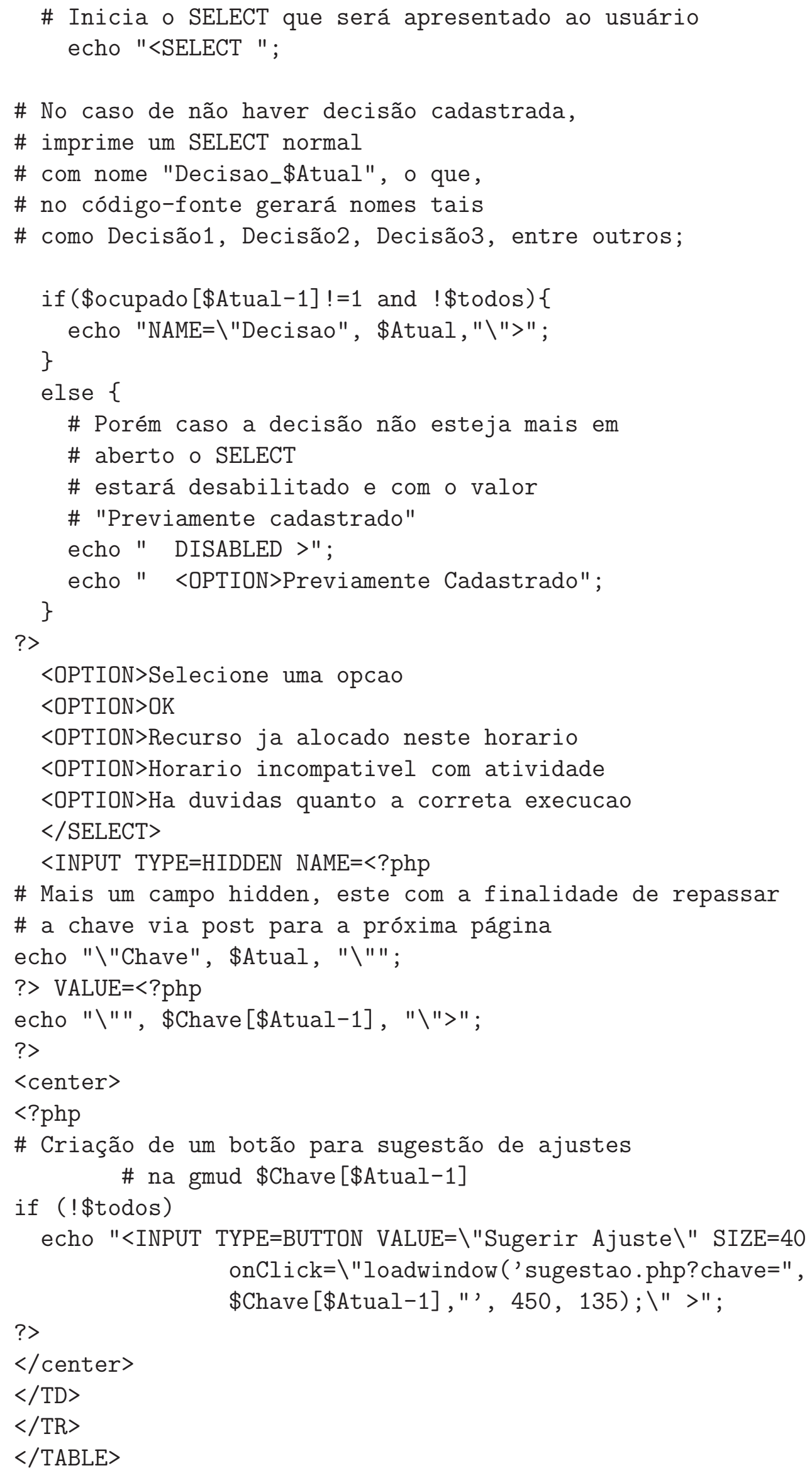




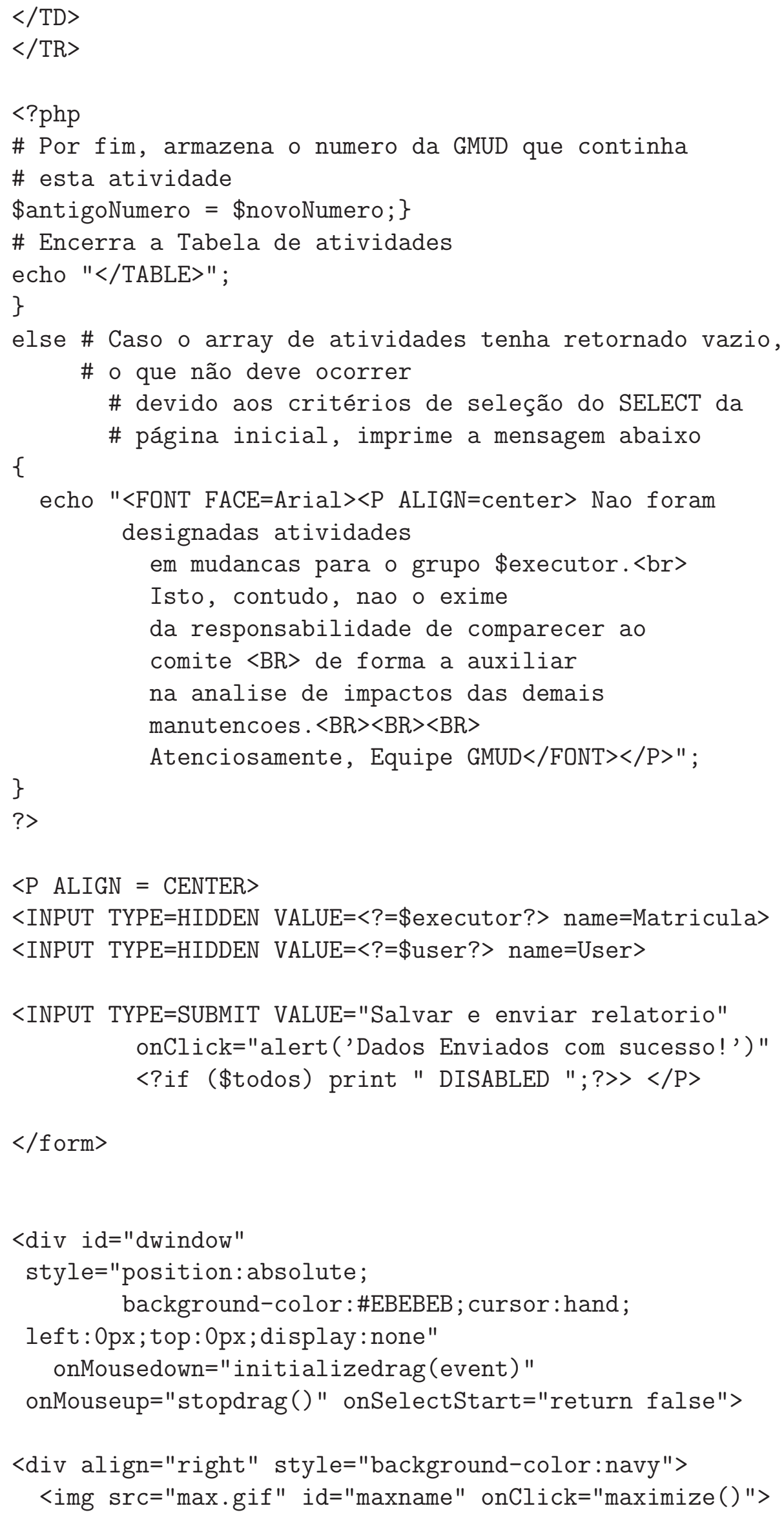




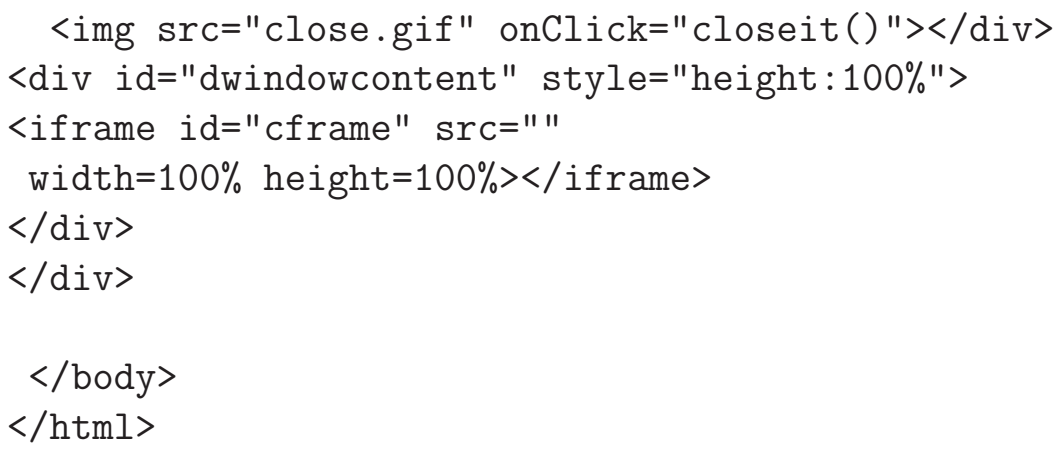

\section{C.2.3 Arquivo sugestao.php}

Página de ajuste de uma RFC. Segue o código fonte.

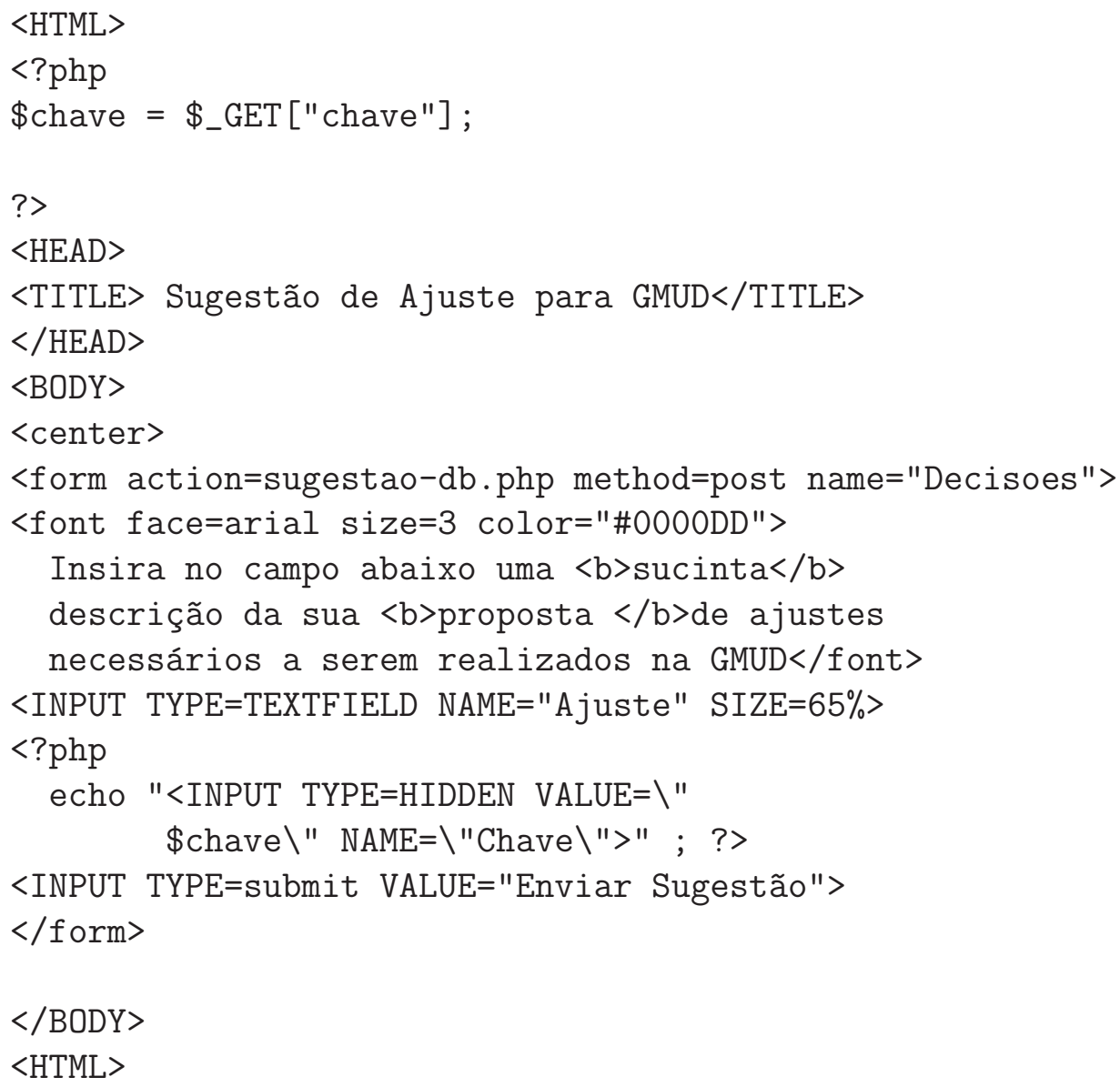




\section{C.2.4 Arquivo sugestao-db.php}

Página de armazenamento de ajustes. Segue o código fonte.

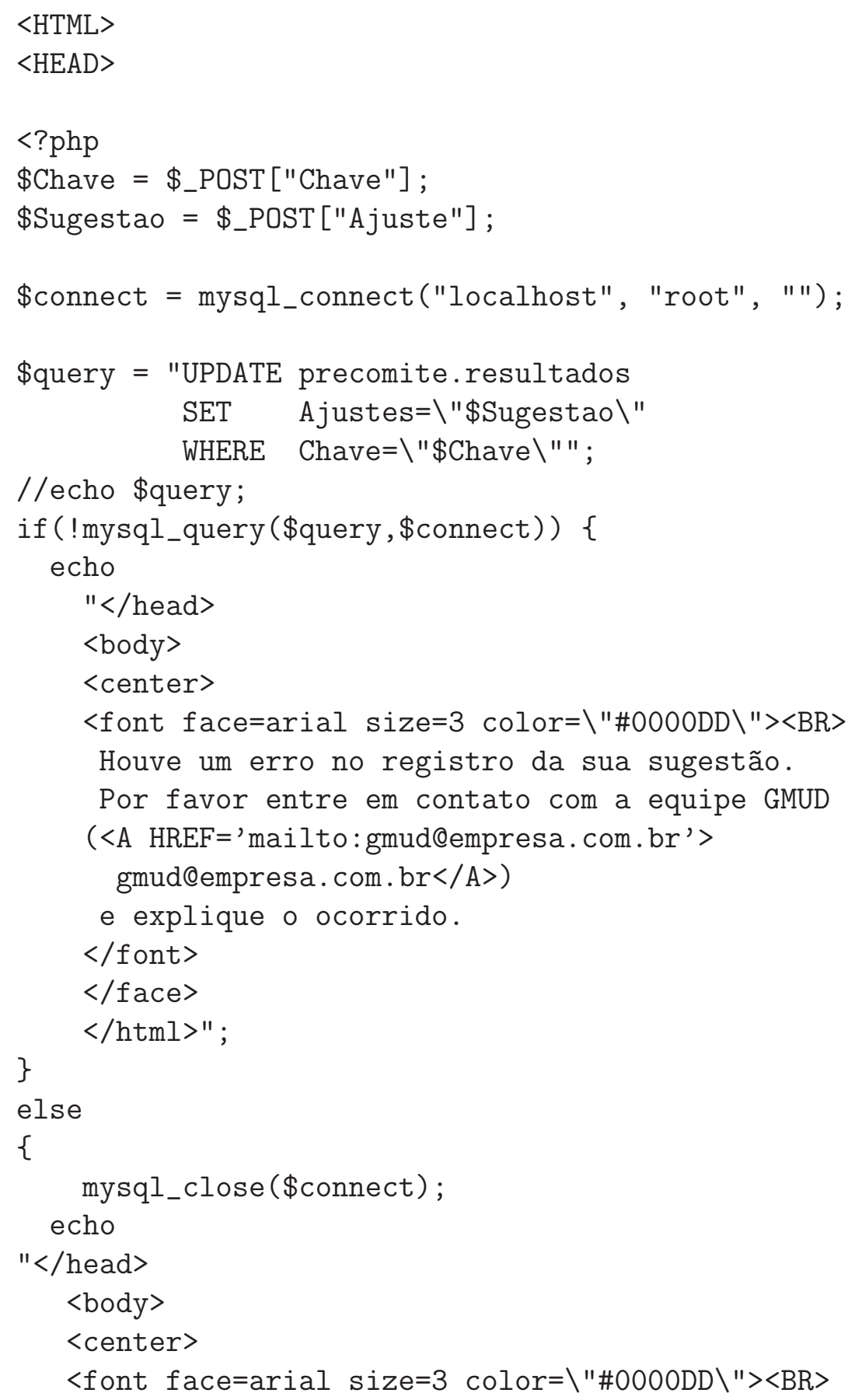




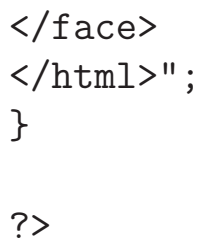

\section{C.2.5 Arquivo spc-db.php}

Página de armazenamento de todos ajustes realizados. Segue o código fonte.

$<? / *$

Cabeçalho do arquivo

NOME :

$\mathrm{spc}-\mathrm{db} \cdot \mathrm{php}$

DATA DA ÚLTIMA EDIÇãO:

$10 / 05 / 2006$

DESCRIÇÃO :

Este arquivo PHP é responsável por armazenar no banco de dados MySQL na máquina local as decisões registradas na página SPC.PHP.

PARÂMETROS RECEBIDOS:

Como parâmetros esta página recebe um conjunto de chaves e decisões feitas na página SPC.PHP. Estes parâmetros são repassados em campos numerados de 1 a N (Chave1, Desisao1, Chave2, Decisao2, ..., ChaveN, DecisaoN), sem poder deixar de fora nenhum número da sequencia.

Além desses parâmetros deve também ser repassado o nome do grupo executor.

OBS: 0 dado \$Executor não é utilizado

PARÂMETROS REPASSADOS:

Esta página não repassa valores a nenhuma outra. */

// ------------- Armazenamento ----------------------// 


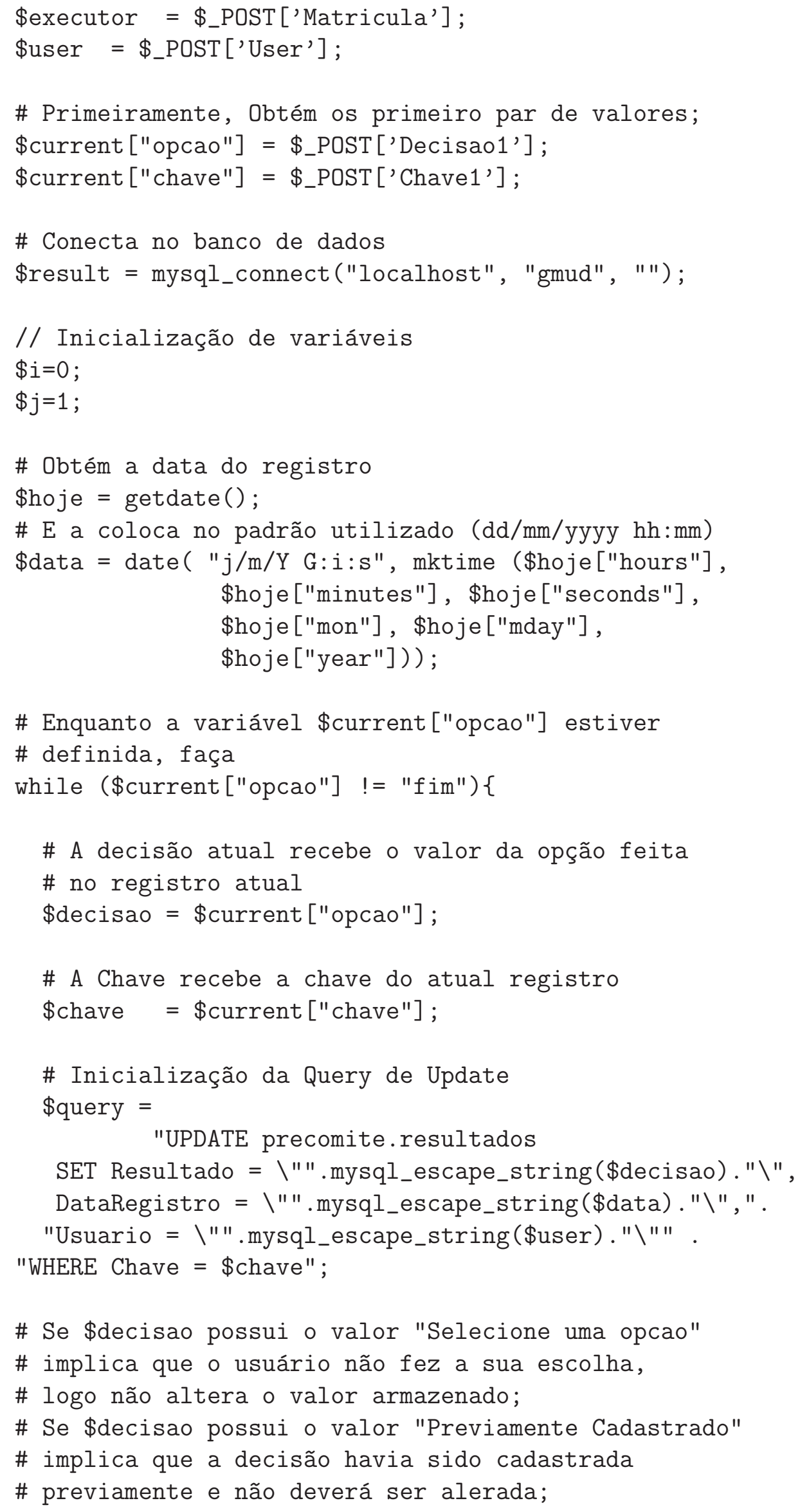




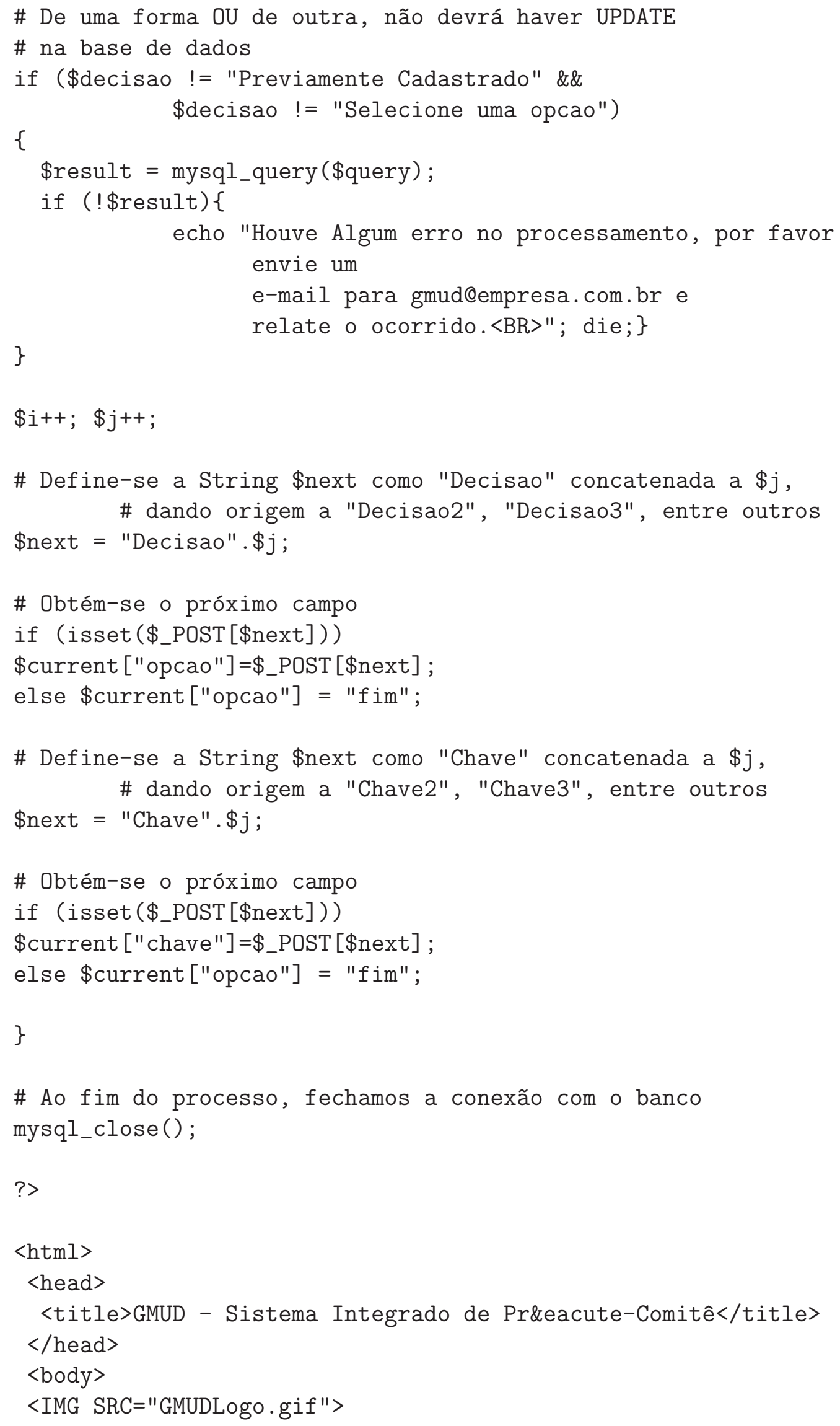


<FONT FACE="TIMES NEW ROMAN" SIZE=7 COLOR="\#0000BB"> Relat\&oacute; rio Pr\&eacute;-Comite </FONT>

$\langle$ br $>$

$<$ P ALIGN $=$ CENTER $>$

<FONT FACE="TIMES NEW ROMAN" SIZE=5 COLOR="\#0000DD">

<?php echo "Decis\&otilde; es Processadas<BR>"?> </FONT>

<FONT FACE="TIMES NEW ROMAN" SIZE=2 COLOR="\#0000DD"> Muito Obrigado por coolaborar no processo de mudan\&ccedil;as Operacionais de TI. 〈br $\rangle$

Esperamos que esta ferramenta tenha sido \&uacute; til para voc\&ecirc; ! $\langle$ br $\rangle\langle\mathrm{BR}\rangle$ Atenciosamente, $<$ BR $>$ Equipe de Gest\&atilde; o de Mudan\&ccedil;as- GMUD $</ \mathrm{P}>$ 


\section{Apêndice D}

\section{Proposta de Sistematização para Modelagem de Processos}

A sistematização na modelagem de processos aqui proposta foi elaborada com base no conhecimento adquirido ao longo da pesquisa deste trabalho. Basicamente, a sistematização na modelagem de processos descrito por [Sawy, 2001] e [IBM, 2003] requer a elaboração inicial de um modelo $A s$ Is, logo após o modelo To $B e$ e por fim as simulações que permitem comparar um ao outro. Afim de minimizar a consulta às obras acima referenciadas, segue uma breve descrição dessa sistematização.

1. Coleta de informações sobre processos adotados (especificar processos, subprocessos, tarefas)

Devem ser definidas as tarefas de cada processo e dividí-las em sub-processos para simplificar o entendimento do modelo. Na especificação das tarefas, sempre verificar qual o acionador da tarefa, definição da mesma e qual o resultado dela.

2. Modelagem dos processos As Is.

Condensar na ferramenta de modelagem as informações obtidas no passo anterior.

3. Coleta de informações teóricas sobre processos de gestões do Suporte a Serviços.

Verificar na documentação ITIL os processos das gestões e coletar informações sobre as tarefas sugeridas.

4. Modelagem das gestões ITIL apresentadas pela teoria do Suporte a Serviços ( To Be teórico).

Modelagem dos processos levantados pelo passo anterior. Essa modelagem deverá servir para uma idealização de como os processos deveriam ser sem se prender aos processos existentes na prática. 
5. Modelagem To Be para os processos existentes na prática.

De acordo com o modelo As Is, verificar onde o processo poderia ser melhorado e propor uma solução para o modelo existente.

6. Coleta de informações sobre estrutura organizacional e medidas de tempo para os processos existentes.

Introduzir na ferramenta de modelagem dados sobre custos de pessoas, a organização delas e métricas de tempo para os processos. Apartir desses dados, a ferramenta pode realizar suas simulações.

7. Realização de simulações

Aqui os 3 modelos podem ser comparados uns aos outros, por meio de gráficos de resultados, tabelas de tempos e custos. O modelo To Be teórico pode auxiliar a suprir lacunas existentes nos modelos $A s$ Is e To Be. Partindo das simulações, obtem-se noção de inconsistência em tarefas, gargalos de processo e custos envolvidos. 